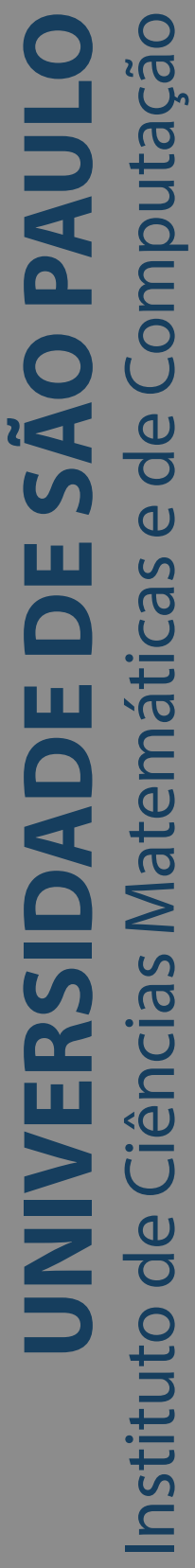

Uma abordagem multinível para construção de redes sociais geolocalizadas a partir de pontos de permanência

\title{
Diego Minatel
}

Dissertação de Mestrado do Programa de Pós-Graduação em Ciências de Computação e Matemática Computacional (PPG-CCMC) 

Data de Depósito:

Assinatura:

\section{Diego Minatel}

\section{Uma abordagem multinível para construção de redes sociais geolocalizadas a partir de pontos de permanência}

Dissertação apresentada ao Instituto de Ciências Matemáticas e de Computação - ICMC-USP, como parte dos requisitos para obtenção do título de Mestre em Ciências - Ciências de Computação e Matemática Computacional. VERSÃO REVISADA

Área de Concentração: Ciências de Computação e Matemática Computacional

Orientador: Prof. Dr. Alneu de Andrade Lopes

\section{USP - São Carlos}

Novembro de 2018 
Ficha catalográfica elaborada pela Biblioteca Prof. Achille Bassi e Seção Técnica de Informática, ICMC/USP, com os dados inseridos pelo(a) autor(a)

Minatel, Diego

M663 Uma abordagem multinível para construção de redes sociais geolocalizadas a partir de pontos de permanência / Diego Minatel; orientador Alneu de Andrade Lopes. -- São Carlos, 2018.

$89 \mathrm{p}$.

Dissertação (Mestrado - Programa de Pós-Graduação em Ciências de Computação e Matemática Computacional) -- Instituto de Ciências Matemáticas e de Computação, Universidade de São Paulo, 2018.

1. construção de redes a partir de trajetórias. 2. pontos de permanência. 3. paradigma multinível. I. Lopes, Alneu de Andrade, orient. II. Título.

Bibliotecários responsáveis pela estrutura de catalogação da publicação de acordo com a AACR2: Gláucia Maria Saia Cristianini - CRB - 8/4938 Juliana de Souza Moraes - CRB - 8/6176 


\title{
Diego Minatel
}

\section{A multilevel approach for building location-based social network by using stay points}

\begin{abstract}
Master dissertation submitted to the Institute of Mathematics and Computer Sciences - ICMC-USP, in partial fulfillment of the requirements for the degree of the Master Program in Computer Science and Computational Mathematics. FINAL VERSION

Concentration Area: Computer Science and Computational Mathematics
\end{abstract}

Advisor: Prof. Dr. Alneu de Andrade Lopes 

Este trabalho é dedicado à memória de Hercílio Dias de Arruda Filho. 

Primeiramente, gostaria de agradecer a todos meus familiares, em especial a minha mãe Marina e as minhas irmãs Tatiane e Talita, sem essas três mulheres eu nunca teria tido o privilégio de estudar. Falando em família, durante a escrita deste documento tive a infelicidade de perder meu pai Luiz, o que tornou a conclusão dessa dissertação algo complicado demais. Enfim, gostaria de deixar esse documento em sua homenagem. Agradeço meu avô Hercílio, mesmo tornando-se estrela há anos tem sido meu espelho e inspiração desde sempre, olho todos os dias para o céu a sua procura.

Aos meus companheiros de LABIC (Laboratório de Inteligência Computacional) queria agradecer pelos bons momentos vividos dentro e fora do laboratório, principalmente, as boas risadas de todos os dias. As constantes chegadas e despedidas, no laboratório, me deram a oportunidade de conhecer pessoas de diversos estados, países e de diferentes pensamentos, tornando a convivência um aprendizado diário. Não poderia deixar de citar os nomes de: André, Alan, Antônio, Diego, João, Jorge, Puma, Renan, RG, Roberta, Vinícius Ferreira e Vinícius Mourão, obrigado por me aturarem, pela troca de conhecimentos e principalmente pela amizade, um grande abraço em todos vocês.

Agradeço ao meu orientador Alneu por depositar a confiança necessária para que eu pudesse iniciar e finalizar esse período de grande aprendizado. A Universidade de São Paulo e ao Instituto de Ciências Matemáticas e de Computação meu agradecimento especial por me acolherem, mais uma vez, e oferecerem todas as condições necessárias para um ambiente de pesquisa. Por fim, deixo o meu agradecimento ao CNPq (Conselho Nacional de Pesquisa e Desenvolvimento) por me apoiar financeiramente no desenvolvimento desta pesquisa.

Muito obrigado à todos! Desejo muita vida em suas vidas. 

"O caos é uma ordem por decifrar."

(José Saramago) 



\section{RESUMO}

MINATEL D. Uma abordagem multinível para construção de redes sociais geolocalizadas a partir de pontos de permanência. 2018. 89 p. Dissertação (Mestrado em Ciências - Ciências de Computação e Matemática Computacional) - Instituto de Ciências Matemáticas e de Computação, Universidade de São Paulo, São Carlos - SP, 2018.

A popularização do GPS tem gerado uma massiva quantidade de dados que são organizados em trajetórias geográficas. Trajetórias geográficas são sequências ordenadas de coordenadas geográficas que representam um caminho de um objeto móvel. Para melhorar a compreensão destas trajetórias, são detectados locais de maior importância que são chamados de pontos de permanência, que indicam que um usuário permaneceu neste local por um tempo significativo. Pontos de permanência são comumente transformados em vértices de redes geolocalizadas para facilitar a mineração de trajetórias, a transformação é feita agrupando pontos geograficamente próximos. Porém, é pouco discutido na literatura a qualidade destas redes. Portanto, este projeto aborda esta lacuna e apresenta duas novas abordagens para construção de redes sociais geolocalizadas a partir de pontos de permanência. A abordagem proposta utiliza a fase de contração do paradigma multinível para realizar a transformação de pontos de permanência em vértices de redes. A fase de contração contrai uma rede original iterativamente até ser obtida uma rede solução, a contração leva em conta a estrutura topológica da rede. Os resultados mostram que as novas abordagens conseguem representar com maior precisão, por meio de redes geolocalizadas, o mundo real.

Palavras-chave: construção de redes a partir de trajetórias, pontos de permanência, paradigma multinível. 



\section{ABSTRACT}

MINATEL D. A multilevel approach for building location-based social network by using stay points. 2018. 89 p. Dissertação (Mestrado em Ciências - Ciências de Computação e Matemática Computacional) - Instituto de Ciências Matemáticas e de Computação, Universidade de São Paulo, São Carlos - SP, 2018.

The popularization of GPS has generated a massive amount of geographic data organized in raw trajectories. Raw trajectories are ordered sequences of geographic coordinates that represent a path of a moving object. To improve the understanding of raw trajectories, important places, referred to as stay points, are detected. They indicate that a user has remained in this correspondent place for a significant time. Stay points are commonly turned into vertices of location-based networks to facilitate trajectory mining, the turning into vertices is done by grouping geographically close points. Nonetheless, to the best of our knowledge, there is a lack of studies addressing the quality of these networks. This piece of research addresses this gap and presents two new approaches to using stay points for building location-based social networks. The proposed approach uses the contraction phase of the multilevel partitioning to turned stay points into vertices. The contraction phase contracts an original network iteratively until a solution network is obtained, the contraction is done considering the topological structure of the network. The results show that the new approaches are able to represent more accurately, through location-based networks, the real world.

Keywords: turning trajectories into networks, stay points, multilevel partitioning. 



\section{LISTA DE ILUSTRAÇÕES}

Figura 1 - Rede que representa o mapa da América do Sul, neste exemplo países fronteiriços estão conectados entre si. . . . . . . . . . . . . . . . . 32

Figura 2 Exemplos de redes . . . . . . . . . . . . . 33

Figura 3 - Exemplos de redes com dois tipos de vértices . . . . . . . . . . 33

Figura 4 - Exemplo de rede com estrutura de comunidades . . . . . . . . . . 37

Figura 5 - Estrutura tradicional de uma LBSN . . . . . . . . . . . . . . . . 38

Figura 6 - Exemplos de redes . . . . . . . . . . . . . . . . 39

Figura 7 - Exemplo de paradigma multinível . . . . . . . . . . . . . 40

Figura 8 - Exemplo de contração utilizando o algoritmo de matching LEM . . . . . . . 41

Figura 9 - Exemplo aplicação do algoritmo k-means . . . . . . . . . . . . . . 42

Figura 10 - Exemplo estratégia hierárquica aglomerativa . . . . . . . . . . . . 43

Figura 11 - Exemplo DBSCAN . . . . . . . . . . . . . . . . 45

Figura 12 - Exemplo de trajetória geográfica . . . . . . . . . . . . . 51

Figura 13 - Exemplo de detecção de pontos de permanência . . . . . . . . . . . . . 52

Figura 14 - Exemplo de construção de rede através da malha viária . . . . . . . . . . 53

Figura 15 - Exemplo de rede baseada em mobilidade construída através de trajetórias geográficas . . . . . . . . . . . . . . . . 55

Figura 16 - Exemplo de incomparabilidade de trajetórias por pontos de permanência . . 56

Figura 17 - Exemplo da transformação de trajetórias por pontos de permanência em rede 56

Figura 18 - Exemplo de rede hierárquica . . . . . . . . . . . . . . 57

Figura 19 - Processo de transformação de trajetórias por pontos de permanência em redes utilizando o paradigma multinível . . . . . . . . . . . . . . . 60

Figura 20 - Gráfico da média do número de níveis necessários para atingir a rede $G_{n}$ utilizando $C P V$ e $C G V$ em relação a distância limite $d_{\text {threshold }}$. . . . . . . . 64

Figura 21 - Exemplo de inserção de pertubação em coordenadas geográficas . . . . . . 66

Figura 22 - Gráfico da média ARI para diferentes valores de $k$ em relação a $d_{\text {threshold }}$. . 72

Figura 23 - Gráfico dos resultados médios de ARI para as melhores configurações de $k \quad 73$

Figura 24 - Gráfico da proporção do tempo total utilizado pela fase de contração em relação a $k \ldots \ldots \ldots$. . . . . . . . . . . . . . . 74

Figura 25 - Gráficos de homogeneidade e completude . . . . . . . . . . . 75

Figura 26 - Gráfico da média do número de níveis necessários para atingir a rede $G_{n}$ utilizando $C P V$ e $C G V$ em relação a distância limite $d_{\text {threshold }}$. . . . . . . . 76

Figura 27 - Gráfico de tempo de processamento dos algoritmos . . . . . . . . . . 78 



\section{LISTA DE ALGORITMOS}

Algoritmo 1 - Procedimento de contração de rede . . . . . . . . . . . . . . 61

Algoritmo 2 - Gerador de pertubação em base de dados de check-ins . . . . . . . . . . 66 



\section{LISTA DE TABELAS}

Tabela 1 - Informações das regiões selecionadas . . . . . . . . . . . . . . . 68

Tabela 2 - Informações dos conjuntos de dados selecionados . . . . . . . . . . . 69

Tabela 3 - Informações das redes local-local geradas por meio do agrupamento perfeito dos conjuntos de dados descritos na Tabela $2 \ldots$. . . . . . . . . . 70

Tabela 4 - Resultados do índice ARI para a melhor configuração dos algoritmos . . . 77 



\section{LISTA DE ABREVIATURAS E SIGLAS}

$\begin{array}{ll}\text { AGNES } & \text { AGglomerative NESting } \\ \text { CGV } & \text { Contract Group of Vertices } \\ \text { CL } & \text { Complete-linkage } \\ \text { CPV } & \text { Contract Pair of Vertices } \\ \text { DBSCAN } & \text { Density-Based Spatial Clustering of Applications with Noise } \\ \text { DIANA } & \text { DIvisive ANAlysis Clustering } \\ \text { GPS } & \text { Global Positioning System } \\ \text { HEM } & \text { Heavy Edge Matching } \\ \text { LBSN } & \text { Location-Based Social Network } \\ \text { LEM } & \text { Light Edge Matching } \\ \text { NGNM } & \text { Nearest Geographical Neighbor Matching } \\ \text { NGNnSM } & \text { Nearest Geographical Neighbor non-Sequential Matching } \\ \text { OPTICS } & \text { Ordering Points to Identify the Clustering Structure } \\ \text { RFID } & \text { Radio-Frequency Identification } \\ \text { RM } & \text { Random Matching } \\ \text { SL } & \text { Single-linkage } \\ \text { SM } & \text { Sorted Matching } \\ \text { UPGMA } & \text { Average-linkage } \\ \text { VGI } & \text { Volunteered Geographic Information }\end{array}$



$G$ - Relação que representa uma rede.

$V$ - Conjunto de vértices.

$E-$ Conjunto de arestas.

$W$ - Conjunto de pesos.

$N(v)$ - Vizinhança do vértice $v$.

$A$ - Matriz de adjacência que representa o grafo.

$A_{i j}$ - Elemento da matriz de adjacência que representa conexão entre os vértices $i$ e $j$.

$k_{i}$ - Grau do vértice $i$.

$k_{i}^{i n}-$ Grau de entrada do vértice $i$ em uma rede direcionada.

$k_{j}^{\text {out }}$ - Grau de saída do vértice $j$ em uma rede direcionada.

$\langle k\rangle$ - Grau médio da rede.

$w_{i}$ - Somatório dos pesos das arestas do vértice $i$.

$d_{i, j}$ - Caminho mínimo entre os vértice i e j.

$l_{i}$ - Tamanho linear da rede.

$\langle l\rangle$ - Média da proximidade.

$\langle B\rangle$ - Média do grau de intermediação.

$C$ - Coeficiente de agrupamento da rede.

$C_{i}$ - Coeficiente de agrupamento do vértice $i$.

CS - Coeficiente de Silhueta

$R I-$ Rand Index.

ARI - Adjusted Rand Index.

$h-$ Coeficiente de homogeneidade.

c-Coeficiente de completude. 

INTRODUÇÃO . . . . . . . . . . . . . . . . . 27

1.1

Hipótese

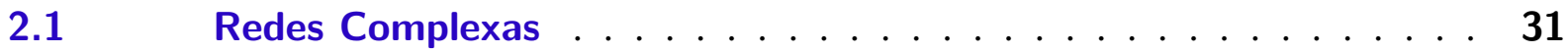

2.1.1 Conceitos Básicos . . . . . . . . . . . . . . . . 32

2.1.2 Características de redes . . . . . . . . . . . . . . 34

$2.2 \quad$ Redes Sociais . . . . . . . . . . . . . . . . . . 37

$2.3 \quad$ Paradigma Multinível . . . . . . . . . . . . . . . . 39

$2.4 \quad$ Agrupamento . . . . . . . . . . . . . . . 42

2.4.1 Métodos de Agrupamento . . . . . . . . . . . . . . . 42

2.4.1.1 Por particionamento . . . . . . . . . . . . . . . . . . 42

2.4.1.2 Hierárquicos ...................... . 43

2.4.1.3 Baseados em densidade . . . . . . . . . . . . . . . 44

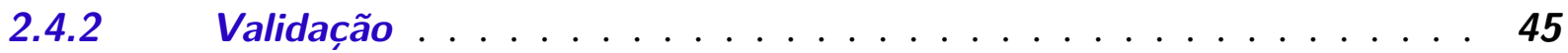

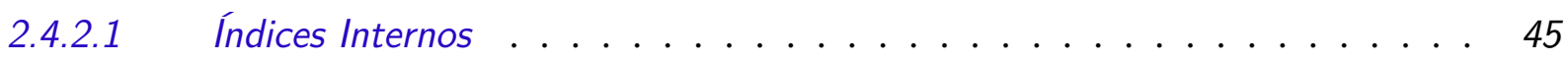

2.4.2.2 Índices Externos . . . . . . . . . . . . . . . . 46

$2.5 \quad$ Considerações Finais . . . . . . . . . . . . . . 48

3 REPRESENTAÇÃO DE TRAJETÓRIAS . . . . . . . . . . . 49

$3.1 \quad$ Conceitos Básicos . . . . . . . . . . . . . . 50

$3.2 \quad$ Representação por Redes . . . . . . . . . . . . . . 52

3.2.1 Rede Baseada em Mapeamento do Espaço Geográfico . . . . . . . . 53

3.2.1.1 Com Malha Viária . . . . . . . . . . . . . . . . . . . . . 53

3.2.1.2 Sem Malha Viária . . . . . . . . . . . . . . . . . . . 54

3.2.2 Rede Baseada na Mobilidade . . . . . . . . . . . . . . 54

3.2.2.1 Trajetórias de check-ins . . . . . . . . . . . . . . . . 54

3.2.2.2 Trajetórias por pontos de permanência . . . . . . . . . . . . . 55

$3.3 \quad$ Considerações Finais . . . . . . . . . . . . . 58

4 UMA ABORDAGEM MULTINÍVEL PARA CONSTRUÇÃO DE RE- 
4.1 Uma abordagem multinível para construir redes a partir de pontos de permanência . . . . . . . . . . . . . . . . . . 59

4.2 Inserção de perturbação em base de dados de check-ins . . . . . . 64

$5 \quad$ AVALIAÇÃO EXPERIMENTAL . . . . . . . . . . . . . . 67

$5.1 \quad$ Base de Dados Utilizadas . . . . . . . . . . . . . . . 67

5.2 Metodologia utilizada . . . . . . . . . . . . 69

$5.3 \quad$ Resultados e Análises . . . . . . . . . . . . . . . 71

5.3.1 Análise do parâmetro $k \ldots \ldots \ldots$. . . . . . . . . . .

5.3.2 Análise do índice ARI . . . . . . . . . . . . . . . 73

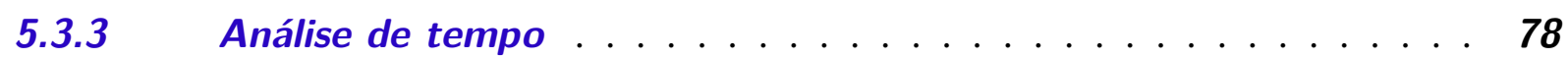

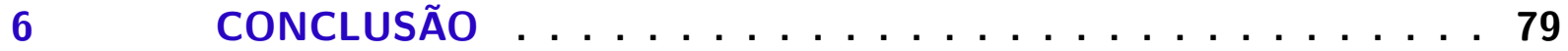

$6.1 \quad$ Limitações do Trabalho . . . . . . . . . . . . . 80

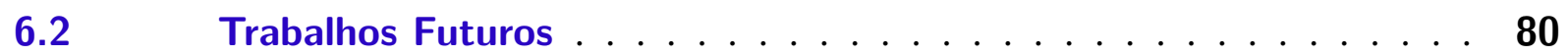

REFERÊNCIAS . . . . . . . . . . . . . . . . . . 83 


\section{1}

\section{INTRODUÇÃO}

Setenta por cento da população mundial irá utilizar smartphones no ano de 2020. Isso equivale a 6,1 bilhões de aparelhos em todo o globo terrestre. Este valor é significativo, pois representa o dobro de aparelhos registrados em 2015 (ERICSSON, 2015). Smartphones caracterizamse por possuírem receptores GPS, estes receptores juntamente com o fenômeno de disponibilização voluntária dos usuários de informações geográficas têm gerado, de forma progressiva, uma massiva quantidade de dados geográficos que são organizados em trajetórias. Com esse grande volume de trajetórias surge a necessidade de obter melhor representação sobre esses dados, que facilitem na descoberta de conhecimento sobre comportamentos de mobilidade.

Trajetória geográfica é uma sequência de coordenadas geográficas que representam o caminho percorrido por um objeto móvel ou usuário. Assim, trajetórias geográficas podem ser modeladas como: sequência de itens (ZHANG et al., 2014; MASCIARI; SHI; ZANIOLO, 2013; GIANNOTTI et al., 2007), séries temporais (LI; WANG; HAN, 2012; LI et al., 2010; CAO; MAMOULIS; CHEUNG, 2007) e redes (KARAGIORGOU; PFOSER; SKOUTAS, 2017; CHEN et al., 2016; HUANG et al., 2016; ZHANG et al., 2015; YANG et al., 2014; XIAO et al., 2014; LUO et al., 2013; YUAN et al., 2013). A representação por redes tem a vantagem de fornecer a relação entre os locais e também entre usuários e os locais visitados pelos mesmos.

Redes são representações simplificadas de sistemas visando abstrair suas estruturas através dos relacionamentos entre seus elementos. Os elementos são caracterizados por vértices e as relações por arestas. De acordo com Newman (2010), redes são utilizadas para representar e resolver problemas de diversas áreas do conhecimento. Assim, Costa et al. (2011) confirma a capacidade de utilização de redes através de muitas aplicações desenvolvidas em diversas áreas da ciência, como: ecologia, genética, epidemiologia, física e computação.

A transformação de trajetórias geográficas por meio de redes pode ser realizada de duas formas: baseada em mapeamento (KARAGIORGOU; PFOSER; SKOUTAS, 2017; HUANG et al., 2016; ZHANG et al., 2015) ou baseada na mobilidade(YANG; CHENG; CHEN, 2018; 
DRIF et al., 2017; CHEN et al., 2016). Essas redes são chamadas de geolocalizadas, pois os vértices contém informações geográficas do local representado. A transformação baseada em mapeamento utiliza o conhecimento do espaço geográfico e a rede é conhecida previamente. A maneira mais usual da utilização de mapeamento é por meio da malha viária, onde o cruzamentos viários são representados por vértices e os segmentos viários que unem os cruzamentos são representados pelas arestas (ZHENG, 2015). Assim, são utilizadas técnicas, chamadas de map matching, que associam coordenadas geográficas a vértices da rede para transformar trajetórias geográficas em sequências de vértices. Trabalhos como os de (HUANG et al., 2016; YUAN et al., 2013; YUAN et al., 2011) utilizam essa representação para encontrar o caminho mais rápido entre dois locais. Em (ZHANG et al., 2015; ZENG; HUANG, 2014) é analisado a influência da malha viária em acidentes de trânsito. Já em (KARAGIORGOU; PFOSER; SKOUTAS, 2017; PUMA-ALVAREZ; LOPES, 2017; ZHENG et al., 2012), a representação é utilizada para a reconstrução de rotas de trajetórias com baixa amostragem de pontos.

$\mathrm{Na}$ transformação de trajetórias baseada na mobilidade a rede é construída a partir do histórico de mobilidade dos usuários. Neste tipo de representação utiliza-se o conceito de pontos de permanência. Um ponto de permanência é um ponto que representa um espaço geográfico onde o usuário permanece por um tempo significativo, ou seja, pontos mais importantes em uma trajetória (LI et al., 2008). Estes pontos são detectados nas trajetórias geográficas e consequentemente, trajetórias geográficas são transformadas em trajetórias por pontos de permanência. As redes são construídas agrupando pontos de permanência próximos. Normalmente, é utilizado o algoritmo de agrupamento baseado em densidade OPTICS (ANKERST et al., 1999) para realizar o agrupamento dos pontos de permanência (YANG; CHENG; CHEN, 2018; DRIF et al., 2017; CHEN et al., 2016; ZOU; YU; CAO, 2016; YANG et al., 2014; ZHENG et al., 2009; LI et al., 2008). Portanto, vértices são conjuntos de pontos de permanência similares e arestas são inseridas se dois locais foram visitados em sequência.

Redes construídas por meio de pontos de permanência podem ser utilizadas na descoberta de comunidades de usuários que possuem trajetórias semelhantes (YANG; CHENG; CHEN, 2018; DRIF et al., 2017). Em (YANG et al., 2014) é realizada a predição de próximo lugar a ser visitado e em (XIAO et al., 2014) são descobertos laços sociais entre os usuários. Trabalhos como os de (ZOU; YU; CAO, 2016; ZHENG; ZHOU, 2011) utilizam essa representação para recomendação de restaurantes, museus e outros tipos de lugares. A representação por redes baseada em mobilidade é utilizada também em alguns tipos de redes sociais geolocalizadas. Portanto, muitas tarefas de mineração de redes sociais geolocalizadas podem ser aplicadas nas redes construídas por meio de trajetórias por pontos de permanência.

A rede construída por meio de pontos de permanência é o retrato da mobilidade de um conjunto de objetos móveis e esse tipo de rede tem a vantagem de ter capacidade de representar qualquer espaço geográfico, urbano ou não urbano, sem conhecê-lo. Na literatura da área, no entanto, são pouco discutidas as formas de construir redes geolocalizadas a partir 
de pontos de permanência e a capacidade destas redes em representar o mundo real. Assim, com o objetivo de ampliar a discussão deste tema, neste trabalho foram propostos duas novas abordagens para construir redes sociais geolocalizadas a partir de pontos de permanência e uma abordagem que possibilita a avaliação destas redes perante suas capacidades de representar o mundo real (MINATEL; VALEJO; LOPES, 2018).

As abordagens propostas para construir redes geolocalizadas a partir pontos de permanência foram baseadas na fase de contração do paradigma multinível. O paradigma multinível é uma abordagem que visa diminuir o espaço de busca de problemas combinatórios. Segundo Karypis e Kumar (1998), o paradigma multinível é dividido em três fases: contração, busca pela solução e projeção. Na fase de contração uma rede original é contraída até uma rede reduzida. Na busca pela solução é aplicado um algoritmo de busca local/global na rede reduzida e na fase final é projetada a solução para a rede original. Vale ressaltar que na fase de contração a rede original é contraída iterativamente considerando sua estrutura topológica, denomina-se de matching a seleção dos vértices que serão contraídos. A construção iterativa da rede considerando sua estrutura é a principal motivação da utilização da fase de contração do paradigma multinível para transformar pontos de permanência em redes.

Os resultados apresentados neste trabalho indicam que os algoritmos propostos possuem boa capacidade em representar o mundo real, por meio de redes utilizando pontos de permanência.

\subsection{Hipótese}

A transformação de pontos de permanência em vértices de redes geolocalizadas, por meio da fase de contração do paradigma multinível, provê representação mais precisa de trajetórias dos locais visitados no mundo real se comparada com as técnicas de agrupamento geralmente utilizadas.

\subsection{Objetivos}

Este trabalho tem como finalidade principal a criação de uma nova abordagem para construir redes geolocalizadas a partir de pontos de permanência que tenham melhor adequação ao mundo real. Com base nisso, foram listados os seguintes objetivos específicos:

- Levantamento bibliográfico: Para compreender os principais tipos de representações utilizados em trajetórias, em específico a representação por redes construídas por meio de pontos de permanência. Além, de entender as principais aplicações, tarefas, formas de avaliação e toda a base teórica envolvida no problema tema deste trabalho.

- Criação de algoritmos de matching: Os algoritmos de matching presentes na literatura sobre paradigma multinível não consideram dados geográficos. Assim, um dos objetivos 
é a criação de algoritmos de matching que considerem dados geográficos e auxiliem na transformação de trajetórias por pontos de permanência em vértices de redes geolocalizadas.

- Criação de método de análise: Contribuir na criação de um método de análise de redes construídas por meio de pontos de permanência em relação a representação do mundo real.

- Avaliação da Abordagem: Avaliar a qualidade de representação da abordagem proposta com a abordagem existente na área. Essa avaliação será feita na capacidade destas abordagens em representar o mundo real.

\subsection{Organização}

Este trabalho está dividido em cinco partes. No Capítulo 2 é apresentada a fundamentação teórica necessária para o entendimento deste projeto de pesquisa, são abordados os fundamentos de redes, redes sociais, paradigma multinível e agrupamento. No Capítulo 3 são apresentados os conceitos básicos de mineração de trajetórias e discutido as diferentes maneiras de transformar trajetórias em redes, dando enfoque para transformação de trajetórias por pontos de permanência em vértices de redes. No Capítulo 4 é apresentada a proposta de construção de redes geolocalizadas a partir de pontos de permanência utilizando a abordagem multinível, além disso, também é apresentada a técnica de inserção de perturbação em base de dados de check-ins que possibilita a avaliação da construção de redes geolocalizadas a partir de pontos de permanência em relação ao mundo real. No Capítulo 5 é discutido os resultados e análises da avaliação experimental. Finalmente, no Capítulo 6 são realizadas as considerações finais sobre o trabalho desenvolvido, são discutidas as principais contribuições, limitações do projeto e os trabalhos futuros. 


\section{FUNDAMENTOS}

Neste capítulo são apresentados conceitos relevantes para o desenvolvimento do projeto de mestrado. Primeiramente, são apresentados os conceitos e algumas métricas básicas das redes complexas. Depois, são abordados os principais conceitos relacionados às redes sociais em geral, e rede sociais geolocalizadas em específico. Na sequência são introduzidos os conceitos referentes ao paradigma multinível. Depois, conceitos básicos e métricas de agrupamento são abordados e, por fim, são realizadas as considerações finais deste capítulo.

\subsection{Redes Complexas}

De acordo com Albert e Barabási (2002), redes complexas descrevem uma ampla gama de sistemas na natureza e na sociedade. Segundo Newman (2010), as redes complexas são caracterizadas pelo estudo do comportamento de vários sistemas naturais dinâmicos modelados através de redes. Por exemplo, a célula é melhor descrita como uma rede complexa de substâncias químicas conectadas por reações químicas. A Internet é uma rede complexa de roteadores e computadores ligados por vários links físicos ou sem fio (ALBERT; BARABáSI, 2002). Assim, uma rede é uma representação simplificada de um sistema visando abstrair sua estrutura através do relacionamento entre seus elementos. A Figura 1 ilustra o mapa do subcontinente sul americano modelado através de uma rede, onde cada país é representado por um vértice e cada aresta simboliza que dois países fazem fronteiras entre si.

Há inúmeras possibilidades de abstração do mundo a nossa volta através de redes complexas e, consequentemente, isso potencializa a descoberta de novos conhecimentos. Segundo Newman (2010), redes são utilizadas para representar e resolver problemas de diversas áreas do conhecimento, tais como: matemática, física, biologia, ciências sociais, computação, entre outras. Costa et al. (2011) afirma que o sucesso e o potencial das redes complexas está na adequação natural para representar sistemas complexos. Segundo Costa et al. (2011), é possível confirmar este potencial através das aplicações desenvolvidas em diversas áreas da ciência como: 
Figura 1 - Rede que representa o mapa da América do Sul, neste exemplo países fronteiriços estão conectados entre si.

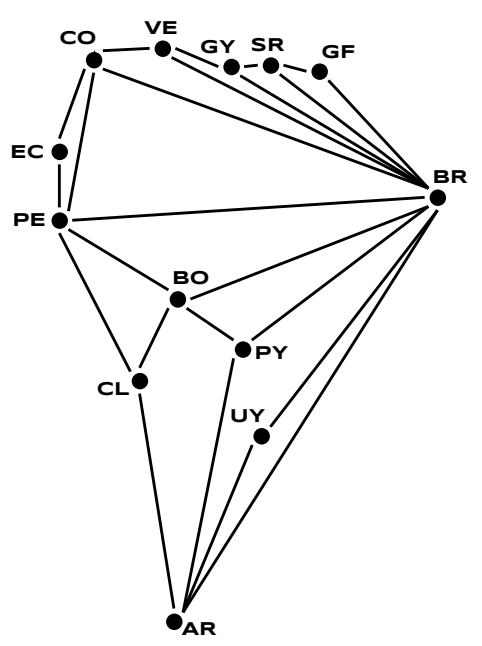

Fonte: Elaborada pelo autor.

ecologia, genética, epidemiologia, física, computação, etc.

Nas subseções seguintes são introduzidos os conceitos necessários de redes para o entendimento desta pesquisa. Na Seção 2.1.1 é mostrado os conceitos básicos sobre redes e na Seção 2.1.2 as principais métricas de redes são abordadas.

\subsubsection{Conceitos Básicos}

Uma rede é um conjunto de vértices conectados por um conjunto de arestas. Formalmente, uma rede $G=(V, E)$, contém um conjunto de $n=|V|$ vértices $V=\left\{v_{1}, v_{2}, v_{3}, \ldots, v_{n}\right\}$ e um conjunto de $m=|E|$ arestas $E=\left\{e_{1}, e_{2}, e_{3}, \ldots, e_{m}\right\}$ (NEWMAN, 2004). Uma aresta $e$ é identificada por um par de vértices $\left(v_{i}, v_{j}\right)$ que representa a existência de conexão entre os vértices $v_{i}$ e $v_{j}$.

Redes direcionadas são redes em que as arestas possuem direções, pois o direcionamento da conexão revela o sentido desta relação. Em redes direcionadas uma aresta $e=\left(v_{i}, v_{j}\right)$ tem a sua origem no vértice $v_{i}$ e destino no vértice $v_{j}$. Na Figura 2 a é mostrado um exemplo de rede direcionada, nota-se que a direção da relação é representada, graficamente, por uma seta. Em contrapartida, quando a relação entre vértices é recíproca (ocorre nos dois sentidos), como visto na Figura 2b, as redes são chamadas de redes não direcionadas.

O valor, ou peso, das arestas representam a intensidade das conexões. Redes que possuem arestas valoradas são conhecidas como redes valoradas, ou ponderadas ${ }^{1}$, e são representadas pela relação $G=(V, E, W)$, onde $W=\left\{w_{1}, w_{2}, w_{3}, \ldots, w_{m}\right\}$ representa o peso das arestas. Na Figura $2 \mathrm{c}$ é mostrado um exemplo de uma rede não direcionada valorada.

1 Valoradas e ponderadas serão utilizadas como sinônimos neste documento. 
Figura 2 - Exemplos de redes

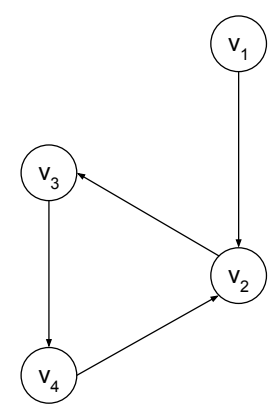

(a) Rede direcionada

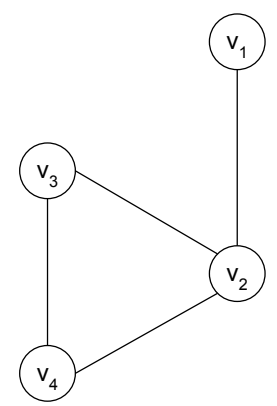

(b) Rede não-direcionada

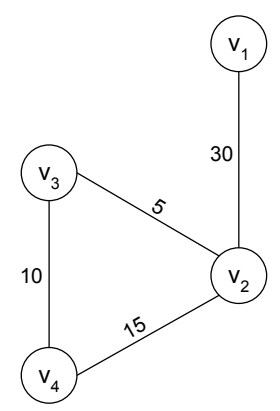

(c) Rede valorada

Fonte: Elaborada pelo autor.

As redes também podem ser classificadas de acordo com a existência de múltiplos tipos de vértices e arestas. As redes mostradas nas Figuras 1, 2a, 2b e 2c possuem apenas um tipo de vértice e são chamadas de redes homogêneas. Redes bipartidas são redes onde há dois tipos diferentes de vértices e apenas ocorre conexão entre vértices de tipos distintos (NEWMAN, 2010). Redes heterogêneas são redes que permitem múltiplos tipos de vértices e arestas (KIVELä et al., 2014). Nas redes heterogêneas não há restrições para conexões entre vértices de tipos iguais.

A rede mostrada na Figura 3a é um exemplo de rede bipartida, onde o formato do vértice identifica de qual tipo cada vértice pertence. Na Figura $3 b$ é apresentada uma rede com a mesma tipagem de vértices da Figura 3a, porém esta rede permite a conexão entre vértices do mesmo tipo, a qual caracteriza uma rede heterogênea. $O$ tracejado das linhas da Figura 3 b identifica o tipo de aresta da rede, por exemplo, as linhas pontilhadas representam arestas que conectam vértices do tipo quadrado.

Figura 3 - Exemplos de redes com dois tipos de vértices

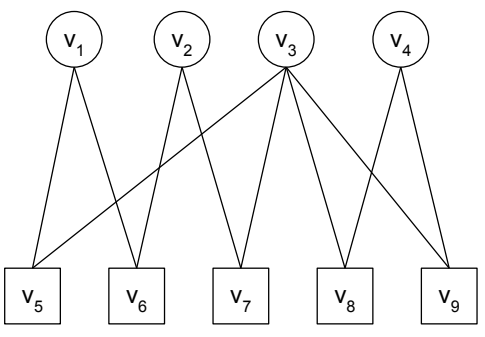

(a) Rede bipartida

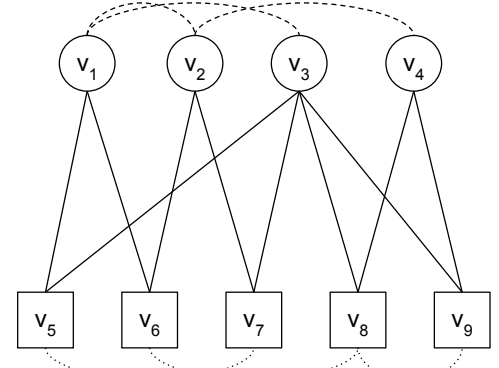

(b) Rede heterogênea

Fonte: Elaborada pelo autor.

Em redes não direcionadas, os vértices $v_{i} \in V$ e $v_{j} \in V$ são considerados adjacentes se compartilham uma mesma aresta. Em redes direcionadas, o vértice $v_{j}$ é considerado adjacente em relação ao vértice $v_{i}$ caso exista uma aresta que conecta os dois vértices e que a origem desta 
aresta seja o vértice $v_{i}$. Os vértices $v_{1}$ e $v_{2}$ são adjacentes entre si na rede não direcionada da Figura $2 \mathrm{~b}$, já na rede direcionada da Figura $2 \mathrm{a}$ o vértice $v_{2}$ é adjacente ao vértice $v_{1}$, porém o oposto não é verdadeiro. A vizinhança $N(v)$ de um vértice $v \in V$ em uma rede $G$ é determinada pelo conjunto de vértices adjacentes a $v$.

A representação gráfica de redes, apresentada até o momento nas Figuras 1, 2 e 3, é útil para redes pequenas e facilita a identificação de algumas propriedades e características destas redes. No entanto, não é adequada para redes que possuem uma grande quantidade de vértices e arestas. Assim, a maneira mais comum de representar redes é através da matriz de adjacência, que é dada por Newman (2010):

$$
A_{i j}=\left\{\begin{array}{l}
1, \text { se existe uma aresta partindo de } j \text { para } i \\
0, \text { c.c. }
\end{array}\right.
$$

Nota-se que a matriz resultante será quadrada, se a rede for simples e não direcionada a matriz de adjacência resultante será simétrica com relação a diagonal principal. $\mathrm{O}$ valor do elemento $A_{i j}$ é o peso da aresta entre os vértices $j$ e $i$, caso a rede for valorada.

\subsubsection{Características de redes}

Segundo Newman (2010), se conhecermos a estrutura de uma rede é possível calcular uma variedade de medidas e, assim, capturar características particulares dessa rede. As características de redes apresentadas a seguir são retiradas de Costa et al. (2007) e Newman (2010).

Grau do vértice: O grau é uma importante característica de um vértice e é dado pela quantidade de arestas conectadas ao vértice. A medida de grau diferencia-se entre redes não direcionadas e direcionadas.

Em uma rede não direcionada o grau é dado por:

$$
k_{i}=\sum_{j=1}^{n} A_{i j}
$$

Em uma rede direcionada existem duas medidas de graus por vértice. O grau de saída é dado pela quantidade de arestas que saem do vértice. Já o grau de entrada que é dado pela quantidade de arestas que incidem em um vértice. As duas medidas são definidas a seguir:

$$
\begin{gathered}
k_{i}^{i n}=\sum_{j=1}^{n} A_{i j}, \\
k_{j}^{\text {out }}=\sum_{i=1}^{n} A_{i j} .
\end{gathered}
$$


O grau médio de uma rede é dado por:

$$
\langle k\rangle=\frac{1}{n} \sum_{i=1}^{n} k_{i}
$$

Vértices com alto grau de conectividade são chamados de hubs.

Força: Em redes valoradas a medida de grau não tem muita utilidade, pois o peso das arestas não é considerado. No entanto, a medida de força surge como uma extensão da medida de grau para redes valoradas. A força de conexão de um vértice é dada pela soma dos pesos das arestas conectadas ao vértice e definida como:

$$
w_{i}=\sum_{j=1}^{n} W_{i, j}
$$

Proximidade (Closeness): A proximidade de um vértice indica quão próximo ele está de todos os demais vértices da rede. Para seu cálculo, primeiro deve-se obter as distâncias geodésicas do vértice em relação aos demais vértices da rede.

O caminho mínimo ou caminho geodésico, denotado por $d_{i, j}$, entre dois vértices $i$ e $j$ é definido pelo número mínimo de arestas necessárias para atingir o vértice $j$ a partir de $i$. Quando dois vértices pertencem a componentes (sub-redes) desconectados da rede define-se $d_{i, j}=\infty$. O maior valor de $d_{i, j}$ entre todos os pares de vértices define o diâmetro $\left(d_{\max }\right)$ da rede.

A Equação 2.6 define a proximidade do vértice $i$. O tamanho linear da rede ou média da proximidade $\langle l\rangle$ é dado pela Equação 2.7.

$$
\begin{gathered}
l_{i}=\sum_{\forall j \in V, j \neq i} \frac{1}{d_{i, j}} . \\
\langle l\rangle=\frac{1}{n} \sum_{\forall i \in V} l_{i} .
\end{gathered}
$$

Intermediação (Betweenness): O grau de intermediação analisa a frequência com que um vértice aparece no caminho geodésico entre dois outros vértices quaisquer. Vértices com maior betweenness fazem parte de um número maior de caminhos mínimos e, assim sendo, dependendo da análise podem ser importantes para a estrutura da rede. Portanto, $d_{i, j}^{v}$ representa o número de caminhos mínimos entre $i$ e $j$ que incluem $v$. O grau de intermediação é definido na Equação 2.8.

$$
B_{v}=\sum_{\forall i \neq v \in V} \sum_{\forall j \neq v \in V} \frac{d_{i, j}^{v}}{d_{i, j}}
$$


A média do grau de intermediação $\langle B\rangle$ para uma rede é definida como:

$$
\langle B\rangle=\frac{1}{n} \sum_{\forall v \in V} B_{v} .
$$

Coeficiente de agrupamento (Clustering coefficient): Coeficiente de agrupamento, ou transitividade, é a probabilidade de quaisquer dois vértices, com um vizinho em comum, estarem conectados entre si. Analogamente, em uma rede de amizades isso significa que se $A$ e $B$ são amigos e $B$ e $C$ também são, existe uma possibilidade de amizade entre $A$ e $C$. O coeficiente de agrupamento quantifica essa probabilidade e é dado por:

$$
C=\frac{3 N_{\Delta}}{N_{3}}
$$

onde $N_{\Delta}$ é número de triângulos em uma rede e $N_{3}$ é a quantidade de conexões triplas presentes na rede. Um triângulo é um conjunto de três vértices com arestas entre cada par de vértices. Conexão tripla é um conjunto de três vértices onde cada vértice pode ser alcançado pelos outros dois vértices (diretamente ou indiretamente), ou seja, dois vértices devem ser adjacentes a um vértice central (COSTA et al., 2007). Também é possível definir o coeficiente de agrupamento para o vértice $i$ :

$$
C_{i}=\frac{N_{\Delta}(i)}{N_{3}(i)}
$$

onde $N_{\Delta}(i)$ é o número de triângulos envolvendo o vértice $i$ e $N_{3}(i)$ é a quantidade de conexões triplas que tenha como vértice central o vértice $i$. O coeficiente de agrupamento para o vértice $i$, também é conhecido como coeficiente de agrupamento local ou redundância. Uma perfeita transitividade somente é alcançada quando todos os vértices estão conectados entre si.

Estrutura de Comunidades: Muitas redes do mundo real apresentam estruturas de conexões caracterizada pela presença de grupos, ou seja, presença de vértices que são densamente conectados entre si e fracamente conectados com o restante da rede. Esse tipo de estrutura é conhecido como estrutura de comunidades. Na Figura 4 é mostrado um exemplo de rede com três comunidades diferentes, cada comunidade é representada por uma coloração distinta.

Segundo Valverde-Rebaza (2013), no contexto social, a sociedade organiza-se de modo natural de diferentes formas de agrupamentos: famílias, círculos de amizade ou de contatos profissionais, cidades, países, entre outros. A difusão da Internet e a existência de redes sociais online levaram à criação de comunidades virtuais, as quais são comumente chamadas de grupos. 
Figura 4 - Exemplo de rede com estrutura de comunidades



Fonte: Elaborada pelo autor.

\subsection{Redes Sociais}

De acordo com Costa et al. (2011), desde a antiguidade indivíduos estabelecem relações entre si, seja para fins diplomáticos, comerciais ou culturais, que contribuíram ativamente para a evolução humana. Tais relações continuam a fazer parte da sociedade contemporânea e podem ser representadas por redes, que neste caso são chamadas de redes sociais. Segundo Newman (2010), redes sociais são redes em que pessoas ou grupo de pessoas são representadas por vértices e as arestas representam alguma relação social entre os indivíduos. Essas relações podem ser de diversas naturezas, tais como: relações de amizade, profissionais, comerciais, etc. A maneira como as relações estão formadas em uma rede social são de extrema importância, pois influenciam diretamente nos costumes, aprendizados e formação de opinião de cada pessoa.

Com a evolução da Internet e a popularização de computadores/smartphones, as redes sociais foram abstraídas para o mundo virtual com a alcunha de online. Redes sociais online são plataformas web que permitem com que usuários estabeleçam relações entre si que refletem o mundo real, além da possibilidade do compartilhamento de fotos, vídeos, ideias e emoções. Atualmente o Facebook ${ }^{2}$ é a mais popular e bem sucedida rede social online atingindo a marca de quase 2,20 bilhões de usuários em março de $2018^{3}$, sendo que 1,45 bilhões de usuários utilizam diariamente a plataforma. Outras redes sociais online tem caráter mais específico, como por exemplo o Skoob ${ }^{4}$, que tem o propósito de unir seus usuários por suas preferências literárias ou o Linkedin ${ }^{5}$, que facilita a interação social com propósitos profissionais.

Redes sociais online geolocalizadas, ou também chamada de Location-Based Social Network ( $L B S N)$, é um tipo de rede social online que possibilita aos seus usuários o compartilhamento de informações geográficas. Segundo Zheng e Zhou (2011), uma LBSN não se constitui apenas na inclusão de informações de localização em uma rede social online existente, trata-se de uma nova estrutura de rede, onde os usuários são conectados tanto pelas interdependências provenientes de suas localizações no mundo físico (conexões entre usuários e locais) quanto pelas interações existentes entre usuários a partir do compartilhamento de suas informações geográficas

\footnotetext{
$<$ https://www.facebook.com>

Dados retirados em Facebook (2018)

$<$ https://www.skoob.com.br/>

$<$ https://www.linkedin.com/>
} 
acompanhadas de fotos, vídeos, texto, e outras fontes de informação (conexões entre usuários). A interdependência vai muito além da identificação de dois usuários na mesma localização no mundo físico, também possibilita o conhecimento de interesses comuns, comportamento e atividades inferidas dos seus históricos de localizações, comumente chamado de trajetórias. $\mathrm{O}$ principal destaque das $L B S N s$ é o fato de permitirem acumular o histórico de localizações dos usuários no mundo físico, e não apenas as informações geográficas compartilhadas em conteúdos da mídia (ZHENG; ZHOU, 2011).

Redes sociais tradicionais são representadas de maneira simples por uma rede. Entretanto, uma $L B S N$ possui estrutura mais complexa. A estrutura de uma $L B S N$ é caracterizada por locais visitados pelos usuários. Portanto, a representação padrão de uma $L B S N$, como visto na Figura 5 , é uma rede heterogênea, onde há dois tipos de vértices (usuário e local) e três tipos de arestas (usuário-usuário, usuário-local, local-local). A partir da estrutura padrão de uma uma $L B S N$ é possível extrair três diferentes tipos de redes, baseadas no tipo de conexão, que facilitam a análise desta $L B S N$. Os três tipos redes são detalhados a seguir:

Figura 5 - Estrutura tradicional de uma $L B S N$

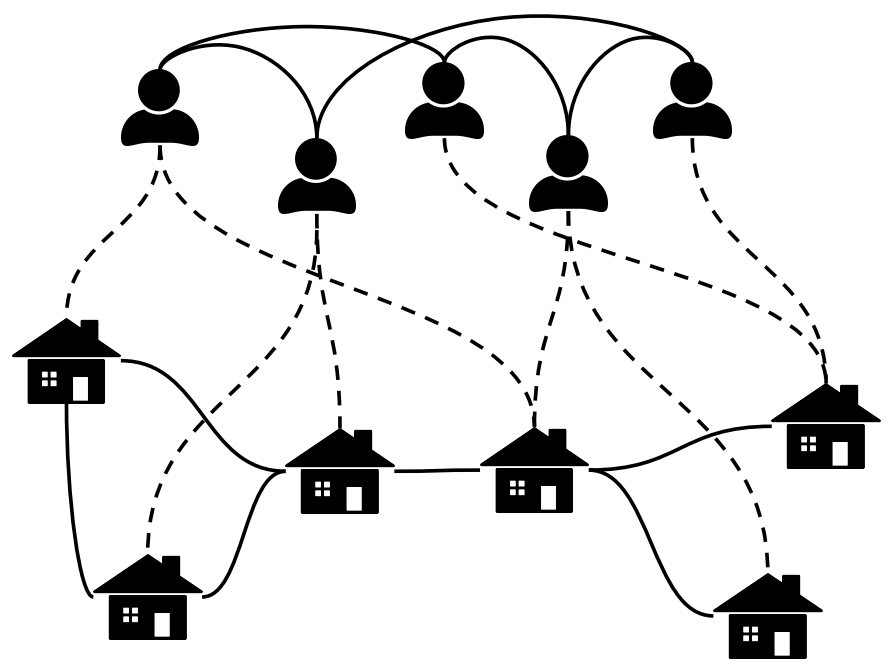

Fonte: Elaborada pelo autor.

- Rede usuário-usuário: neste tipo de rede, os vértices representam os usuários e as arestas representam algum tipo de relação entre os usuários conectados. Esta estrutura é similar à estrutura que representa às redes sociais tradicionais. A Figura $6 a$ exemplifica uma rede usuário-usuário.

- Rede local-local: neste tipo de rede geolocalizada, como mostrado na Figura 6b, os vértices representam locais e as arestas indicam que os dois locais conectados foram visitados de maneira consecutiva durante uma trajetória. Os pesos das arestas indicam a correlação entre os locais, por exemplo, a distância entre estes locais ou até mesmo quantidade de vezes que os locais foram visitados em sequência. 
- Rede usuário-local: Esta rede geolocalizada tem dois tipos distintos de vértices (usuário e local) e é caracterizada por ter apenas conexões entre vértices de tipos diferentes, como visto na Figura 6c. Portanto a rede usuário-local é uma rede bipartida, onde as arestas indicam que o usuário visitou um determinado local, o peso destas arestas revela a quantidade de visitas do usuário no lugar em questão.

Figura 6 - Exemplos de redes

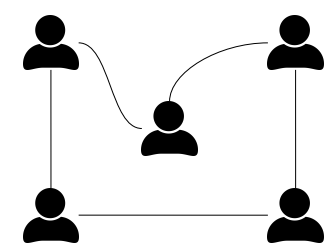

(a) Rede Usuário-Usuário

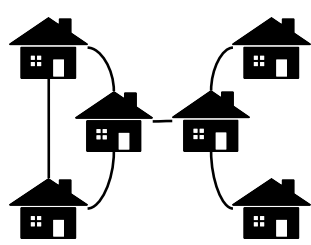

(b) Rede Local-Local

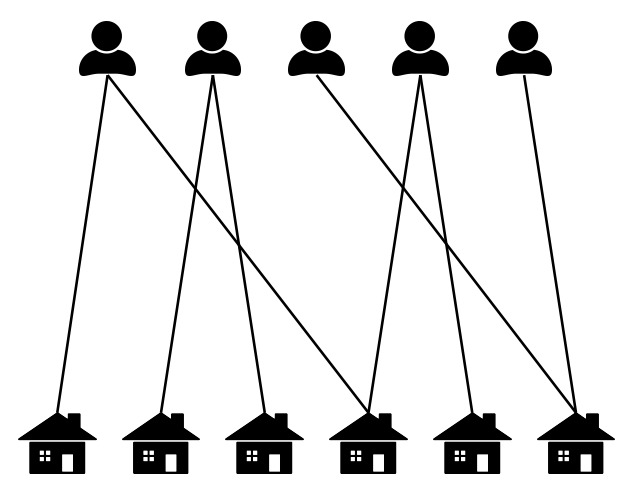

(c) Rede Usuário-Local

Fonte: Elaborada pelo autor.

Segundo Zheng e Zhou (2011), as LBSNs se diferenciam pela forma de representação das localizações: absolutas (e.g. Bikely ${ }^{6}$, Geolife $^{7}$ ) ou simbólicas (e.g. Foursquare ${ }^{8}$, Gowalla ${ }^{7}$, Brightkite $^{7}$ ). Na forma absoluta os vértices do tipo local são identificados por coordenadas geográficas que podem indicar um ponto exato da superfície terrestre ou uma área desta superfície. Já na representação simbólica as localizações são representadas pelo seu significado no mundo real, por exemplo: Shopping Iguatemi São Carlos, Estádio Cícero Pompeu de Toledo, Jardim Botânico de Curitiba, etc.

\subsection{Paradigma Multinível}

O paradigma multinível é uma abordagem que visa diminuir o espaço de busca de problemas combinatórios para aplicação de algoritmos de busca local/global, nesse espaço reduzido, para depois projetar a solução no espaço original. Segundo Karypis e Kumar (1998), esse processo é realizado sequencialmente e é dividido em três etapas: a) contração da rede; b) busca pela solução inicial; e c) projeção da solução. Na Figura 7 é mostrado um exemplo de aplicação do paradigma multinível. Neste exemplo primeiramente a rede $G_{0}$ é contraída até a

$<$ https://www.bikely.com/>

7 Redes sociais geolocalizadas que foram descontinuadas, mas suas bases de dados são utilizadas para fins de pesquisa.

8 <https://foursquare.com> 
rede $G_{n}$, depois é aplicado um algoritmo de detecção de comunidades na rede $G_{n}$ e, por fim, a solução é projetada aos diferentes níveis até ser observada na rede original $G_{0}$. A seguir são discutidas as três fases do paradigma multinível.

Figura 7 - Exemplo de paradigma multinível

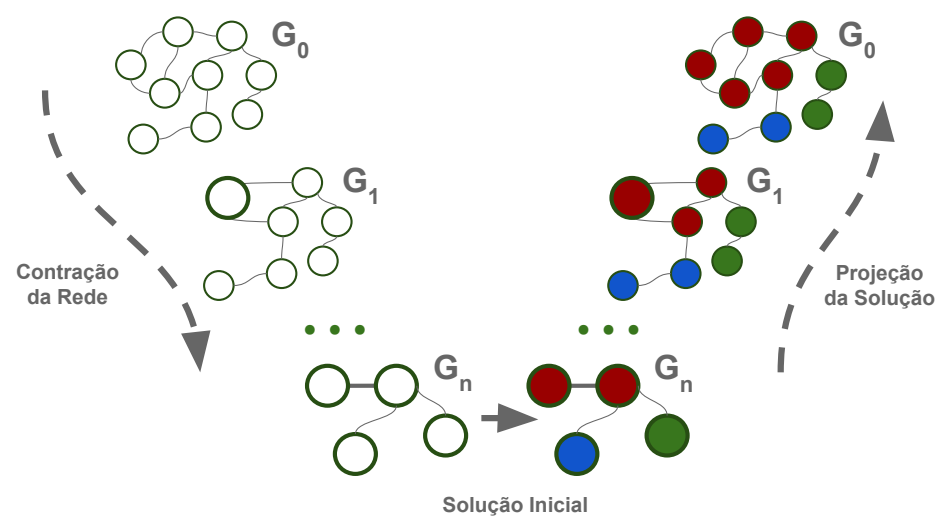

Fonte: Elaborada pelo autor.

Na primeira fase, ou fase de contração, uma rede inicial $G_{0}=\left(V_{0}, E_{0}\right)$ é contraída em redes $G_{1}, G_{2}, \ldots G_{n}$, tal que $\left|V_{0}\right|>\left|V_{1}\right|>\left|V_{2}\right|>\ldots>\left|V_{n}\right|$.

Para cada nível $l$ de contração, sendo $l=\{1,2, \ldots, n\}$, são selecionadas arestas da rede $G_{l-1}$ para o conjunto de matching ${ }^{9}$. Cada par de vértices de uma aresta selecionada (conjunto de matching) são transformados em um super-vértice. Existem diversas abordagens para a seleção das arestas que serão inseridas no conjunto de matching, essas abordagens são denominadas algoritmos de matching. Um resumo desses algoritmos é apresentado a seguir (KARYPIS; KUMAR, 1998).

- Random Matching (RM): No algoritmo RM os vértices são visitados aleatoriamente. Para cada vértice $u$ selecionado é buscado aleatoriamente, entre seus vizinhos, um vértice $v$. Caso os vértices $u$ e $v$ não tenham sidos selecionados anteriormente, estes são selecionados para o conjunto de matching.

- Light Edge Matching (LEM): No algoritmo LEM os vértices também são visitados aleatoriamente. Porém, para cada vértice $u$, selecionado entre seus vizinhos, o vértice $v$ conectado pela aresta $(u, v)$ de menor peso é selecionado.

- Heavy Edge Matching (HEM): No algoritmo HEM os vértices são visitados aleatoriamente. Porém, ao contrário do $L E M$, para cada vértice $u$, selecionado entre seus vizinhos, o vértice $v$ conectado pela aresta $(u, v)$ de maior peso é selecionado.

9 A quantidade de arestas selecionadas pelo algoritmo de matching é configurada pelo fator de redução. Este parâmetro limita a redução da rede nível a nível. 
- Sorted Matching (SM): No algoritmo SM as arestas são ordenadas conforme os pesos, e assim, são selecionados os pares de vértices $u$ e $v$ no qual o peso da aresta $(u, v)$ seja o maior possível.

Cada super-vértice obtido em $G_{l-1}$ é transformado em vértice na rede $G_{l}$ e os vértices que não fizeram parte do conjunto de matching são mantidos na rede $G_{l}$. Na nova rede reduzida $G_{l}$ a conectividade é mantida, caso haja mais de uma aresta entre o vértice (resultante de um super-vértice) e qualquer outro vértice a aresta resultante é dada pela soma dos pesos dessas arestas. Na Figura 8 é mostrado o processo de contração. Utilizando o algoritmo $L E M$, o vértice $v_{1}$ é selecionado na rede $G_{l-1}$, como visto na Figura 8 a, entre seus vizinhos o que é conectado com a aresta de menor peso é o vértice $v_{2}$. O par de vértices $v_{1}$ e $v_{2}$ são selecionados para o conjunto de matching e são transformados em um super-vértice. A Figura $8 \mathrm{~b}$ mostra a rede resultante $G_{l}$ contraída a partir da rede $G_{l-1}$.

Figura 8 - Exemplo de contração utilizando o algoritmo de matching LEM

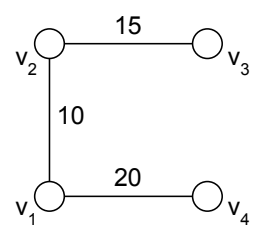

(a) Rede $G_{l-1}$

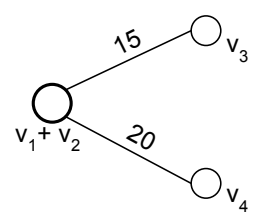

(b) Rede $G_{l}$

Fonte: Elaborada pelo autor.

A segunda fase do paradigma multinível, ou fase da busca da solução inicial, inicia-se após terminadas as $n$ iterações de contração e obtida a rede reduzida $G_{n}$. Na rede $G_{n}$ é aplicado um algoritmo de busca local/global, conforme a necessidade da aplicação, e assim, é obtido a solução nesta rede reduzida, chamada de solução inicial.

A última fase do paradigma multinível, conhecida como fase de projeção, projeta a solução inicial encontrada na rede $G_{n}$ para a rede $G_{n-1}$, sucessivamente, até atingir a solução final na rede $G_{0}$. Na Figura 7, é possível perceber que a comunidade atribuída para qualquer supervértice $v$ na rede $G_{l}$ é a mesma comunidade atribuída aos vértices da rede $G_{l-1}$ decompostos do super-vértice $v$.

Segundo Walshaw (2004), na literatura observa-se um maior uso de tal paradigma no problema de particionamento de redes/detecção de comunidades (LASALLE; KARYPIS, 2015; VALEJO; VALVERDE-REBAZA; LOPES, 2014; DJIDJEV, 2008; BAñOS et al., 2004; KARYPIS; KUMAR, 1998). Entretanto, o paradigma multinível pode resolver diferentes problemas de otimização combinatória, como coloração de grafos (WALSHAW, 2001), cálculo de medidas de centralidade (CHERNOSKUTOV; INEICHEN; BEKAS, 2015) e mais recentemente Silva (2018) utilizou esta abordagem para a tarefa de predição de links. Valejo et al. (2018b) expande os conceitos do paradigma multinível para aplicação em redes bipartidas (VALEJO et al., 2018a). 


\subsection{Agrupamento}

Segundo Xu e Wunsch (2005), vivemos em um mundo cheio de dados, consequentemente, a quantidade destes dados evoluem diariamente, assim torna-se necessário a compreensão destas informações que são geradas constantemente. Um dos meios de lidar com esses dados, quando os dados não são rotulados, é agrupá-los conforme suas semelhanças. Agrupamento, ou clustering, é uma técnica de aprendizado não-supervisionado que tem como objetivo agrupar objetos (ou exemplos) de acordo com a similaridade ${ }^{10}$ entre eles, de modo que a semelhança dos objetos dentro de um mesmo grupo seja maior que a similaridade entre objetos de grupos diferentes. Assim, a partição resultante de um agrupamento é dada pelo conjunto de $n$ objetos particionados em $k$ grupos, também chamado de clusters, baseado em uma estratégia predefinida.

\subsubsection{Métodos de Agrupamento}

Os métodos de agrupamento são divididos de acordo com a abordagem utilizada para particionar o conjunto de dados. Nesta seção, são apresentados três abordagens (por particionamento, hierárquicos e baseados em densidade) de agrupamento que são utilizadas para construir redes a partir de trajetórias.

\subsubsection{Por particionamento}

Os métodos de agrupamento por particionamento caracterizam-se pela definição prévia do número de grupos do agrupamento resultante. $\mathrm{O}$ algoritmo mais conhecido deste grupo de algoritmos é o k-means (KANUNGO et al., 2002). Neste algoritmo, após determinado o número $k$ de grupos é calculado o centroide para cada grupo aleatoriamente. Assim, para cada objeto atribui-se o grupo mais próximo e recalcula o centroide dos grupos. Isso é repetido até as atribuições dos objetos aos grupos não se alterarem mais. Na Figura 9 é mostrado um exemplo de aplicação do algoritmo $k$-means com diferentes valores de $k$.

Figura 9 - Exemplo aplicação do algoritmo k-means

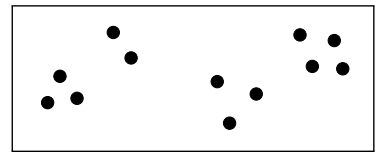

(a) Conjunto de dados

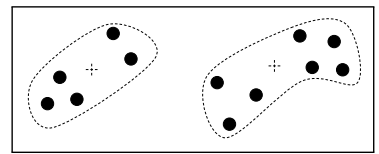

(b) $k=2$

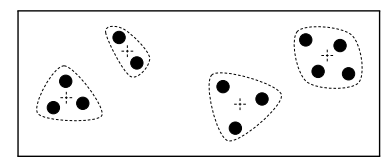

(c) $k=4$

Fonte: Elaborada pelo autor.

${ }_{10}$ Geralmente, a similaridade é dada pela distância entre dois objetos, sendo que a distância pode ser: euclidiana, geodésica, manhattan, etc. 


\subsubsection{Hierárquicos}

Segundo Xu e Wunsch (2005), o agrupamento hierárquico organizam os dados em uma estrutura hierárquica e os resultados deste agrupamento são representados por dendrogramas. $\mathrm{O}$ nó raiz do dendrograma representa todo o conjunto de dados e cada nó da folha é considerado como um objeto de dados. Os nós intermediários, portanto, descrevem a extensão em que os objetos estão próximos uns dos outros e a altura do dendrograma, geralmente, expressa a distância entre cada par de objetos ou grupos. Os resultados finais de agrupamento podem ser obtidos cortando o dendrograma em diferentes níveis. Existem duas estratégias de abordagem para o agrupamento hierárquico: aglomerativa e divisiva.

$\mathrm{Na}$ estratégia hierárquica aglomerativa um conjunto de $n$ objetos, onde inicialmente cada objeto é considerado um grupo. Iterativamente, agrupa-se objetos semelhantes. Este procedimento ocorre até haver apenas um grupo de $n$ objetos ou atingir algum critério de parada (DAY; EDELSBRUNNER, 1984). No algoritmo AGglomerative NESting (AGNES) (KAUFMAN; ROUSSEEUW, 1990), o agrupamento é realizado entre pares de grupos mais próximos a cada iteração. Na Figura 10a é exemplificada o resultado do agrupamento hierárquico aglomerativo e na Figura 10b é mostrado o dendrograma resultante do agrupamento realizado na Figura 10a.

Figura 10 - Exemplo estratégia hierárquica aglomerativa

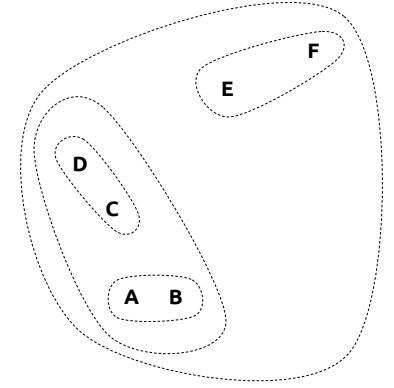

(a) Agrupamento hierárquico

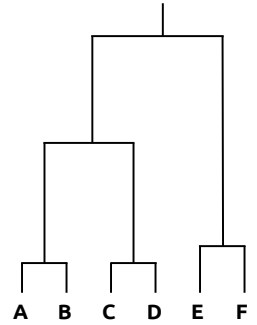

(b) Dendrograma

Fonte: Elaborada pelo autor.

O algoritmo de agrupamento hierárquico aglomerativo, descrito acima, diferencia-se pela forma como considera a distância entre dois grupos. Abaixo os critérios mais tradicionais utilizados para definir a distância entre grupos no agrupamento hierárquico aglomerativo:

Single-linkage $(\boldsymbol{S L})$ : neste critério, a Figura 10 é um exemplo de Single-linkage, a distância entre dois grupos $X$ e $Y$ é dada como a menor distância de um objeto $x \in X$ para um objeto $y \in Y$. Formalmente, a distância entre dois grupos é dada por:

$$
D_{\min }(X, Y)=\min _{\forall x \in X, \forall y \in Y} \operatorname{dist}(x, y)
$$


Complete-linkage $(\boldsymbol{C L})$ : neste critério, a distância entre dois grupos $X$ e $Y$ é dada por:

$$
D_{\max }(X, Y)=\max _{\forall x \in X, \forall y \in Y} \operatorname{dist}(x, y)
$$

Average-linkage (UPGMA): neste critério, a distância entre dois grupos $X$ e $Y$ é dada por:

$$
D_{\text {average }}(X, Y)=\frac{1}{|X| .|Y|} \sum_{\forall x \in X} \sum_{\forall y \in Y} \operatorname{dist}(x, y)
$$

$\mathrm{Na}$ estratégia hierárquica divisiva inicia-se todos os $n$ objetos em um mesmo grupo. Em cada nível da hierarquia dividi-se os objetos em grupos menores (e.g. aplicando o k-means) até alcançar $n$ grupos ou alguma condição de parada ser alcançada. Os conceitos da estratégia hierárquica divisiva foram apresentados juntamente com o algoritmo de agrupamento hierárquico divisivo DIvisive ANAlysis Clustering (DIANA)(KAUFMAN; ROUSSEEUW, 1990).

\subsubsection{Baseados em densidade}

Nos métodos baseados em densidade um grupo é formado de acordo com a densidade de uma região, assim grupos são regiões densas de objetos separados por regiões de baixa ou nula densidade. A seguir são explanados os dois principais métodos de agrupamento baseados em densidade.

O algoritmo Density-Based Spatial Clustering of Applications with Noise (DBSCAN) (ESTER et al., 1996) permite a formação de grupos não-convexos e com formas arbitrárias. Neste algoritmo o parâmetro $E$ ps define o raio de alcance da vizinhança dos objetos e o parâmetro MinPts define a quantidade mínima de objetos dentro de um grupo. Assim, um objeto de núcleo tem uma vizinhança maior ou igual a MinPts dentro do raio Eps. Um objeto de borda é um objeto que alcançável por um objeto de núcleo, mas a vizinhança alcançável de um objeto de borda é menor que MinPts. Portanto, um grupo no DBSCAN é formado pelo conjunto de objetos núcleos alcançáveis entre si e seus respectivos objetos de borda. Objetos que não são objetos de borda ou objetos núcleo são considerados ruídos. No exemplo da Figura 11 o objeto $P_{1}$ é um um objeto núcleo, pois sua vizinhança é igual ao valor de MinPts, objeto $P_{4}$ é um objeto de borda, consequentemente o um grupo é formado pelos objetos $P_{1}, P_{2}, P_{3}$ e $P_{4}$ e o objeto $P_{5}$ é um ruído.

O algoritmo Ordering Points to Identify the Clustering Structure (OPTICS) (ANKERST et al., 1999) é uma extensão do DBSCAN que ataca seu principal problema: detectar grupos significativos em dados com densidade variável. Assim, o OPTICS realiza a ordenação da base de dados permitindo que objetos sejam processados de modo a expandir um grupo, ou seja, garantindo que grupos altamente densos sejam processados primeiro. Portanto, a estrutura ordenada (pode ser visualizada como uma hierarquia) é equivalente a execução do DBSCAN para infinitos valores de Eps, no qual o parâmetro MinPts seja fixo. 
Figura 11 - Exemplo DBSCAN

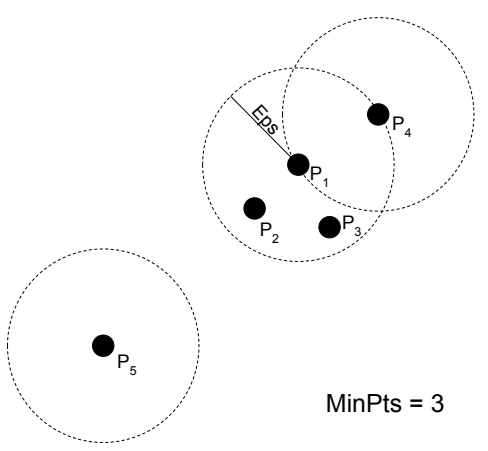

Fonte: Elaborada pelo autor.

\subsubsection{Validação}

Validação é o nome dado aos diferentes procedimentos que avaliam os resultados de análise de agrupamento. Os procedimentos de validação que quantificam estes resultados são chamados de índices. Estes índices são divididos em: índices de validação internos e índices de validação externos. As definições e nomenclaturas apresentadas a seguir são retiradas de Vendramin, Campello e Hruschka (2010) e Rosenberg e Hirschberg (2007).

\subsubsection{Indices Internos}

Os índices internos analisam a partição resultante em relação a algum critério. Estes critérios podem ser: separabilidade dos grupos e/ou compacidade. A seguir, são mostrados alguns índices internos.

Coeficiente de Silhueta: indica a similaridade de um objeto em relação ao seu grupo em comparação com os demais grupos. Assim, temos que a silhueta de um objeto $x_{j}$, do conjunto de dados, que pertence ao grupo $p \in\{1,2, \ldots, k\}$ é dada por:

$$
s_{x_{j}}=\frac{b_{p, j}-a_{p, j}}{\max \left\{a_{p, j}, b p, j\right\}}
$$

Onde, $a_{p, j}$ indica a distância média do objeto $x_{j}$ para todos os outros objetos de classe $p$ e $b_{p, j}$ indica a distância média do objeto $x_{j}$ para todos os outros objetos pertencentes ao grupo mais próximo de $p$. O denominador é utilizado para normalizar o resultado. Temos que $s_{x_{j}} \in[-1,1]$, sendo que valores negativos representam uma maior similaridade do objeto com o grupo vizinho, enquanto valores positivos indicam o grau de pertinência ao grupo atribuído ao objeto. 
O coeficiente de silhueta é dado pela média das silhuetas de todos os objetos do conjunto de dados, como mostrado a seguir:

$$
C S=\frac{1}{N} \sum_{j=1}^{N} s_{x_{j}}
$$

\subsubsection{Indices Externos}

Os índices externos comparam a partição resultante com uma partição previamente conhecida, ou seja, com as classes definidas (dados rotulados). A seguir, são apresentadas e discutidas os principais índices externos utilizados neste trabalho:

Rand Index: indica a similaridade entre a partição resultante (sob avaliação) e a partição esperada (ou partição de referência). Sendo $R$ a partição de referência dividida em $k *$ grupos conhecidos e $Q$ a partição resultante dividida em $k$ grupos a serem avaliados, o índice Rand Index é dado por:

$$
R I=\frac{a+d}{a+b+c+d}
$$

Onde:

- $a$ : número de pares de elementos pertencentes a mesma classe em $R$ e ao mesmo grupo em $Q$.

- $b$ : número de pares de elementos pertencentes a mesma classe em $R$ que não pertencem ao mesmo grupo em $Q$.

- c: número de pares de elementos pertencentes ao mesmo grupo em $Q$ que não pertencem a mesma classe em $R$.

- $d$ : número de pares de elementos pertencentes a classes diferentes em $R$ e a grupos diferentes em $Q$.

Segundo Vendramin, Campello e Hruschka (2010) os termos a e d indicam as classificações consistentes, enquanto os termos b e c indicam as classificações inconsistentes.

Adjusted Rand Index: A principal crítica ao Rand Index é que ele não é ajustado para o acaso, ou seja, seu valor não é zero ao comparar partições aleatórias. Em Hubert e Arabie (1985), os autores propuseram o ajuste necessário para corrigir este problema, como mostrado a seguir:

$$
A R I=\frac{a-\frac{(a+c)(a+b)}{M}}{\frac{(a+c)+(a+b)}{2}-\frac{(a+c)(a+b)}{M}}
$$


Onde, $M=a+b+c+d$. Assim, o valor 0 indica que a partições foram selecionadas ao acaso e o valor 1 indica que a clusterização perfeita foi alcançada.

Homogeneidade: é uma propriedade que é satisfeita quando todos os grupos, da partição resultante, contiverem apenas objetos de uma única classe. Em um conjunto de dados de N objetos e duas partições: um conjunto de classes, $C=\left\{c_{i} \mid i=1, \ldots, n\right\}$ e um conjunto de grupos (partição resultante), $K=\left\{k_{j} \mid j=1, \ldots, m\right\}$. Seja $A$ a tabela de contingência produzida pelo agrupamento, de forma que $A=\left\{a_{i j}\right\}$ onde $a_{i j}$ é o número de objetos que são membros da classe $c_{i}$ e elementos do grupo $k_{j}$. Formalmente, a homogeneidade é definida como:

$$
h=\left\{\begin{array}{l}
1, \text { se } H(C, K)=0 \\
1-\frac{H(C, K)}{H(C)}, \text { c.c. }
\end{array}\right.
$$

Onde,

$$
\begin{aligned}
& H(C \mid K)=-\sum_{k=1}^{|K|} \sum_{c=1}^{|C|} \frac{a_{c k}}{N} \log \frac{a_{c k}}{\sum_{c=1}^{|C|} a_{c k}} \\
& H(C)=-\sum_{c=1}^{|C|} \frac{\sum_{k=1}^{|K|} a_{c k}}{n} \log \frac{\sum_{k=1}^{|K|} a_{c k}}{n}
\end{aligned}
$$

Sendo $h \in[0,1]$, onde o valor 0 é indesejável e o valor 1 indica a homogeneidade perfeita da partição resultante.

Completude: é uma propriedade que é satisfeita quando todos os objetos que são membros de uma determinada classe forem elementos de um mesmo grupo. A nomenclatura utilizada é a mesma apresentada em Homogeneidade. Assim, a completude é definida como:

$$
c=\left\{\begin{array}{l}
1, \text { se } H(K, C)=0 \\
1-\frac{H(K, C)}{H(K)}, \text { c.c. }
\end{array}\right.
$$

Onde,

$$
\begin{gathered}
H(K \mid C)=-\sum_{c=1}^{|C|} \sum_{k=1}^{|K|} \frac{a_{c k}}{N} \log \frac{a_{c k}}{\sum_{k=1}^{|K|} a_{c k}} \\
H(K)=-\sum_{k=1}^{|K|} \frac{\sum_{c=1}^{|C|} a_{c k}}{n} \log \frac{\sum_{c=1}^{|C|} a_{c k}}{n}
\end{gathered}
$$

Sendo $c \in[0,1]$, onde o valor 0 é indesejável e o valor 1 indica a completude perfeita da partição resultante. 


\subsection{Considerações Finais}

Rede é uma poderosa representação de problemas ou de abstrações do mundo real, muitas relações do nosso cotidiano são facilmente extraídas no formato de uma rede, como é o caso das redes sociais. Redes sociais fornecem as diversas relações que ocorrem em uma sociedade, além de mostrar a segregação dessa sociedade em comunidades que são formadas por características comuns entre as pessoas pertencentes a esses grupos.

As redes sociais online possibilitam expandir as relações sociais para o mundo virtual, além de manter o histórico dessas relações. Em termos de pesquisa, essas plataformas fornecem um conteúdo amplo para investigação em diversas áreas do conhecimento com o objetivo final de melhorar o entendimento da sociedade e suas relações.

As redes sociais geolocalizadas fornecem, além das relações sociais, informações sobre as relações dos usuários e o espaço geográfico, ou seja, informações sobre a mobilidade humana. Redes sociais geolocalizadas são abstraídas em redes heterogêneas de acordo com as trajetórias de seus usuários, na qual podem ser extraídas três diferentes tipos de redes: rede usuário-usuário, rede local-local e rede usuário-local.

Agrupamento é uma técnica que tem como objetivo agrupar objetos similares. Esta técnica é utilizada, como será visto no Capítulo 3, em Mineração de Trajetórias e Mineração de Redes Sociais Geolocalizadas para a construção de redes baseadas em trajetórias.

O paradigma multinível é uma abordagem poderosa na área de redes, pois visa reduzir o espaço de busca para a aplicabilidade de algoritmos de alto custo computacional. O paradigma é divido em três etapas: contração, busca pela solução inicial e projeção. A etapa de contração, como será proposto no Capítulo 4, também pode ser utilizada para construção de redes baseadas em trajetórias. 


\section{REPRESENTAÇÃO DE TRAJETÓRIAS}

Segundo Ericsson (2015), em 2020 setenta por cento da população mundial irá utilizar smartphones, isso significa que haverá 6,1 bilhões de aparelhos em todo o globo terrestre, o dobro que o valor computado em 2015. Uma das características dos smartphones é a incorporação de receptores Global Positioning System (GPS) que possibilitam a aquisição de dados geográficos dos usuários. Além do constante crescimento na utilização de GPS, através dos smartphones, há também a popularização de outras formas de aquisição de dados geográficos como o RadioFrequency Identification (RFID) ${ }^{1}$ e o beacon ${ }^{2}$.

Redes sociais online, tais como Facebook e Foursquare, são plataformas online que possibilitam que seus usuários compartilhem ideias, fotos e check-ins. Já nas redes sociais geolocalizadas ( $L B S N)$ são compartilhadas informações geográficas, tendo assim, informações mais detalhadas sobre o histórico de localizações dos usuários. A obtenção dessas informações geográficas, seja através de check-ins ou de coordenadas geográficas captadas por GPS, só é possível aliada ao fenômeno Volunteered Geographic Information (VGI) que é a permissão ou disponibilização voluntária dos usuários de informações geográficas pessoais.

A popularização do GPS, em conjunto com o surgimento das $L B S N s$ e do VGI, têm gerado uma massiva quantidade de dados geográficos que são organizados em trajetórias. Trajetórias são sequências ordenadas de coordenadas geográficas ou de check-ins que representam o caminho de qualquer objeto móvel, sejam esses objetos pessoas, animais ou veículos. A partir desse grande volume de trajetórias surge a necessidade de obter melhor representação sobre esses dados, e a partir destas representações descobrir conhecimento sobre o comportamento de locomoção do(s) objeto(s) de estudo. Esses desafios são enfrentados e estudados na Mineração de Trajetórias.

De acordo com Mazimpaka e Timpf (2016), a Mineração de Trajetórias é uma adaptação dos conceitos e métodos da Mineração de Dados por causa da especifidade dos dados geográficos,

Método de identificação automática através de sinais de rádio

2 Aparelhos de proximidade que emitem informações, por meio da tecnologia bluetooth 
tendo em vista suas relações espaciais e temporais. Em (ZHENG, 2015), o autor caracteriza a Mineração de Trajetórias como a descoberta de conhecimento de objetos móveis, de um indivíduo ou grupos, dando ênfase no poder de aplicação das técnicas em $L B S N$ e Sistemas de Transporte Inteligentes. Ainda em (ZHENG, 2015), o autor diz que a Mineração de Trajetórias está em grande expansão e cada vez mais atrai o interesse de diferentes áreas do conhecimento, principalmente na sociologia, geografia e ciência da computação.

Neste capítulo são apresentados os principais conceitos relacionados a trajetórias e suas formas de representação, além de introduzir algumas tarefas de mineração de trajetórias. Na Seção 3.1 são apresentados os principais conceitos de mineração de trajetórias que são utilizados na representação de trajetórias. Na Seção 3.2 são apresentadas as diferentes formas de transformar trajetórias em vértices de redes, tema principal desta pesquisa. Por fim, são realizadas as considerações finais deste capítulo.

\subsection{Conceitos Básicos}

Todos os conceitos e definições apresentadas nesta seção foram baseados em Zheng e Zhou (2011), Zheng (2015) e Feng e Zhu (2016).

Chamamos de espaço geográfico qualquer região ou parte da superfície terrestre. Portanto, a região delimitada por uma casa, bairro, cidade, país ou até mesmo toda superfície terrestre são considerados espaços geográficos. O sistema de mapeamento terrestre é dado através de coordenadas geográficas. Este mapeamento permite distinguir qualquer ponto da superfície do planeta por meio de uma coordenada geográfica. Coordenada geográfica é uma dupla (latitude, longitude) que representa um ponto exato na superfície terrestre. Atualmente, a maneira mais fácil de descobrir a coordenada geográfica de uma localização é através de aparelhos que contém a tecnologia GPS. Em um $G P S^{3}$ cada coordenada geográfica é associada a data e horário de captura da coordenada. Portanto, um ponto de GPS $p$ é uma quadrupla (id, latitude,longitude,data_hora) e representa um ponto exato terrestre visitado em uma determinada data e horário, o campo id é o identificador do aparelho/usuário. Consequentemente, um GPS log é o conjunto de pontos de GPS realizado por um ou vários aparelhos GPS.

O caminho cronológico percorrido por um objeto móvel (pessoas, animais, carros, etc.) caracteriza uma trajetória. Por meio do GPS log é possível organizar pontos de GPS em uma ou diversas trajetórias. Trajetória geográfica é uma sequência temporal de pontos de GPS realizados por um objeto móvel. Formalmente, uma trajetória geográfica é um conjunto de pontos de $G P S$, denominado $T=\left\{p_{1}, p_{2}, \ldots, p_{n}\right\}$, onde $p_{i-1}$ foi visitado anteriormente a $p_{i}$ e assim sucessivamente. A sequência de pontos de GPS $\left\{p_{1}, p_{2}, p_{3}, \ldots, p_{9}\right\}$, visto na Figura 12, é um exemplo de trajetória geográfica.

3 Esse conceito pode ser expandido para tecnologias como RFID e beacon, mas para facilitar a discussão utilizaremos a tecnologia GPS como exemplo. 
Figura 12 - Exemplo de trajetória geográfica

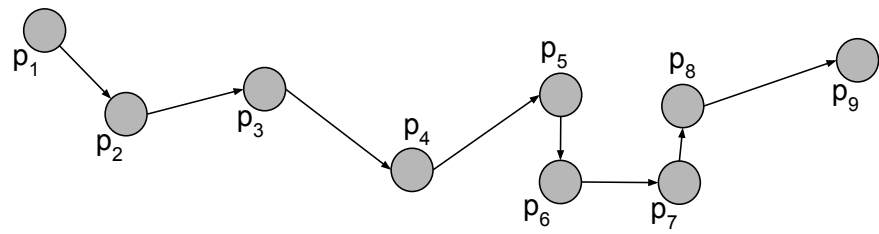

Fonte: Elaborada pelo autor.

Check-ins são registros realizados em LBSNs, onde usuários compartilham sua localização no mundo real em um determinado momento. Os check-ins caracterizam-se por possuírem etiquetas. Estas etiquetas, ou símbolos, representam um espaço geográfico que tem uma função específica no mundo real, por exemplo: Bumbódromo de Parintins, Instituto de Ciências Matemáticas e de Computação, Padaria Universo, Shopping Rio Claro, etc. As etiquetas estão associadas com uma coordenada geográfica, que geralmente representam o ponto central do local descrito na etiqueta. Portanto, um check-in é uma quadrupla (usuario,local,coordenada,data_hora). Assim, check-ins também podem ser organizados como trajetórias. Trajetórias de check-ins, ou trajetória semântica ${ }^{4}$, é uma sequência ordenada cronologicamente de check-ins.

Toda trajetória está associada a um usuário ${ }^{5}$. Portanto, uma trajetória pode corresponder a todo o histórico de mobilidade deste usuário. Porém, via de regra, é interessante segmentar essas trajetórias, pois de acordo com Zheng (2015), a segmentação diminui a complexidade computacional e proporciona uma extração de conhecimento mais rica. A maneira mais comum de segmentar trajetórias é a divisão destas trajetórias por intervalos de tempo (hora, dia, semana, etc.), assim, uma trajetória é dividida em subtrajetórias, onde cada subtrajetória corresponde a um intervalo de tempo predeterminado.

Um ponto de permanência é um ponto que representa um espaço geográfico onde o usuário permanece por um tempo significativo (LI et al., 2008). A extração de pontos de permanências em uma trajetória geográfica depende de dois parâmetros, um limitante de tempo $\left(T_{\text {threshold }}\right)$ e uma distância limite $\left(D_{\text {threshold }}\right)$. Assim, um ponto de permanência é um grupo de coordenadas geográficas consecutivas $P^{\prime}=\left\{p_{m}, p_{m+1}, \ldots, p_{n}\right\}$ em uma trajetória geográfica, onde $\forall m<i \leq n$ satisfaz as seguintes restrições:

$$
\begin{gathered}
\text { Distance }\left(p_{m}, p_{i}\right) \leq D_{\text {threshold }} \\
\left|p_{n} \cdot T-p_{m} \cdot T\right| \leq T_{\text {threshold }}
\end{gathered}
$$

A coordenada de um ponto de permanência $s$ é a média das coordenadas do grupo

4 Trajetória semântica é toda trajetória que associa semântica à trajetória.

5 A partir daqui, o termo usuário é utilizado para referir-se a um objeto móvel. 
de pontos $P^{\prime}$. Na Figura 13, o conjunto de pontos de GPS consecutivo $P^{\prime}=\left\{p_{6}, p_{7}, p_{8}, p_{8}\right\}$ exemplifica a detecção de um ponto de permanência na trajetória geográfica. A sequência cronológica de pontos de permanência é considerada uma trajetória de pontos de permanência.

Figura 13 - Exemplo de detecção de pontos de permanência

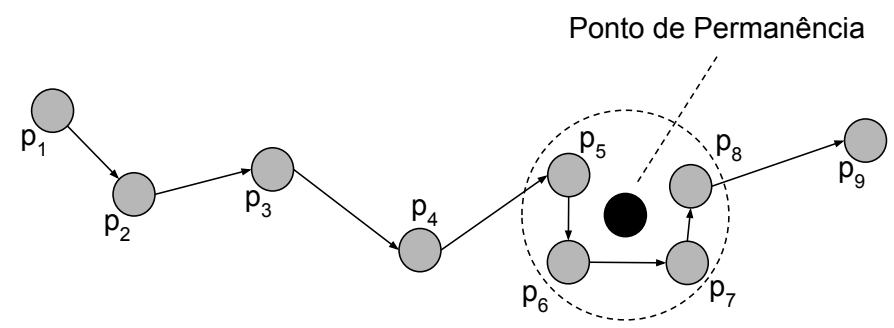

Fonte: Elaborada pelo autor.

Pontos de permanência podem ser vistos como pontos mais importantes em uma trajetória geográfica, pois cada ponto de permanência representa a utilização daquele espaço geográfico pelo usuário por um determinado tempo. Portanto, trajetória de pontos de permanência é a compressão de uma trajetória geográfica, onde só pontos relevantes fazem parte da trajetória.

\subsection{Representação por Redes}

Por sua característica temporal, naturalmente, trajetórias podem ser representadas como séries temporais (LI; WANG; HAN, 2012; LI et al., 2010; CAO; MAMOULIS; CHEUNG, 2007). Outra forma de representação é como sequência de itens (ZHANG et al., 2014; MASCIARI; SHI; ZANIOLO, 2013; GIANNOTTI et al., 2007), onde trajetórias geográficas são transformadas em trajetórias semânticas e os conceitos de Mineração de Padrões Sequenciais são adaptados para trajetórias. Porém, este trabalho tem como foco o estudo da representação de trajetórias através de suas relações, seja esta relação entre locais ou entre usuários e locais. Redes são poderosas representações de elementos e suas relações, contudo, construir redes ${ }^{6}$ a partir de trajetórias não é tarefa simples.

Uma base de dados de trajetórias ${ }^{7} U$ pode ser usada para construir uma rede local-local $G_{l l}$, onde o conjunto $V_{l} \in G_{l l}$ de vértices são do tipo local. Portanto, após obtida a rede $G_{l l}$, uma trajetória $T \in U$, é transformada em sequência de vértices de $V_{l}$.

Com a rede $G_{l l}$, tem-se a definição do conjunto de vértices $V_{l}$. Logo, utilizando $V_{l}$ é possível construir de maneira simples, como visto na Seção 2.2, a rede $G_{u l}$ usuário-local.

Segundo Zheng (2015), o principal desafio de construir redes a partir de trajetórias está na modelagem do que serão os vértices do tipo local. A seguir, são apresentadas duas

6 Redes construídas a partir de trajetórias são redes geolocalizadas, pois os vértices contém informações geográficas do local representado. A partir daqui, o termo redes indicará redes geolocalizadas.

7 Trajetórias geográficas, trajetórias de check-ins ou trajetórias de pontos de permanência. 
estratégias para construir redes a partir de trajetórias, ou seja, estratégias que definem o conjunto de vértices do tipo local da rede a ser construída. Na Seção 3.2.1 é apresentada a estratégia baseada em mapeamento do espaço geográfico e na Seção 3.2.2 é apresentada a estratégia baseada na mobilidade.

\subsubsection{Rede Baseada em Mapeamento do Espaço Geográfico}

Nesta estratégia utiliza-se o mapeamento do espaço geográfico para a modelagem da rede. Essa modelagem pode ser feita utilizando a malha viária ou desconsiderando-a. A seguir são apresentadas estas duas abordagens.

\subsubsection{Com Malha Viária}

Neste tipo de abordagem a estrutura viária das cidades é utilizada na modelagem da rede. Geralmente, os vértices indicam um cruzamento viário ${ }^{8}$ e as arestas são segmentos de ruas, avenidas, ou rodovias que conectam dois cruzamentos viários. As redes são direcionadas, onde a direção da aresta indica o sentido de circulação da via em questão. No exemplo da Figura 14 é mostrado um exemplo de construção de rede utilizando mapeamento da malha viária. $\mathrm{Na}$ Figura 14a é selecionado um espaço geográfico e na Figura 14b este mesmo espaço geográfico é representado através de uma rede, nota-se que os cruzamentos de vias dão origem aos vértices.

Figura 14 - Exemplo de construção de rede através da malha viária

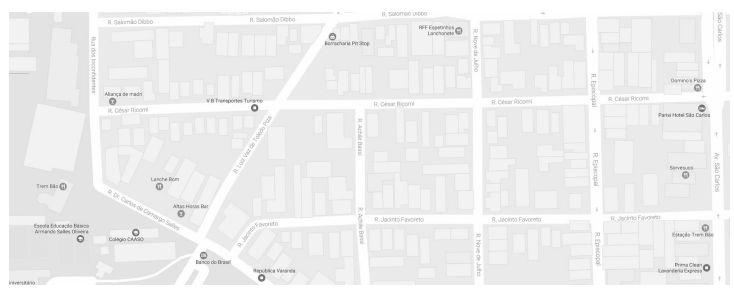

(a) Espaço geográfico

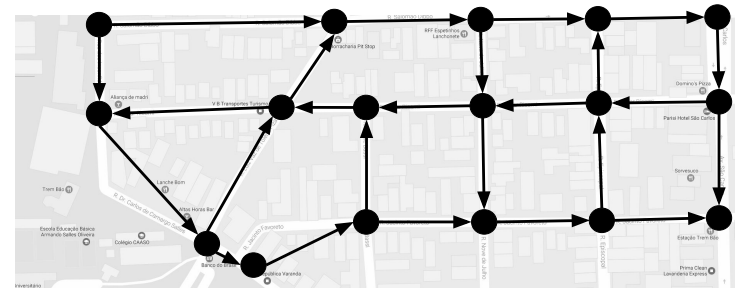

(b) Rede utilizando malha viária

Fonte: Elaborada pelo autor.

Após a construção da rede, são utilizadas técnicas de Map Matching para transformar trajetórias geográficas em sequência de vértices. A técnica de Map Matching associa uma coordenada geográfica a um vértice e, consequentemente, uma grande quantidade de coordenadas geográficas são associadas a um mesmo vértice, o que torna a representação da trajetória mais compacta. Abordagens geométricas para realizar o Map Matching, como em (GREENFELD, 2002), têm problemas em diferenciar ruas paralelas. Para resolver o problema citado anteriormente foram propostos, ao longo dos anos, diversas abordagens. Tendo maior destaque as abordagens topológica (YUAN et al., 2010) e probabilística (PINK; HUMMEL, 2008).

8 Cruzamento entre ruas, avenidas, rodovias, etc. 
Uma das principais aplicações utilizando este tipo de abordagem é a de encontrar o caminho mais rápido entre dois locais (HUANG et al., 2016; YUAN et al., 2013; YUAN et al., 2011). Em (LUO et al., 2013), são encontrados os caminhos mais frequentes durante um determinado dia e hora da semana. Outros trabalhos (KARAGIORGOU; PFOSER; SKOUTAS, 2017; ZHENG et al., 2012) tentam reconstruir a rota de trajetórias com baixa amostragem de pontos. Já em (ZHANG et al., 2015; ZENG; HUANG, 2014), é investigada a influência da malha urbana nos acidentes de trânsito ocorridos e a segurança de pedestres no espaço geográfico em questão.

Assim, a abordagem descrita acima é amplamente utilizada quando o objeto móvel em questão é um veículo terrestre (e.g. carros e motocicletas). Entretanto, para outros tipos de objetos móveis, por exemplo: pedestres ou animais, o mapeamento utilizando a malha viária pode não ser fiel a trajetória original, principalmente quando a trajetória representar a mobilidade em áreas não urbanas ou em grandes espaços urbanos como parques, universidades, etc.

\subsubsection{Sem Malha Viária}

Neste tipo de abordagem, um espaço geográfico a ser estudado, tais como parques de diversões, universidades, shoppings, etc., é mapeado manualmente por um especialista, assim, vértices representam as coordenadas dos locais de interesse do estudo (e.g. lojas de um shopping).

O mapeamento sem malha viária pode ser útil em espaços geográficos pequenos em que não há alteração do espaço geográfico de estudo. Porém, em espaços geográficos grandes ou na análise de diversos espaços geográficos a modelagem manual das redes torna-se impeditiva.

\subsubsection{Rede Baseada na Mobilidade}

A representação de trajetórias por redes baseada na mobilidade utiliza apenas as localidades visitadas presentes no conjunto de dados ou de trajetórias para definir os vértices (do tipo local) que estarão presentes na rede. Esta abordagem difere-se da utilizada por mapeamento, pois utilizando mapeamento a rede é obtida de maneira prévia, já na representação de trajetórias por redes baseada na mobilidade é necessário processamento dos dados para identificar os vértices e, consequentemente, construir a rede. Existem duas abordagens, que diferem-se pelo tipo de trajetória utilizada, que serão apresentadas a seguir.

\subsubsection{Trajetórias de check-ins}

Esse tipo de abordagem é utilizada por LBSNs que representam as localizações de maneira simbólica (e.g. Foursquare). Assim, vértices são as diferentes etiquetas encontradas nas trajetórias de check-ins, ou seja, se houve check-in em um determinado local este local será um vértice na rede. Portanto, o conjunto de vértices representa um conjunto de locais com seus 
significados no mundo real (e.g. Livraria Machado de Assis, Trem Bão da Avenida São Carlos, etc.).

Trabalhos como de (VALVERDE-REBAZA et al., 2018; BAYRAK; POLAT, 2016; VALVERDE-REBAZA et al., 2016; KYLASA; KOLLIAS; GRAMA, 2015), predizem relações de amizades em LBSNs de representação simbólica das localizações. Em (BROWN et al., 2012), o foco do trabalho é descobrir amigos que se encontraram no mundo físico através de seus check-ins. Já nos trabalhos de (XU et al., 2016; ZHAO et al., 2013), os autores propõem métodos para detectar comunidades em LBSNS.

\subsubsection{Trajetórias por pontos de permanência}

Trajetórias geográficas são transformadas em redes em um processo dividido em duas etapas: primeiramente trajetórias geográficas são transformadas em trajetórias de pontos de permanência e depois, pontos de permanência similares são agrupados e transformados em vértices (ZHENG, 2015). No decorrer desta seção é discutido este processo. No exemplo da Figura 15, é mostrado uma possível rede, construída pelo método descrito acima, do espaço geográfico mostrado na Figura 14a.

Figura 15 - Exemplo de rede baseada em mobilidade construída através de trajetórias geográficas

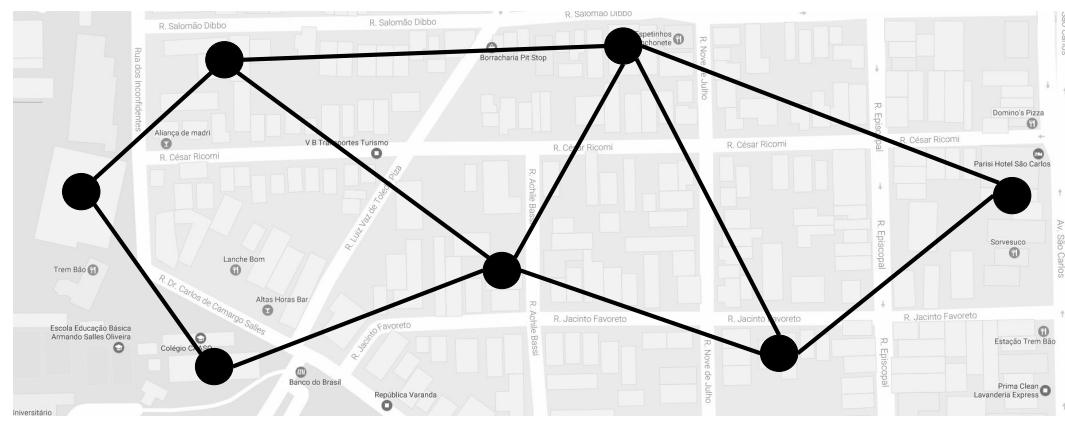

Fonte: Elaborada pelo autor.

Em trajetórias por pontos de permanência, um único espaço geográfico pode ser representado por diferentes pontos de permanência. Assim, trajetórias por pontos de permanência realizadas por um ou mais usuários não são diretamente comparáveis. Na Figura 16 é mostrado um exemplo da inconsistência de comparação de pontos de permanência. No exemplo são mostradas as trajetórias $T_{1}=\left\{p_{11}, p_{12}, p_{13}\right\}, T_{2}=\left\{p_{21}, p_{22}, p_{23}\right\}$ e $T_{3}=\left\{p_{31}, p_{32}, p_{33}\right\}$ realizadas por usuários distintos. No mundo real, esses três usuários passaram pelos mesmos lugares, EmpresaX $\rightarrow$ RestauranteA $\rightarrow$ MuseuY, porém suas trajetórias por pontos de permanência são distintas.

Assim, surge a necessidade de agrupar pontos de permanência próximos. Aplica-se um algoritmo de agrupamento e pontos próximos são unidos em um mesmo grupo, consequentemente, grupos são transformados em vértices da rede. Na Figura 17 é mostrado o processo 
Figura 16 - Exemplo de incomparabilidade de trajetórias por pontos de permanência

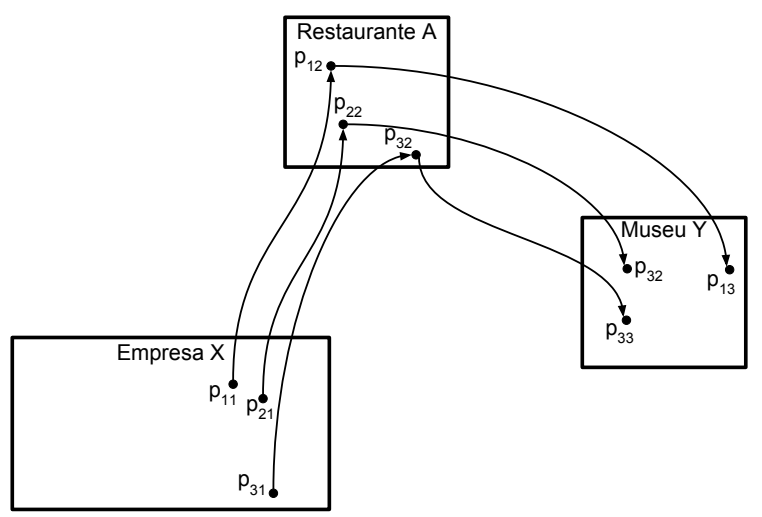

Fonte: Elaborada pelo autor.

de transformar trajetórias de pontos de permanência em rede. Primeiro é visto o conjunto de trajetórias, visto na Figura 17a, depois é aplicado o algoritmo de agrupamento (Figura 17b) e por fim, os grupos são transformados em vértices e as arestas da rede são atribuídas aos dois grupos visitados em sequência, Figura 17c.

Figura 17 - Exemplo da transformação de trajetórias por pontos de permanência em rede

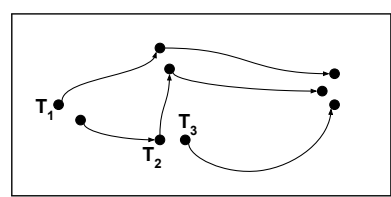

(a) Trajetórias

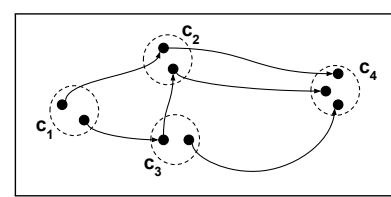

(b) Agrupamento dos pontos

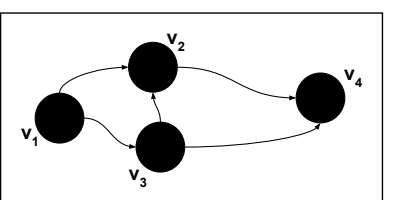

(c) Rede local-local

Fonte: Elaborada pelo autor.

A forma mais utilizada para agrupar os pontos de permanência é aplicando algoritmos de agrupamento baseado em densidade (e.g. $D B S C A N$ ), por causa de sua capacidade de encontrar grupos de formas arbitrárias (ZHENG et al., 2009). Porém, são encontrados na literatura, menos comumente, a aplicação de outros tipos de algoritmo, por exemplo do algoritmo $k$ means (KANDA et al., 2007). O problema deste algoritmo, no entanto, o problema deste algoritmo está na definição do parâmetro $k$, que para esta aplicação é o número de vértices da rede a ser determinada.

Em (LI et al., 2008), é apresentado o método mais utilizado na construção de redes a partir de pontos de permanência. Os autores aplicam agrupamento hierárquico divisivo nos pontos de permanência para construir uma rede hierárquica. É utilizado o algoritmo OPTICS para agrupar os pontos de permanência. O OPTICS é utilizado devido a sua capacidade de extrair grupos com diferentes valores de raio. Em cada nível é construída uma rede com um valor de raio específico, de modo que o valor do raio é reduzido conforme cada novo nível é construído. Assim, a hierarquia funciona como uma escala espacial, portanto, descendo no nível hierárquico 
diminui-se o tamanho das regiões geográficas representadas pelos agrupamentos. A Figura 18 mostra a construção de uma rede hierárquica, no exemplo é criada uma rede hierárquica com três níveis de escala espacial.

Figura 18 - Exemplo de rede hierárquica
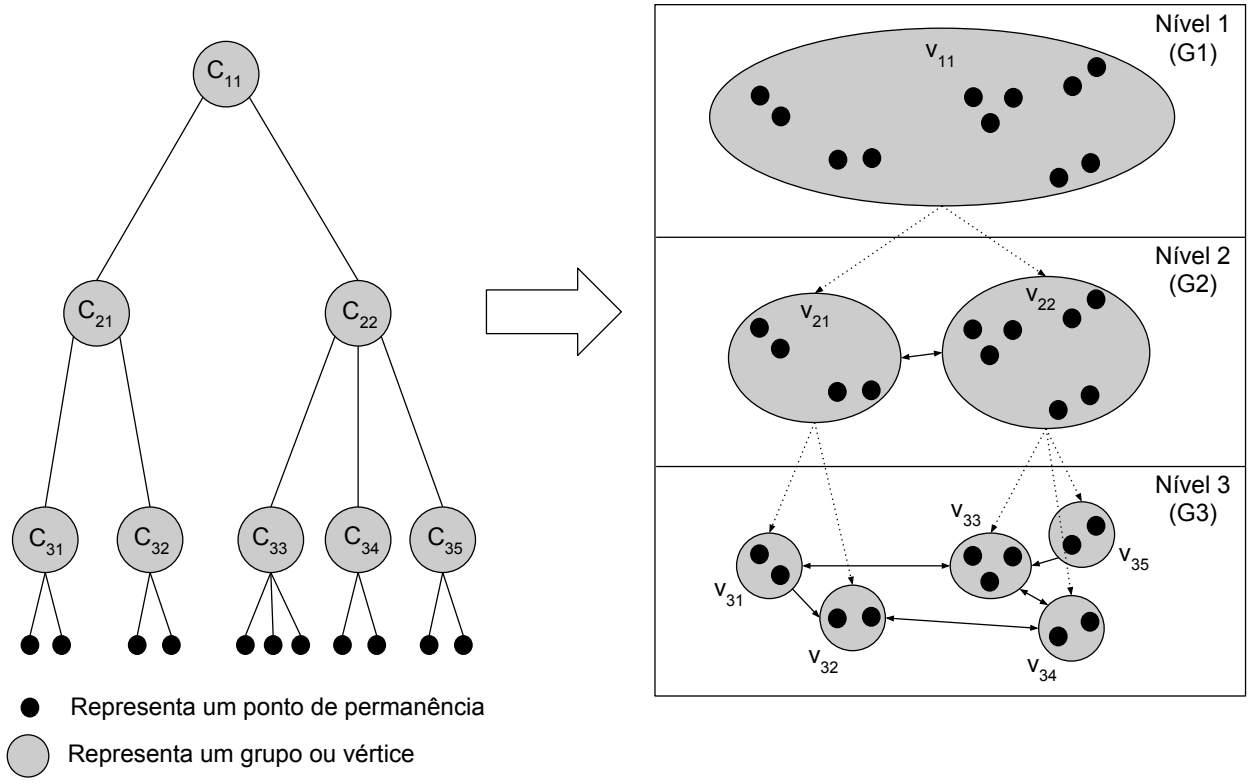

Fonte: Elaborada pelo autor.

A transformação de pontos de permanência em redes permite representar qualquer tipo de espaço geográfico, desde cidades até regiões selvagens. Diversas aplicações em mineração de trajetórias utilizam esta abordagem. Em (ZHENG et al., 2009), uma rede usuário-local é construída para descobrir lugares importantes. Em (CHEN et al., 2016), os autores estendem a técnica para descobrir lugares importantes e assim, realizar a descoberta de atividades periódicas dos usuários. Em (YANG; CHENG; CHEN, 2018; DRIF et al., 2017), comunidades de usuários são descobertas. Em (LI et al., 2008), as redes construídas são usadas para descobrir padrões de mobilidade de usuários. Predição de próximo lugar a ser visitado (YANG et al., 2014) e recomendação de restaurantes, museus, entre outros tipos de lugares (ZOU; YU; CAO, 2016; ZHENG; XIE, 2011). Já em (XIAO et al., 2014), é realizada a descoberta de laços sociais entre usuários.

LBSNs que representam localizações de maneira absoluta (e.g. Geolife) também utilizam esta abordagem para construir redes por meio de trajetórias por pontos de permanência. Após obter a rede local-local, a partir das relações entre usuários e os locais, facilmente é construído as redes: usuário-usuário e usuário-local. Portanto, as aplicações para esta abordagem estendem as aplicações de LBSNs. Assim, estimar similaridade entre usuários, encontrar especialista em uma região, descoberta de comunidades ou de locais interessantes, planejamento de itinerários, recomendação de atividades e descoberta de eventos, são algumas das tarefas de mineração de LBSNs apresentadas por Zheng e Zhou (2011) que podem ser realizadas com a representação 
apresentada nesta seção.

Redes construídas por mapeamento assemelham-se ao mapa do espaço geográfico, enquanto redes construídas através da estratégia apresentada nesta seção são o reflexo da mobilidade de seus usuários. Portanto, somente a representação em si carrega informações e conhecimentos sobre a mobilidade, seja esta urbana ou não, dos usuários. Outra vantagem da estratégia por mobilidade é a capacidade de representar qualquer espaço geográfico sem conhecê-lo.

Apesar da grande utilização desta abordagem, na literatura é pouco discutida a qualidade de construção destas redes. Neste presente trabalho é dado foco de avaliar este método de construção em relação a representação do mundo real, além de propor dois novos algoritmos, apresentados no Capítulo 4, para construir redes a partir de trajetórias por pontos de permanência.

\subsection{Considerações Finais}

Trajetórias são sequências ordenadas de coordenadas geográficas ou de check-ins que representam a mobilidade de um ou de vários usuários. A crescente utilização de aparelhos com GPS geram uma massiva quantidade de dados de trajetórias e um dos desafios da área de mineração de trajetórias é representar esses dados.

Diferentes tipos representações podem ser utilizadas para representar trajetórias, por exemplo, como séries temporais ou sequência de itens. Porém, este presente trabalho tem o interesse na relação entre locais visitados e seus usuários. Portanto, uma das melhores formas de representar elementos e suas relações é por meio de redes. A principal dificuldade em usar trajetórias na construção de redes está na definição dos vértices. Assim, existem duas estratégias para a construção destas redes: por mapeamento e por mobilidade.

Na estratégia por mapeamento as redes são construídas de maneira prévia utilizando a malha viária, onde cruzamentos viários são vértices e as arestas são segmentos viários, ou modelada por um especialista, onde vértices indicam algum local importante do objeto de estudo.

Já na estratégia por mobilidade, foco deste trabalho, redes são construídas após processamento dos dados e refletem a mobilidade dos usuários. Trajetórias geográficas são transformadas em trajetórias por pontos de permanência, depois agrupa-se pontos de permanência similares, e por fim, grupos são transformados em vértices nas redes. Na literatura é pouco discutido a qualidade da abordagem apresentada neste capítulo para a construção destas redes. No Capítulo 4 são apresentadas duas novas abordagens para construir redes a partir de pontos de permanência e uma técnica de inserção de perturbação em check-ins que permite avaliar a construção destas redes em relação a representação do mundo real. 
CAPÍTULO

\section{4}

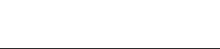

\section{UMA ABORDAGEM MULTINÍVEL PARA CONSTRUÇÃO DE REDES SOCIAIS GEOLOCALIZADAS}

Neste capítulo são apresentadas as propostas deste trabalho. Na Seção 4.1 é apresentada uma nova abordagem para construir redes geolocalizadas a partir de pontos de permanência. $\mathrm{Na}$ Seção 4.2 é apresentado um método de inserção de perturbação em base de dados de check-ins que possibilita a avaliação de métodos de construção de redes a partir de pontos de permanência em relação a sua capacidade de representar o mundo real.

\subsection{Uma abordagem multinível para construir redes a par- tir de pontos de permanência}

Nesta seção é proposta uma nova abordagem para construir redes geolocalizadas a partir de pontos de permanência. A abordagem proposta utiliza a fase de contração do paradigma multinível para realizar a construção de redes a partir de trajetórias por pontos de permanência, pois construindo a rede iterativamente é possível extrair características topológicas que auxiliem na construção da rede final.

Primeiramente, transformam-se as trajetórias geográficas em trajetórias por pontos de permanência, como visto na Seção 2.1.1, e depois aplica-se a abordagem proposta. A nova abordagem é dividida em quatro etapas, como ilustradas na Figura 19, e essas etapas são detalhadas a seguir.

1. Seleciona-se uma base de dados de trajetórias por pontos de permanência $U$, como visto na Figura 19a, que será transformada em uma rede local-local $G_{l l}$. 
Figura 19 - Processo de transformação de trajetórias por pontos de permanência em redes utilizando o paradigma multinível

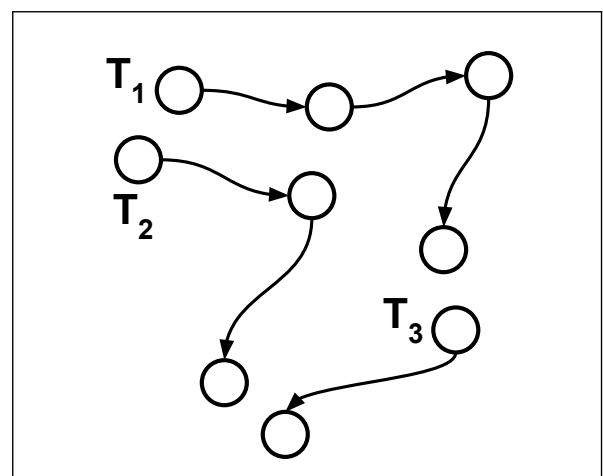

(a) Conjunto de Trajetórias

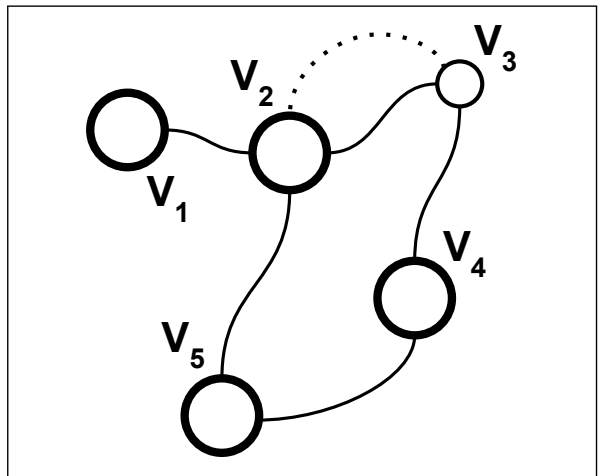

(c) Contração do paradigma multinível

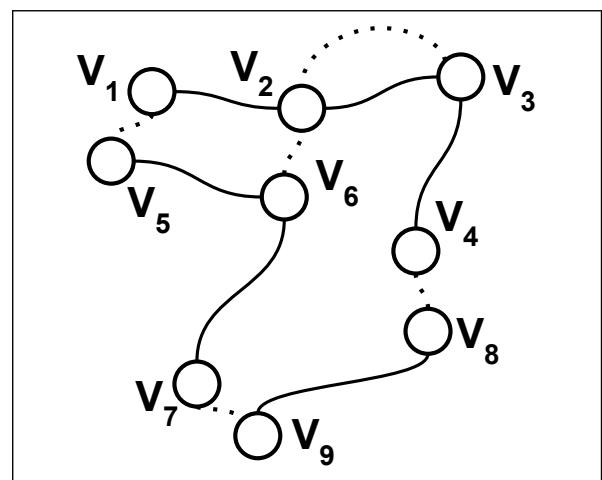

(b) Conecta k-vizinhos mais próximos

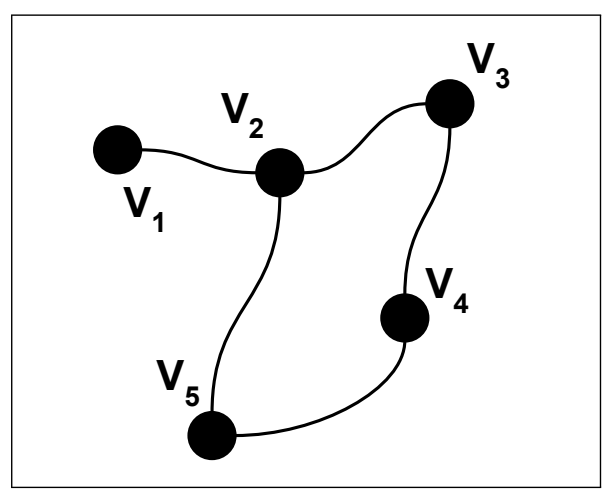

(d) Rede solução

Fonte: Elaborada pelo autor.

2. Uma rede multiaresta $G$ é criada. O conjunto de vértices $V$ da rede $G$ é dado pelos pontos de permanência contidos em $U$, onde vértices conservam as informações geográficas dos pontos de permanência. O conjunto de arestas $E$ é dado por $E=E_{S} \cup E_{p}$, onde $E_{S}$ são arestas do tipo sequência e $E_{p}$ são arestas do tipo proximidade. Uma aresta do tipo sequência $e_{s} \in E_{s}$ é inserida entre os vértices $v_{i}$ e $v_{j}$ se estes vértices foram visitados em sequência em um mesmo dia, este tipo de aresta não é valorada. Já uma aresta do tipo proximidade $e_{p} \in E_{p}$ é inserida entre $v_{i}$ e $v_{j}$ se $v_{j}$ está entre os $k$ vizinhos mais próximos ${ }^{1}$ de $v_{i}$ ou se $v_{i}$ está entre os $k$ vizinhos mais próximos de $v_{j}$. Arestas do tipo proximidade são valoradas, sendo o valor da aresta a distância entre vértices. No exemplo da Figura 19b é utilizado o valor de $k=1$ para criar a rede $G$, sendo as arestas do tipo sequência representadas por linhas contínuas e as arestas do tipo proximidade representadas por linhas pontilhadas.

3. A rede $G$, nesta etapa denominada de rede $G_{0}$, é contraída $n$ vezes até ser obtida a rede $G_{n}$, através do procedimento descrito no Algoritmo 1. Sendo que $\left|V_{0}\right|>\left|V_{n}\right|$ e $\left|E_{0}\right|>\left|E_{n}\right|$. A Figura $19 \mathrm{c}$ mostra a rede $G_{0}$ contraída na rede $G_{n}$. 
4. A partir da rede $G_{n}$ é criada a rede solução $G_{l l}$. O conjunto de vértices $V_{n}$ e o conjunto de arestas do tipo sequência $E_{S_{n}}$ são conservados na rede $G_{l l}$, como visto no exemplo da Figura 19d.

O algoritmo 1 apresenta o procedimento de contração utilizado na etapa 3 do processo descrito, anteriormente, para transformação de trajetórias por pontos de permanência em redes. Os parâmetros de entrada deste procedimento são: uma rede $G$, construída como explicado na etapa 2, e uma distância limite $d_{\text {threshold }}$. Da linha 2 até 4, do Algoritmo 1, são realizadas as inicializações das variáveis. A variável $l$ indica o nível de contração da rede e a variável reduction_factor indica o quanto, em porcentagem, a rede foi reduzida. Entre as linhas 5 e 11 é realizada a contração da rede $G_{0}$ até a rede $G_{n}$. A contração é realizada enquanto houver redução da rede $G_{l+1}$ em relação a rede $G_{l}$. Na linha 6, é criado o conjunto auxiliar de matching $M^{\prime}$. Na linha 7, o conjunto auxiliar de matching é transformado no conjunto de matching $M$. Na linha 8 é construída a rede $G_{l+1}$ através da contração da rede $G_{l}$. Na linha 9 é calculado o fator de redução dos vértices da rede $G_{l+1}$ em relação a rede $G_{l}$. No final do Algoritmo 1 a rede $G_{n}$ é obtida.

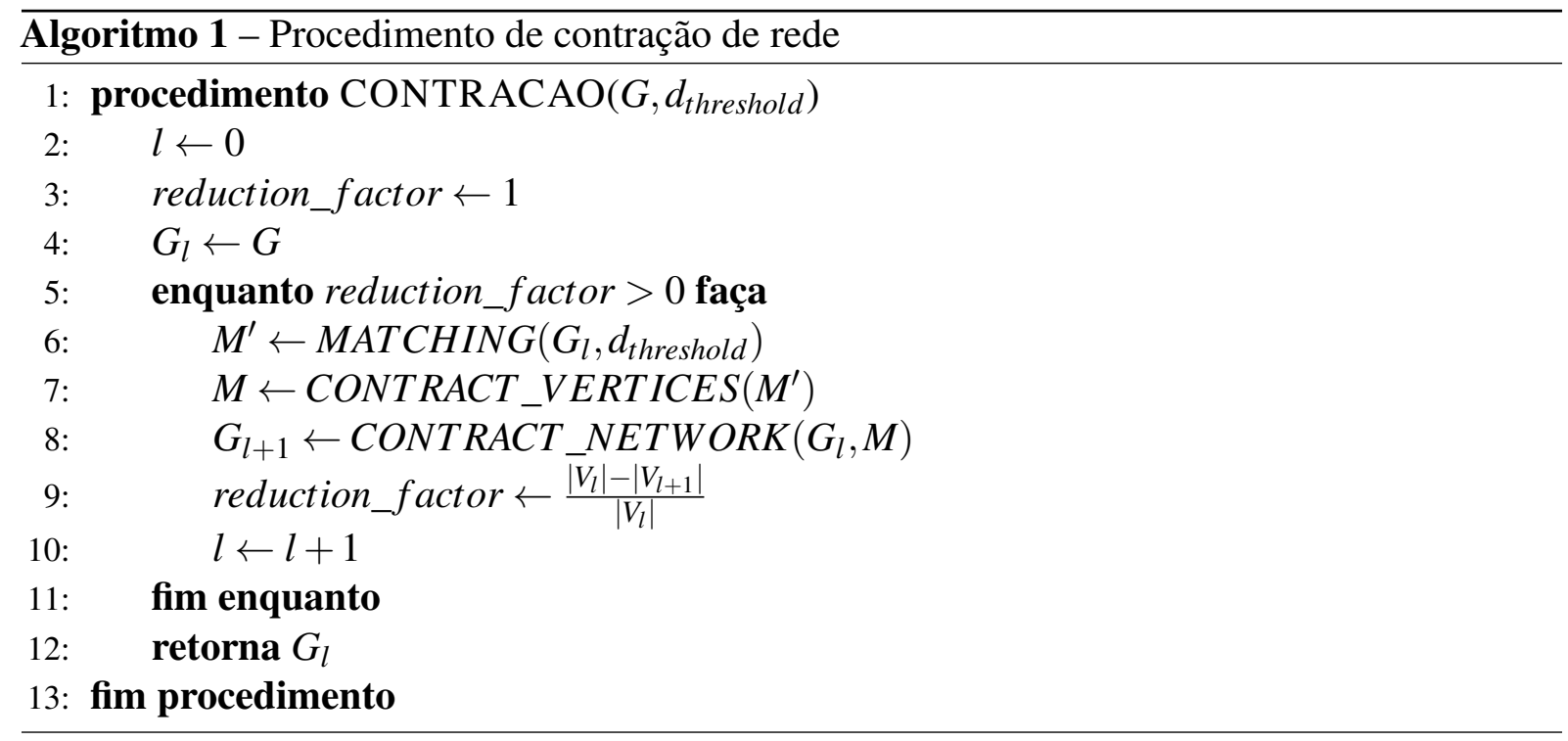

Para o procedimento de matching, linha 6 do Algoritmo 1, não foi encontrado nenhum algoritmo de matching adaptado para dados geográficos. Portanto, foram propostos e desenvolvidos dois novos algoritmos de matching neste trabalho. Os algoritmos propostos são descritos a seguir:

- Nearest Geographical Neighbor Matching (NGNM): tendo que $E_{p i}$ é o conjunto de arestas do tipo proximidade conectados ao vértice $v_{i}$, sendo $E_{p i} \subset E_{p}$. Temos que $\forall v_{i} \in V$ são visitados seus vértices vizinhos, conectados por arestas do tipo proximidade, e uma, apenas uma, aresta $e_{p i}$ pode ser selecionada para ser inserida como elemento de $M^{\prime}$ se as seguintes condições forem satisfeitas: 


$$
\begin{gathered}
\exists e_{p i}=\left(v_{i}, v_{j}, w\right) \in E_{p i} \\
w \leq d_{\text {threshold }} \\
w=\min W_{p i}
\end{gathered}
$$

- Nearest Geographical Neighbor non-Sequential Matching (NGNnSM): tendo que $E_{p i}$ é o conjunto de arestas do tipo proximidade e $E_{s i}$ o conjunto de arestas do tipo sequência, onde ambos estão conectados ao vértice $v_{i}$, sendo $E_{p i} \subset E_{p}$ e $E_{s i} \subset E_{s}$. Temos que $\forall v_{i} \in V$ são visitados seus vértices vizinhos, conectados por arestas do tipo proximidade, e uma, apenas uma, aresta $e_{p i}$ pode ser selecionada para ser inserida como elemento de $M^{\prime}$ se as seguintes condições forem satisfeitas:

$$
\begin{gathered}
\exists e_{p i}=\left(v_{i}, v_{j}, w\right) \in E_{p i} \\
\nexists e_{s i}=\left(v_{i}, v_{j}\right) \in E_{s i} \\
w \leq d_{\text {threshold }} \\
w=\text { min } W_{p i}
\end{gathered}
$$

Para ambos algoritmos, $N G N M$ e $N G N n S M$, o conjunto auxiliar de pares de vértices selecionados em $M^{\prime}$ é o conjunto auxiliar de matching. A diferença entre os dois algoritmos está no fato do $N G N n S M$ não permitir que dois vértices visitados de forma consecutivas (em que haja uma aresta do tipo sequência entre os vértices) sejam selecionados no conjunto auxiliar de matching $M^{\prime}$. Assim, no NGNSSM evita-se que dois locais visitados em sequência, em um mesmo dia, sejam unidos em um mesmo vértice.

A principal adaptação para o uso de algoritmos de matching em dados geográficos foi a inclusão da restrição $w \leq d_{\text {threshold }}$, ou seja, restringir a distância máxima em que dois vértices podem ser unidos em um mesmo super-vértice.

O conjunto definitivo de matching é definido pelo procedimento CONTRACT_VERTICES, linha 7. O conjunto de matching é dado por $M=\left\{s v_{1}, s v_{2}, \ldots, s v_{m}\right\}$, onde cada elemento $s v_{k}$ é um conjunto de vértices extraídos do conjunto $M^{\prime}$. Para definir o conjunto $M$ foram utilizadas duas abordagens que diferem entre si pela forma que consideram os elementos $s v \in M$, as abordagens são apresentadas a seguir:

- Contract Pair of Vertices (CPV): as arestas $e_{p} \in M^{\prime}$ são ordenadas do menor para o maior peso. Assim, sequencialmente, para cada aresta $e_{p}=\left(v_{i}, v_{j}\right)$, o par de vértices $\left(v_{i}, v_{j}\right)$ é adicionado como elemento do conjunto de matching $M$ se nenhum dos vértices $v_{i}$ ou $v_{j}$ compõem um elemento existente em $M$. 
- Contract Group of Vertices (CGV): para cada aresta $e_{p} \in M^{\prime}$, o par de vértices $\left(v_{i}, v_{j}\right)$ é adicionado como novo elemento do conjunto de matching $M$ se nenhum dos vértices $v_{i}$ ou $v_{j}$ compõem um elemento existente em $M$. Caso $v_{i}$ ou $v_{j}$ compõem um elemento $s v \in M$ o elemento $s v$ é atualizado da seguinte forma: $s v=s v \cup\left(v_{i}, v_{j}\right)$.

Portanto, cada conjunto de vértices $s v \in M$ é condensado em um super-vértice em $G_{l}$. As coordenadas geográficas associadas a cada super-vértice é dada pela média das coordenadas geográficas dos vértices pertencentes a $s v$ correspondente ao super-vértice em questão.

Assim, na linha 8, é construída a rede $G_{l+1}$ a partir da contração da rede $G_{l}$. Todo super-vértice $G_{l}$ é transformado em vértice na rede $G_{l+1}$ e os vértices de $G_{l}$ que não fazem parte do conjunto $M$ são conservados na rede $G_{l+1}$. As arestas do tipo sequência e proximidade são conservadas, sendo eliminada qualquer duplicidade de arestas. As arestas do tipo proximidade têm seus pesos recalculados devido a atualização de posicionamento (coordenadas geográficas) dos vértices derivados de super-vértices.

No gráfico ${ }^{2}$ da Figura 20 é mostrada a diferença dos valores de $n$ para alcançar a rede desejada $G_{n}$ com as duas diferentes abordagens utilizadas no procedimento CONTRACT_VERTICES. Nota-se que o $C G V$ converge a $G_{n}$ mais rapidamente, ou seja, a abordagem por $C G V$ utiliza menos níveis de contração em relação a $C P V$.

Como visto na Seção 3.2.2.2, o principal desafio em construir redes a partir de trajetórias por pontos de permanência está na definição dos vértices do tipo local. O processo descrito nesta seção foca neste desafio. Na etapa 4 é citado como exemplo a construção de uma rede locallocal $^{3} G_{l l}$ a partir da rede $G_{n}$. Porém, nesta etapa diversos tipos de redes podem ser construídas utilizando como base a rede $G_{n}$, pois os vértices do tipo local já foram definidos em $G_{n}$. Portanto, como mostrado na Seção 2.2, na etapa 4 é possível construir redes do tipo local-local com diferentes significados de arestas e redes do tipo usuário-local. Consequentemente, o processo descrito pode ser utilizado na construção de redes sociais geolocalizadas que representam localizações de maneira absoluta.

O processo discutido nesta seção também é utilizado para construir uma rede hierárquica, como visto na Seção 3.2.2.2. Para isso, o parâmetro $d_{\text {threshold }}$ recebe uma lista de valores ordenados do menor para o maior valor. As etapas 3 e 4 são repetidas para cada valor de $d_{\text {threshold }}$, sendo que a rede $G_{n}$ resultante de cada nível da hierarquia é utilizada como parâmetro de entrada (rede $G_{0}$ ) no nível seguinte.

2 As bases de dados utilizadas neste experimento são apresentadas no Capítulo 5. Foram utilizados valores de $k$ de 1 até 20 para criar as redes $G_{0}$ e foram utilizados os dois algoritmos de matching apresentados anteriormente.

3 Para simplificar a explicação do processo. 
Figura 20 - Gráfico da média do número de níveis necessários para atingir a rede $G_{n}$ utilizando $C P V$ e $C G V$ em relação a distância limite $d_{\text {threshold }}$

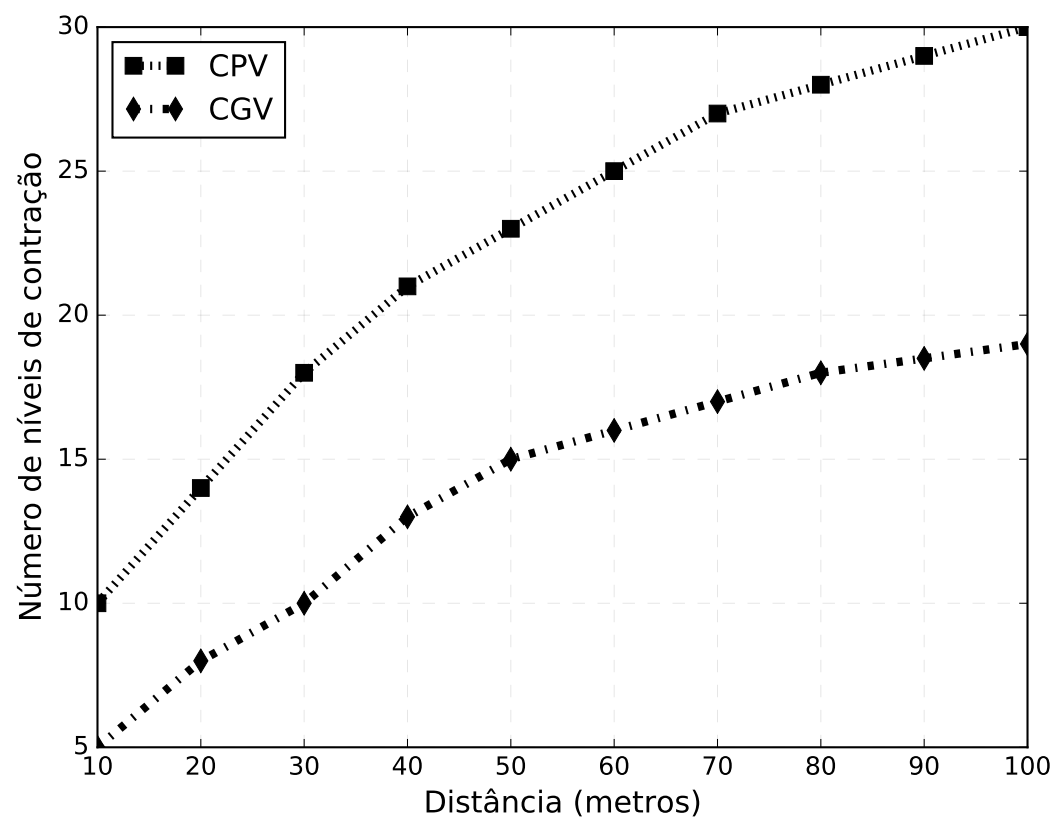

Fonte: Elaborada pelo autor.

\subsection{Inserção de perturbação em base de dados de check- ins}

No mundo real, grandes espaços geográficos, como: cidades, bairros ou países, são divididos em pequenos espaços geográficos ou locais, onde cada local tem um significado de acordo com sua funcionalidade, por exemplo: Escola A, Restaurante B, Biblioteca Central, Casa do Endereço W, etc. Portanto, considerando um local X (um hospital) e um local Y (uma biblioteca), então X e Y são distintos porque têm significados diferentes no mundo real, independentemente de estarem geograficamente próximos.

Para avaliar a capacidade de representar o mundo real através de trajetórias por pontos de permanência é necessário verificar se o conjunto de pontos de permanência que representam um vértice tem apenas pontos de permanência que representem o mesmo local e se todos pontos de permanência que representam o local em questão estão representados pelo mesmo vértice. A melhor representação do mundo real potencializa tarefas de recomendação de locais a serem visitados, recomendação de itinerários de turismo, recomendação de amizades, etc. No entanto, essa análise não é trivial, pois não sabe-se o significado real de cada ponto de permanência.

Para realizar esta avaliação, Minatel, Valejo e Lopes (2018) propuseram um método que simula o comportamento de pontos de permanência em base de dados de check-ins. O método consiste em inserir perturbações nas coordenadas associadas aos check-ins. Deste modo, cada 
check-in assemelha-se a um ponto de permanência, porém o identificador do local é preservado. Assim, torna-se possível aplicar as técnicas de transformação de trajetórias em redes através da mobilidade de seus usuários e avaliar a capacidade destas técnicas em representar o mundo real.

Check-ins e pontos de permanência assemelham-se pelo fato de representarem um estado de permanência dos usuários em um determinado local, todavia a diferença está na forma de representação deste local. Check-ins utilizam etiquetas, que contém informações do significado do mundo real (como visto na Seção 3.1), para representar estes locais. Pontos de permanência utilizam apenas as coordenadas do ponto detectado, de trajetórias geográficas, para representar este mesmo local.

Em pontos de permanência há inconsistência de comparação destes pontos, como discutido na Seção 3.2.2.2, enquanto que todo check-in realizado em um mesmo local está associado a mesma etiqueta. Assim, a alteração proposta em Minatel, Valejo e Lopes (2018), para cada check-in seja inserido uma perturbação nas coordenadas originais do local. Consequentemente, todo check-in realizado em um mesmo local terá coordenadas diferentes, como ocorre em pontos de permanência, porém o identificador do local será conservado. A inserção de perturbação torna possível a aplicação das técnicas apresentadas na Seção 3.2.2.2 e no Capítulo 4 para construir redes geolocalizadas. O identificador do local é usado como rótulo na validação através de índice externo para avaliar a capacidade destas técnicas em representar o mundo real.

O Algoritmo 2, apresenta o procedimento para gerar um conjunto de dados através da inserção de perturbação em um conjunto de check-ins. Os parâmetros de entrada deste procedimento são: um conjunto $U$ de check-ins e uma lista de distâncias distances. Na linha 2 é criado um conjunto vazio $U_{p}$ que receberá os check-ins com perturbação. O procedimento da linha 3 atribui para cada etiqueta (local) um raio que define a área deste local. Para realizar esta atribuição o procedimento DEFINE_LABELS_RADIUS calcula a distância do local mais próximo do local em questão e aleatoriamente seleciona uma distância em distances, o menor valor entre as duas distâncias é atribuído como raio do local. Este procedimento permite definir uma área para cada local ${ }^{4}$, como ocorre no mundo real.

Entre as linhas 4 e 9, $\forall$ check_in $\in U$ é criado um novo elemento new $\in U_{p}$ que conserva as informações de identificador do local, identificador do usuário e data/hora da realização do check_in, e para as coordenadas geográficas de new são atribuídas as informações de latitude e longitude do check_in com uma perturbação em seus valores. Na linha 5 é retornado o raio do local em que foi realizado o check_in. Na linha 6 é gerada a perturbação nas coordenadas geográficas originais do local onde foi realizado o check_in e atribuída ao novo elemento new.

A perturbação máxima nas coordenadas é o valor do raio atribuído ao local, ou seja, as novas coordenadas estão dentro da área do local em questão. A Figura 21 mostra o procedimento de inserção das perturbações nas coordenadas geográficas. Na Figura 21a é mostrado a inserção

4 Este procedimento é necessário, pois somente a coordenada central do local está associada ao check-in, portanto, com as atribuições dos raios são simuladas as áreas dos locais. 


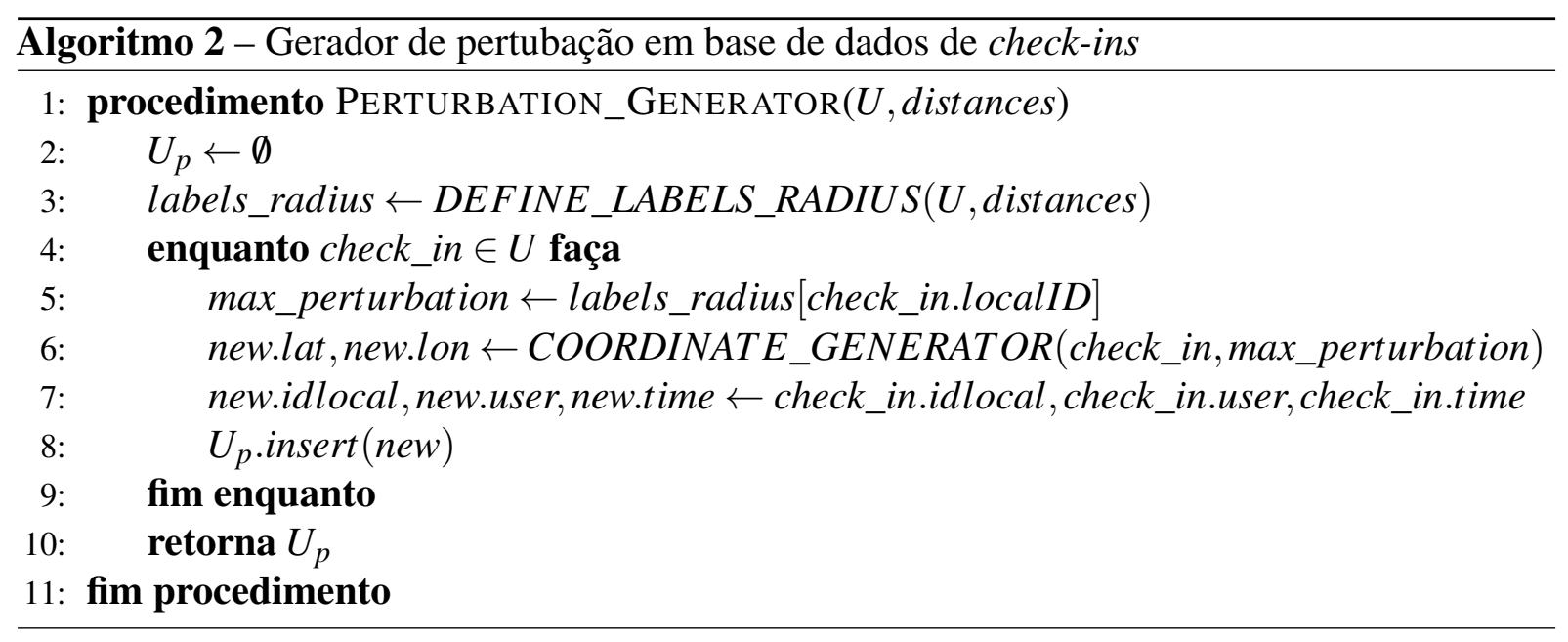

de perturbação em três check-ins realizados no mesmo local, nota-se que cada novo check-in com pertubação tem coordenadas diferentes (limitada pelo raio que está graficamente representada pela linha pontilhada) entre si, comportamento semelhante ao de detecção de pontos de permanência. Já na Figura 21 b é mostrada a diferença entre os conjuntos de check-ins originais e o conjunto de check-ins com perturbação. Na linha 7 as informações de identificação de usuário, local $^{5}$ e a data/hora em que foi realizado o check_in são conservadas no novo elemento new. Na linha 8 o elemento new é adicionado ao conjunto $U_{p}$ de check-ins com perturbação. No final do Algoritmo 2 é retornado o conjunto $U_{p}$.

Figura 21 - Exemplo de inserção de pertubação em coordenadas geográficas

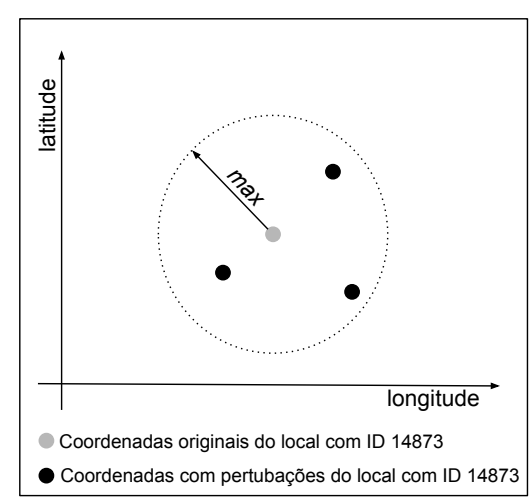

(a) Inserção de pertubação

\begin{tabular}{|c|c|c|c|c|}
\hline \multicolumn{5}{|c|}{ Conjunto de Check-ins } \\
\hline user & check-in time & latitude & longitude & location-id \\
\hline 98 & 2010-06-18T19:06:52Z & 28.42068359 & -81.58289552 & 14873 \\
\hline$\cdots$ & & & & \\
\hline 233 & 2010-05-24T16:52:08Z & 28.42068359 & -81.58289552 & 14873 \\
\hline$\cdots$ & & & & \\
\hline 237 & 2010-08-01T16:09:04Z & 28.42068359 & -81.58289552 & 14873 \\
\hline \multicolumn{5}{|c|}{ Conjunto de Check-ins com Perturbações } \\
\hline user & check-in time & latitude & longitude & location-id \\
\hline 98 & 2010-06-18T19:06:52Z & 28.42060711 & -81.58307262 & 14873 \\
\hline$\cdots$ & & & & \\
\hline 233 & 2010-05-24T16:52:08Z & 28.42078154 & -81.58263195 & 14873 \\
\hline$\cdots$ & & & & \\
\hline 237 & 2010-08-01T16:09:04Z & 28.42054877 & -81.58249814 & 14873 \\
\hline
\end{tabular}

(b) check-ins $\mathrm{X}$ check-ins com pertubações

Fonte: Adaptada de Minatel, Valejo e Lopes (2018).

Portanto, o conjunto $U_{p}$ possibilita utilizar as técnicas descritas na Seção 3.2.2.2 e na Seção 4.1 para construir redes a partir de trajetórias por pontos de permanência e, consequentemente, utilizar a validação através de índices externos (identificador de local utilizado como rótulo), como visto na Seção 2.4.2.2, para avaliar a capacidade destas técnicas em representar o mundo real.

5 A identificação do local é utilizada, posteriormente, como rótulo na validação por índices externos 


\section{AVALIAÇÃO EXPERIMENTAL}

Neste capítulo é avaliada a qualidade da transformação de trajetórias por pontos de permanência em redes em relação ao mundo real, ou seja, na capacidade de representar o mundo real. Na Seção 5.1 são apresentadas as bases de dados, geradas através do método explanado na Seção 4.2, utilizadas para os experimentos utilizados na avaliação experimental. Na Seção 5.2 são apresentados os algoritmos selecionados para os experimentos e a forma de avaliação destes algoritmos. Por fim, na Seção 5.3 são mostrados os desempenhos, tempos de execução e análise dos resultados dos experimentos propostos.

\subsection{Base de Dados Utilizadas}

Esta seção apresenta as bases de dados utilizadas nos experimentos. Foram selecionadas as seguintes bases de dados:

- Brightkite ${ }^{1}$ : é uma rede social geolocalizada onde usuários compartilham suas localizações através de check-ins. Esta base de dados é composta de 4491143 check-ins realizados por 58228 usuários no período de abril de 2008 até outubro de 2010. Os check-ins foram realizados por todo território dos Estados Unidos da América (CHO; MYERS; LESKOVEC, 2011).

- Gowalla : é uma rede social geolocalizada onde usuários compartilham suas localizações através de check-ins. Esta base de dados é composta de 6442890 check-ins realizados por 196591 usuários no período de fevereiro de 2009 até outubro de 2010 (CHO; MYERS; LESKOVEC, 2011). Os check-ins foram realizados por todo território dos Estados Unidos da América (CHO; MYERS; LESKOVEC, 2011).

2 Disponível em: < https://snap.stanford.edu/data/loc-gowalla.html > 
O principal desafio de representar trajetórias geográficas em redes através da mobilidade de seus usuários em relação ao mundo real está na dificuldade de diferenciar locais geograficamente próximos. Assim, torna-se possível partilhar as bases de dados, citadas acima, em conjunto de dados menores, onde cada conjunto de dados represente os check-ins realizados em um espaço geográfico específico. Portanto, neste experimento foram selecionadas as seguintes dez regiões (cidades, bairros e parques), mostradas na Tabela 1 que foram representadas através de redes:

Tabela 1 - Informações das regiões selecionadas

\begin{tabular}{|c|c|c|c|c|c|}
\hline \multirow{2}{*}{ Nome da Região } & \multirow{2}{*}{ Área Total $\left(\mathrm{km}^{2}\right)$} & \multicolumn{4}{|c|}{ Coordenadas Limítrofes } \\
\cline { 3 - 6 } & & Latitude & \multicolumn{2}{c|}{ Longitude } \\
\cline { 3 - 6 } & & Min & Max & Min & Max \\
\hline \hline Atlanta & 805 & 33.60775 & 33.91886 & -84.47387 & -84.22256 \\
\hline Beverly Hills & 107 & 34.04074 & 34.0973 & -118.46001 & -118.27576 \\
\hline Indianapolis & 514 & 39.70084 & 39.92553 & -86.2619 & -86.02157 \\
\hline Kansas & 1442 & 38.9327 & 39.34491 & -94.818876 & -94.45495 \\
\hline Las Vegas & 1149 & 35.98911 & 36.31069 & -115.31867 & -114.96162 \\
\hline Manhattan & 65 & 40.72722 & 40.79288 & -74.02072 & -73.91464 \\
\hline Tucson & 4793 & 31.85481 & 32.46806 & -111.36978 & -110.62477 \\
\hline Universal Studios & 20 & 28.45812 & 28.49404 & -81.50928 & -81.45881 \\
\hline Walt Disney World & 215 & 28.31888 & 28.45631 & -81.63734 & -81.49383 \\
\hline Washington D.C. & 185 & 38.85708 & 38.9578 & -77.12368 & -76.93313 \\
\hline
\end{tabular}

Para cada região descrita na Tabela 1 foram criados um conjunto de check-ins realizados nessa região utilizando a rede social geolocalizada Brightkite e outro conjunto de check-ins realizados nessa região utilizando a rede social geolocalizada Gowalla. Esses conjuntos de check-ins foram sumarizados na Tabela 2.

$\mathrm{Na}$ Tabela 2 temos algumas características dos conjuntos de check-ins. A coluna Checkins indica o total de check-ins realizados. Na coluna Usuários é mostrado o total de usuários que realizaram check-ins. A coluna $\mathrm{C} / \mathrm{U}$ indica a proporção de check-ins por usuário, ou seja, o tamanho médio das trajetórias. Na coluna Locais é indicado o número total de locais, ou etiquetas, existentes no total de check-ins. A coluna $\mathrm{C} / \mathrm{L}$ indica a média de check-ins realizados em um mesmo local.

Cada conjunto $U$ de check-ins, representado pelas linhas da Tabela 2, foram processados pelo Algoritmo 2, apresentado na Seção 4.2, e consequentemente, foram gerados novos conjuntos de check-ins com perturbação, chamados de conjuntos $U_{p}$. A lista de valores utilizadas em distances foi a seguinte:

$$
\text { distances }=[5,10,15,20,25,30,35,40,45,50]
$$

Esses valores possibilitam representar locais de diferentes áreas, como ocorre no mundo 
Tabela 2 - Informações dos conjuntos de dados selecionados

\begin{tabular}{|c|c|c|c|c|c|c|}
\hline Base de dados & Nome da Região & Check-ins & Usuários & C/U & Locais & C/L \\
\hline \hline \multirow{5}{*}{ Brightkite } & Atlanta & 43642 & 1592 & 27.4 & 5411 & 8.1 \\
\cline { 2 - 7 } & Beverly Hills & 21046 & 1180 & 17.8 & 2848 & 7.4 \\
\cline { 2 - 7 } & Indianapolis & 12981 & 395 & 32.9 & 1327 & 9.8 \\
\cline { 2 - 7 } & Kansas & 42617 & 756 & 56.4 & 4739 & 9.0 \\
\cline { 2 - 7 } & Las Vegas & 23960 & 1594 & 15.0 & 2801 & 8.6 \\
\cline { 2 - 7 } & Manhattan & 45397 & 2270 & 20.0 & 7922 & 5.7 \\
\cline { 2 - 7 } & Tucson & 4337 & 234 & 18.5 & 557 & 7.8 \\
\cline { 2 - 7 } & Universal Studios & 505 & 121 & 4.2 & 118 & 4.3 \\
\cline { 2 - 7 } & Walt Disney World & 4857 & 552 & 8.8 & 604 & 8.0 \\
\cline { 2 - 7 } & Washington D.C. & 47493 & 1623 & 29.3 & 5715 & 8.3 \\
\hline \hline \multirow{5}{*}{ Gowalla } & Atlanta & 46593 & 3239 & 14.4 & 5194 & 9.0 \\
\cline { 2 - 7 } & Beverly Hills & 20034 & 2401 & 8.3 & 3339 & 6.0 \\
\cline { 2 - 7 } & Indianapolis & 7898 & 603 & 13.1 & 1860 & 4.2 \\
\cline { 2 - 7 } & Kansas & 31008 & 1281 & 24.2 & 3780 & 8.2 \\
\cline { 2 - 7 } & Las Vegas & 55550 & 3487 & 15.9 & 6512 & 8.5 \\
\cline { 2 - 7 } & Manhattan & 78845 & 5386 & 14.6 & 10073 & 7.8 \\
\cline { 2 - 7 } & Tucson & 4409 & 310 & 14.2 & 1164 & 3.8 \\
\cline { 2 - 7 } & Universal Studios & 3804 & 560 & 6.8 & 338 & 11.3 \\
\cline { 2 - 7 } & Walt Disney World & 21891 & 1338 & 16.4 & 1371 & 16.0 \\
\cline { 2 - 7 } & Washington D.C. & 36879 & 2411 & 15.3 & 4172 & 8.8 \\
\hline
\end{tabular}

real. Os conjuntos de dados ${ }^{3} U_{p}$ gerados a partir do Algoritmo 2 são os utilizados nos experimentos apresentados neste capítulo. Todas as informações contidas nas Tabelas 1 e 2 são válidas para os os conjuntos de dados $U_{p}$.

Na Tabela 3 são mostradas as características resultante do agrupamento perfeito dos conjuntos de dados $U_{p}$ e da rede local-local correspondente. A coluna $C S$ mostra o coeficiente de silhueta do agrupamento perfeito. Nas colunas seguintes são mostradas as seguintes características das redes local-local resultante: número de vértices, número de arestas, grau médio da rede e o coeficiente de agrupamento.

\subsection{Metodologia utilizada}

Nesta seção são descritos os algoritmos que foram selecionados para os experimentos deste capítulo. Cada algoritmo é avaliado por sua capacidade de construir redes geolocalizadas a partir de pontos de permanência em relação ao mundo real. A forma de avaliação e os índices utilizados para avaliar os algoritmos são apresentados no decorrer desta seção.

O principal algoritmo utilizado, como mostrado na Seção 3.2.2.2, para realizar a transformação de trajetórias por pontos de permanência em redes é o algoritmo OPTICS. No Capí-

3 Os conjuntos de dados $U_{p}$ gerados para os experimentos estão disponível em: < https://github.com/ diegominatel/databases/wiki> 
Tabela 3 - Informações das redes local-local geradas por meio do agrupamento perfeito dos conjuntos de dados descritos na Tabela 2

\begin{tabular}{|c|c||c||c|c|c|c|}
\hline Base de dados & Nome da Região & $C S$ & $|V|$ & $|E|$ & $\langle k\rangle$ & $C$ \\
\hline \hline \multirow{5}{*}{ Brightkite } & Atlanta & $52.63 \%$ & 5411 & 13313 & 4.9 & $3.80 \%$ \\
\cline { 2 - 7 } & Beverly Hills & $45.97 \%$ & 2848 & 4496 & 3.2 & $4.05 \%$ \\
\cline { 2 - 6 } & Indianapolis & $55.36 \%$ & 1327 & 2374 & 3.6 & $7.46 \%$ \\
\cline { 2 - 6 } & Kansas & $58.72 \%$ & 4739 & 11501 & 4.9 & $5.17 \%$ \\
\cline { 2 - 6 } & Las Vegas & $55.36 \%$ & 2801 & 5628 & 4.0 & $8.30 \%$ \\
\cline { 2 - 6 } & Manhattan & $39.59 \%$ & 7922 & 12832 & 3.2 & $3.73 \%$ \\
\cline { 2 - 7 } & Tucson & $58.56 \%$ & 557 & 670 & 2.4 & $5.89 \%$ \\
\cline { 2 - 7 } & Walt Disney World & $61.28 \%$ & 604 & 1042 & 3.5 & $16.52 \%$ \\
\cline { 2 - 7 } & Washington D.C. & $50.61 \%$ & 5715 & 12057 & 4.2 & $3.49 \%$ \\
\hline \hline \multirow{5}{*}{ Gowalla } & Atlanta & $64.18 \%$ & 5194 & 28927 & 11.1 & $5.02 \%$ \\
\cline { 2 - 7 } & Beverly Hills & $58.18 \%$ & 3339 & 13129 & 7.9 & $5.46 \%$ \\
\cline { 2 - 7 } & Indianapolis & $64.18 \%$ & 1860 & 5670 & 6.1 & $6.74 \%$ \\
\cline { 2 - 7 } & Kansas & $64.86 \%$ & 3780 & 20693 & 10.9 & $7.24 \%$ \\
\cline { 2 - 7 } & Las Vegas & $63.63 \%$ & 6512 & 35883 & 11.0 & $6.88 \%$ \\
\cline { 2 - 7 } & Manhattan & $57.09 \%$ & 10073 & 54920 & 10.9 & $4.31 \%$ \\
\cline { 2 - 7 } & Tucson & $65.09 \%$ & 1164 & 3018 & 5.2 & $6.16 \%$ \\
\cline { 2 - 7 } & Universal Studios & $59.76 \%$ & 338 & 1926 & 11.4 & $24.07 \%$ \\
\cline { 2 - 7 } & Walt Disney World & $60.37 \%$ & 1371 & 12214 & 17.8 & $17.85 \%$ \\
\cline { 2 - 6 } & Washington D.C. & $61.87 \%$ & 4172 & 23575 & 11.3 & $7.14 \%$ \\
\hline
\end{tabular}

tulo 4 foram propostos os algoritmos ${ }^{4} N G N M$ e $N G N n S M$ para gerar redes através de pontos de permanência. Para complementar a comparação foram utilizados os seguintes algoritmos ${ }^{5}$ de agrupamento hierárquico aglomerativo usando: Complete-linkage (CL) e Average-linkage (UPGMA), descritos na Seção 2.4.1.2, a seleção destes algoritmos deve-se à natureza hierárquica dos algoritmos além de possibilitar a extração de grupos utilizando valores de distância. Portanto, os seguintes algoritmos são utilizados nos experimentos: OPTICS, NGNM, NGNSSM, CL e UPGMA.

Para cada algoritmo selecionado foi criada uma rede hierárquica com dez níveis de hierarquia. Os valores, em metros, das distâncias utilizadas como escala espacial de cada nível da hierarquia são os seguintes: 10, 20, 30, 40, 50, 60, 70, 80, 90, 100. Essas distâncias foram utilizadas como valores no parâmetro de distância dos algoritmos. No algoritmo OPTICS cada valor é utilizado como parâmetro Eps para extração dos grupos. Nos algoritmos $N G N M$ e

4 Não há diferença significativa entre os resultados utilizando $C P V$ ou $C G V$ em combinação com os algoritmos $N G N M$ e $N G N n S M$, porém, como mostrado na Seção 4.1, o $C P V$ utiliza mais níveis de contração para alcançar a rede final, consequentemente, requer um tempo de execução muito maior. Pelo motivo citado, apenas será apresentado os resultados dos algoritmos $N G N M$ e $N G N n S M$ em combinação com o $C G V$.

5 O algoritmo hierárquico aglomerativo Single-linkage, mostrado na Seção 2.4.1.2, foi testado e apresenta resultados semelhantes ao OPTICS, mas com tempo de execução muito superior. Por esse motivo, o Single-linkage foi omitido das comparações apresentadas neste capítulo. 
NGNnSM os valores são utilizados no parâmetro de entrada $d_{\text {threshold }}$. Nos algoritmos $C L$ e UPGMA cada valor é utilizado como valor de corte no dendrograma resultante para extração dos grupos.

Conforme discutido neste documento, o principal fator de qualidade para construir redes por meio de pontos de permanência é a qualidade da partição resultante do agrupamento, ou seja, da definição dos vértices. Portanto, a avaliação é realizada na partição resultante de cada nível das redes hierárquicas construídas através dos algoritmos selecionados para este experimento. Para cada algoritmo foi selecionado o nível que obteve a melhor qualidade em representar o mundo real para realizar a comparação com os demais algoritmos. A validação ${ }^{6}$ da partição resultante é feita através do índice externo Adjusted Rand Index (ARI). Porém, também são utilizados os índices externos Completude (c) e Homogeneidade (h), apresentados na Seção 2.4.2.2, como medidas auxiliares para complementar as análises. O índice $A R I$ é o responsável por medir a similaridade entre a partição resultante e a partição ideal, ou seja, o índice $A R I$, neste caso, indica a qualidade em representar o mundo real por meio dos vértices resultantes do agrupamento.

\subsection{Resultados e Análises}

Nesta seção são apresentados os resultados dos experimentos ${ }^{7}$ propostos, o desempenho foi medido conforme explanado na Seção 5.2. Na Seção 5.3.1 é discutida a influência do parâmetro $k$ nos resultados dos algoritmos $N G N M$ e $N G N S S M$, propostos no Capítulo 4 . Na Seção 5.3.2 é comparado os resultados $A R I$ de todos os algoritmos selecionados para este experimento. Por fim, na Seção 5.3.3 é realizada a análise de tempo dos algoritmos.

\subsubsection{Análise do parâmetro $k$}

Nesta seção é discutida e analisada a influência do parâmetro $k$ nos algoritmos, propostos no Capítulo 4, $N G N M$ e $N G N s S M$. A análise é realizada sobre os resultados do índice ARI obtidos por diferentes parametrizações no valor de $k$.

Na Figura 22 é mostrado o desempenho médio ARI em relação ao parâmetro $d_{\text {threshold }}$ para diferentes valores de $k$ para os algoritmos $N G N M$ e $N G N S S M$. Na Figura 22a é mostrado os resultados do algoritmo $N G N M$ e na Figura 22b é mostrado os resultados para o algoritmo $N G N S S M$. Nota-se que para ambos os algoritmos o valor de $k=1$ produz resultados não satisfatórios independentemente do valor utilizado no parâmetro $d_{\text {threshold }}$. Para $3 \leq k \leq 20$, ambos os algoritmos fornecem bons resultados, acima de $A R I \geq 80 \%$, a partir de $d_{\text {threshold }} \geq 30$. O valor $k=5$ gera os melhores resultados médios de ARI para os algoritmos $N G N M$ e $N G N S S M$. $\mathrm{O}$ algoritmo $N G N S S M$ apresenta a característica de convergência do resultado médio ARI, pois a

Os índices citados foram apresentados na Seção 2.4.2.2

7 Os experimentos foram realizados em uma máquina 4-core Linux com $2.0 \mathrm{Ghz}$ de CPU e 32 GB de RAM. Os algoritmos foram implementados em Python. 
partir de um determinado valor de $d_{\text {threshold }}$ alcança-se o valor máximo de $A R I$ e esse resultado mantém-se mesmo com o aumento do valor do parâmetro $d_{\text {threshold }}$. $\mathrm{O}$ algoritmo $N G N M$ apresenta comportamento semelhante ao algoritmo $N G N S S M \operatorname{com} k \leq 5$, mas a partir de $k=10$ é visto um decaimento suave no resultado $A R I$ ao aumentar o valor de $d_{\text {threshold }}$ após chegar no valor de pico de $A R I$. Este comportamento do algoritmo NGNM é intensificado com o aumento do valor de $k^{8}$, vide $k=20$.

Figura 22 - Gráfico da média $A R I$ para diferentes valores de $k$ em relação a $d_{\text {threshold }}$

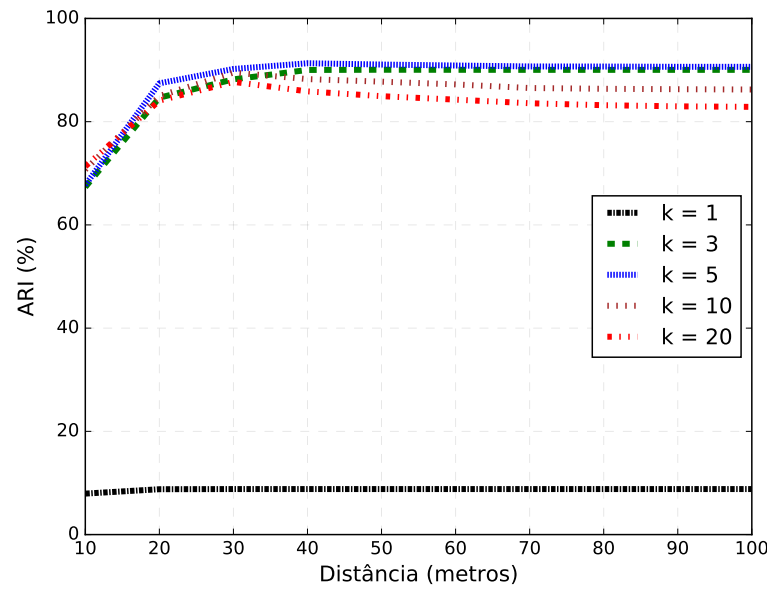

(a) NGNM

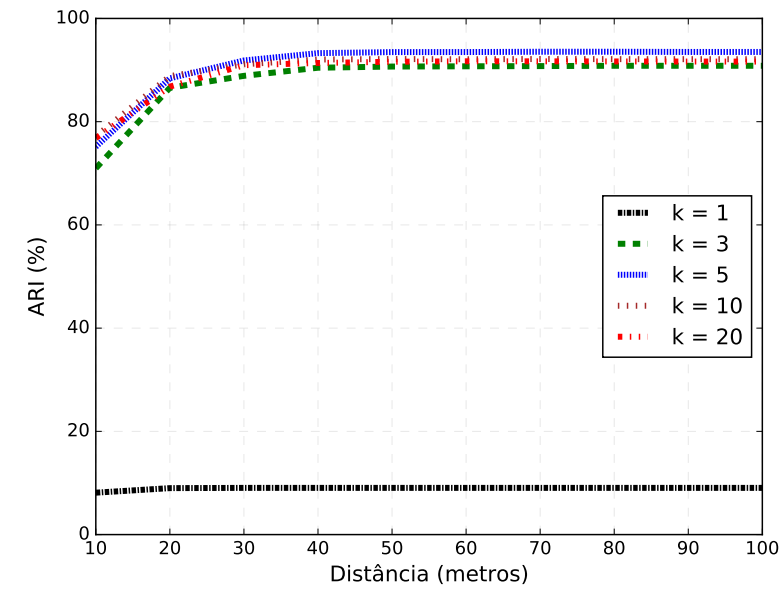

(b) NGNsSM

Fonte: Elaborada pelo autor.

Na Figura 23 é mostrado o valor médio do índice ARI para as melhores configurações de $d_{\text {threshold }}$ em relação ao parâmetro $k$. Nota-se que a partir, como visto anteriormente, de $k \leq 3$ os algoritmos $N G N M$ e $N G N s S M$ apresentam bons resultados de ARI. A diferença máxima dos resultados $A R I$ no algoritmo $N G N M$ é de $3,61 \%^{9}$ e no algoritmo $N G N S S M$ é de $1,83 \%{ }^{10}$, para $3 \leq k \leq 20$. A baixa diferença nos resultados do índice $A R I$ apresentada nos algoritmos $N G N M$ e NGNSSM mostra que estes algoritmos são eficientes para um valor, suficientemente grande de $k$, que para os experimentos deste trabalho é $k=3$. É possível notar também um aumento suave na diferença entre os resultados de $N G N M$ e $N G N S S M$ a medida que o valor de $k$ aumenta. Os melhores resultados ARI para ambos os algoritmos são encontrados com o valor $k=5$.

O número de níveis de contração dos algoritmos $N G N M$ e $N G N s S M$ está associado com o valor do parâmetro $k$ e esse valor interfere o tempo de processamento da fase de contração. Na Figura 24 é mostrado o gráfico do tempo relativo de processamento da fase de contração dos algoritmos $N G N M$ e $N G N S S M$. O eixo y do gráfico mostra a porcentagem do tempo de consumo da fase de contração em relação ao tempo total de processamento e o eixo x indica $\mathrm{o}$

8 O resultado $A R I$ para $k=10$ decaiu 3,28\%, enquanto que para $k=20$ esse valor é de 4,84\%.

$9 \quad \operatorname{ARI}(k=5)-A R I(k=20)=91,31 \%-87,71 \%=3,61 \%$.

$10 A R I(k=5)-A R I(k=20)=93,52 \%-91,70 \%=1,83 \%$. 
Figura 23 - Gráfico dos resultados médios de ARI para as melhores configurações de $k$

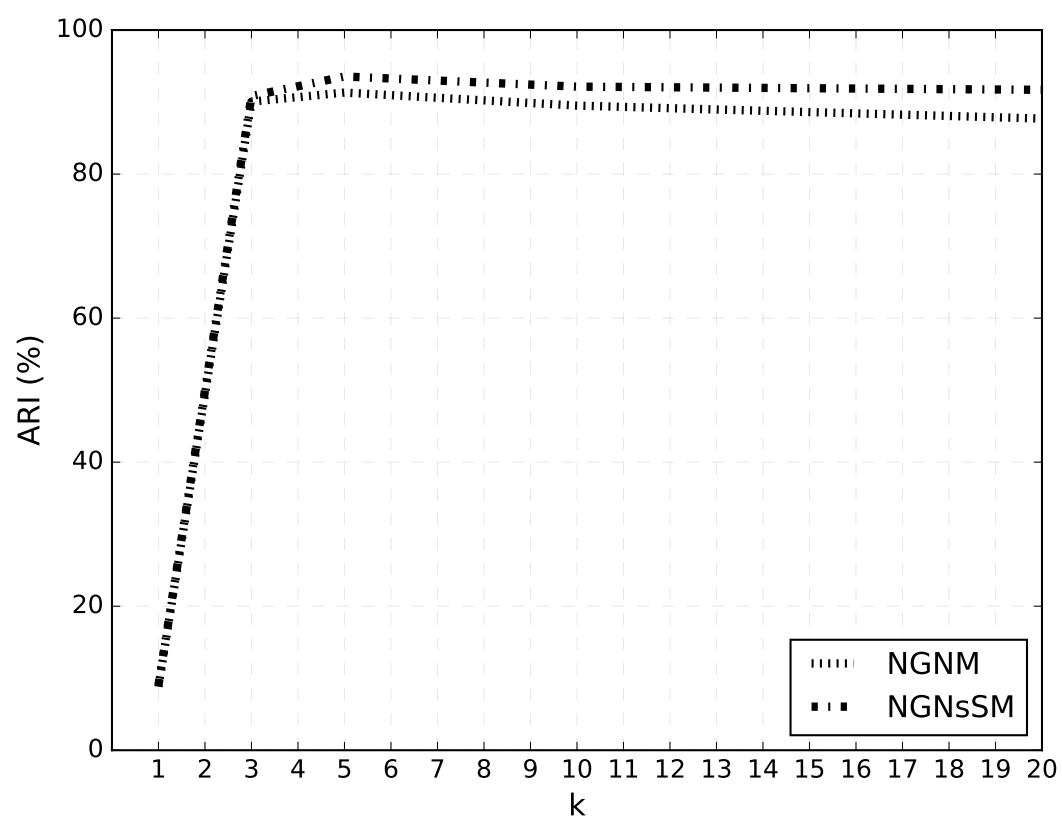

Fonte: Elaborada pelo autor.

valor de $k$. Nota-se que para os dois algoritmos o tempo da fase de contração aumenta na medida que aumenta o valor do parâmetro $k$, exceto para $1 \leq k \leq 3$ no algoritmo NGNSSM. Consequentemente, o aumento do valor de $k$ gera um aumento no tempo absoluto de processamento dos algoritmos $N G N M$ e $N G N S S M$.

\subsubsection{Análise do índice ARI}

Nesta seção são apresentados os resultados do índice ARI para os algoritmos OPTICS, $N G N M, N G N S S M, C L$ e UPGMA. Para os algoritmos $N G N M$ e $N G N S S M$ é utilizado $k=5$ nas análises, pois como visto na seção anterior é a configuração que gera os melhores resultados para os algoritmos em questão. Primeiramente, é discutida e analisada a influência do parâmetro referente a distância nos algoritmos e depois é selecionada as melhores configurações dos algoritmos e, consequentemente, verificado qual dos algoritmos tem a maior capacidade de representar o mundo real por meio de redes.

$\mathrm{Na}$ Figura 25b é apresentado o desempenho de duas características que influenciam no diretamente no desempenho $A R I$ dos algoritmos. Na Figura 25a é mostrado o índice médio de homogeneidade em relação a distância, a homogeneidade perfeita indica que todos os grupos contém apenas pontos de permanência que representem um mesmo local. Na Figura 25b é mostrado o índice médio de completude em relação a distância, a completude perfeita indica que todos os pontos de permanência que representem um mesmo local estão alocados em um mesmo grupo. 
Figura 24 - Gráfico da proporção do tempo total utilizado pela fase de contração em relação a $k$

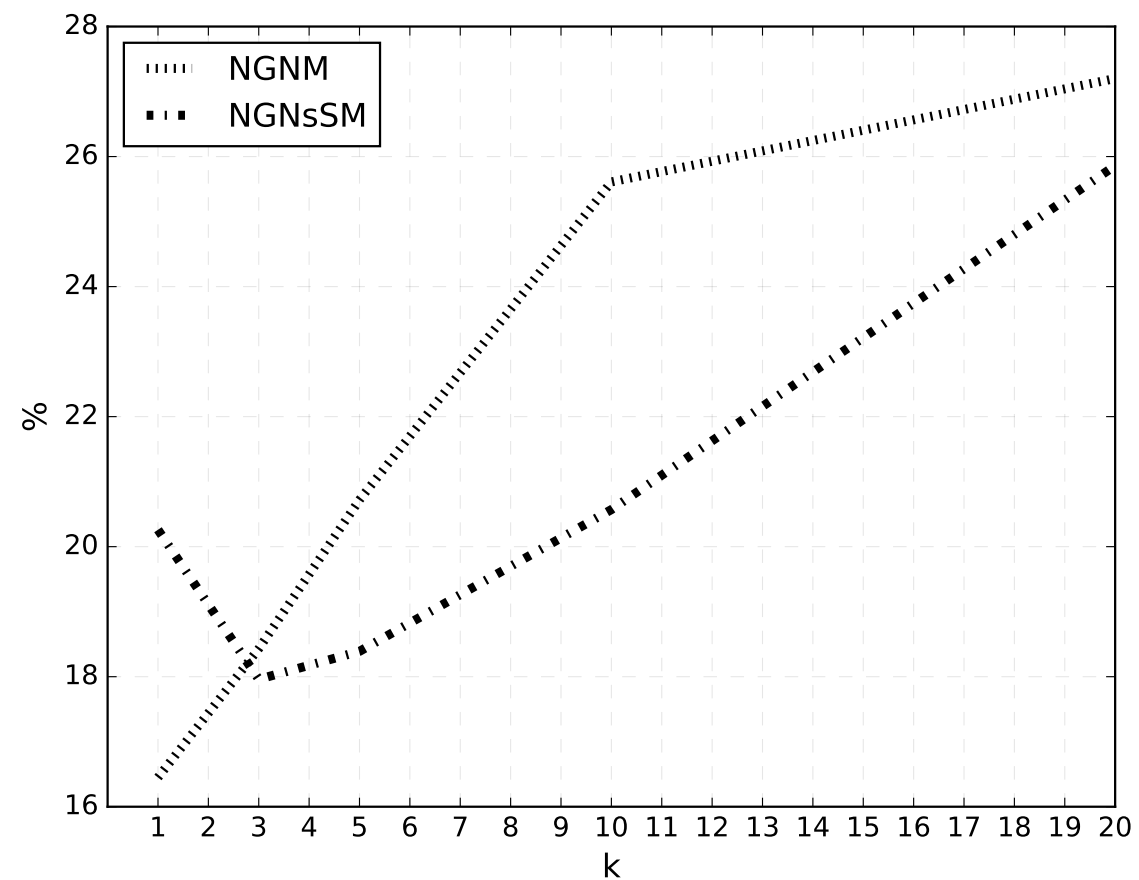

Fonte: Elaborada pelo autor.

A homogeneidade para o algoritmo OPTICS é extremamente sensível a distância, portanto, conforme a distância aumenta o algoritmo OPTICS tende agrupar pontos de permanência referentes a locais diferentes em um mesmo grupo. Os algoritmos CL e UPGMA apresentam resultados semelhantes para o índice de homogeneidade, porém estes resultados apresentam menor sensibilidade a distância em relação ao OPTICS. Os algoritmos NGNM e NGNSSM apresentam os melhores desempenhos de homogeneidade e possuem pouca sensibilidade ao aumento do valor do parâmetro de distância.

Os algoritmos OPTICS, CL e UPGMA apresentam uma tendência de convergência a completude perfeita conforme aumenta-se a distância. O OPTICS alcança a completude perfeita com valores menores de distância comparado aos algoritmos CL e UPGMA. Entretanto, os algoritmos $N G N M$ e $N G N S S M$ não possuem este mesmo comportamento de convergência a completude perfeita. O algoritmo NGNSSM tem 98,69\% como valor máximo de completude e o NGNM tem o valor máximo de $98,86 \%$.

Na Figura 26 é mostrado o gráfico do valor médio ARI para os algoritmos selecionados em relação a distância. O algoritmo OPTICS apresenta o melhor desempenho em distância $=10$, mas com o aumento da distância seu desempenho ARI decai, este comportamento ocorre por causa do decaimento do índice de homogeneidade, como visto na Figura 25a. O algoritmo UPGMA apresenta o melhor desempenho em distância $=30$, enquanto que o algoritmo $C L$ obtém seu melhor desempenho ARI em distância $=50$, os dois algoritmos apresentam compor- 
Figura 25 - Gráficos de homogeneidade e completude

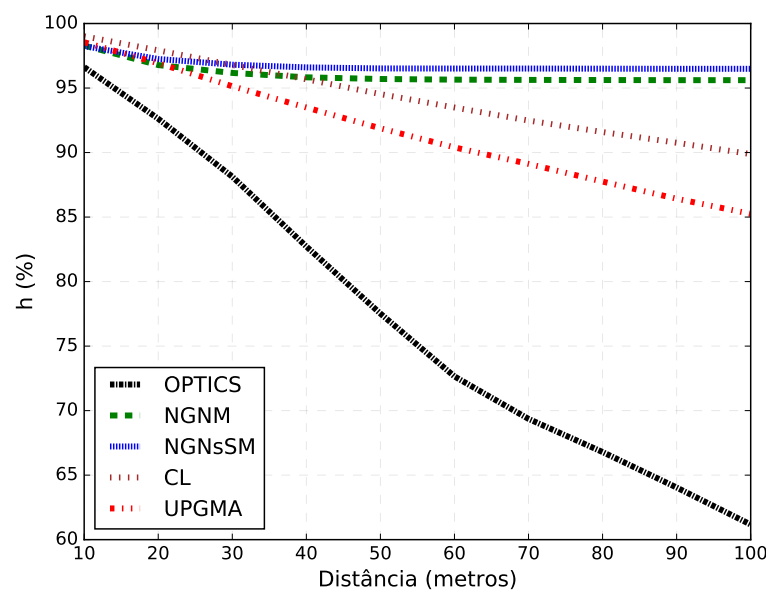

(a) Homogeneidade

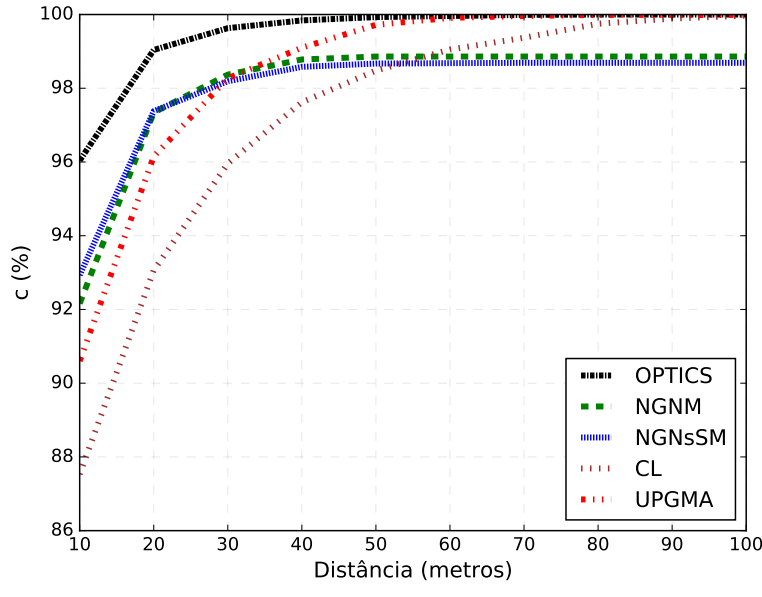

(b) Completude

Fonte: Elaborada pelo autor.

tamentos parecidos em relação a distância, porém com valor de pico diferente. Os algoritmos $N G N M$ e $N G N S S M$ possuem comportamentos semelhantes, pois convergem para o melhor resultado com o aumento da distância. Este comportamento de convergência é justificado pelo comportamento também de convergência nos índices de homogeneidade e completude dos algoritmos $N G N M$ i e NGNSSM. O NGNSSM tem os melhores resultados, dentre todos algoritmos, no índice médio ARI para distância $\geq 20$.

Importante evidenciar que a diferença de desempenho entre os algoritmos $N G N M \mathrm{e}$ NGNSSM ocorre pela diferença de desempenho no índice de homogeneidade, pois o desempenho em completude dos dois algoritmos são semelhantes. O NGNSSM possui melhores resultados em homogeneidade no geral, comparado ao algoritmo $N G N M$, e isso reflete-se nos resultados do índice $A R I$.

Para verificar qual dos algoritmos possui a maior capacidade de representação do mundo real por meio de redes, foi selecionada a melhor parametrização de cada algoritmo para realizar a análise. Na Tabela 4 são apresentados os resultados ARI para as melhores parametrizações ${ }^{11}$ dos algoritmos. Na primeira coluna é mostrado qual a base de dados de origem do conjunto de dados. Na coluna Região é mostrado a região correspondente ao conjunto de dados. Nas colunas 3-7 é apresentado os resultados ARI dos algoritmos. Na coluna $\sigma$ é exposto o desvio padrão dos resultados para cada conjunto de dados.

As duas regiões com as menores áreas territoriais, Universal Studios e Manhattan, foram as que obtiveram piores resultados do índice $A R I$, independentemente da base de dados de origem: Brightkite ou Gowalla, e dos algoritmos utilizados. Este fato demonstra a dificuldade de

11 UPGMA $=30$ metros, $C L=50$ metros, OPTICS $=10$ metros, NGNM $=100$ metros e NGNsSM $=$ 100 metros. 
Figura 26 - Gráfico da média do número de níveis necessários para atingir a rede $G_{n}$ utilizando $C P V$ e $C G V$ em relação a distância limite $d_{\text {threshold }}$

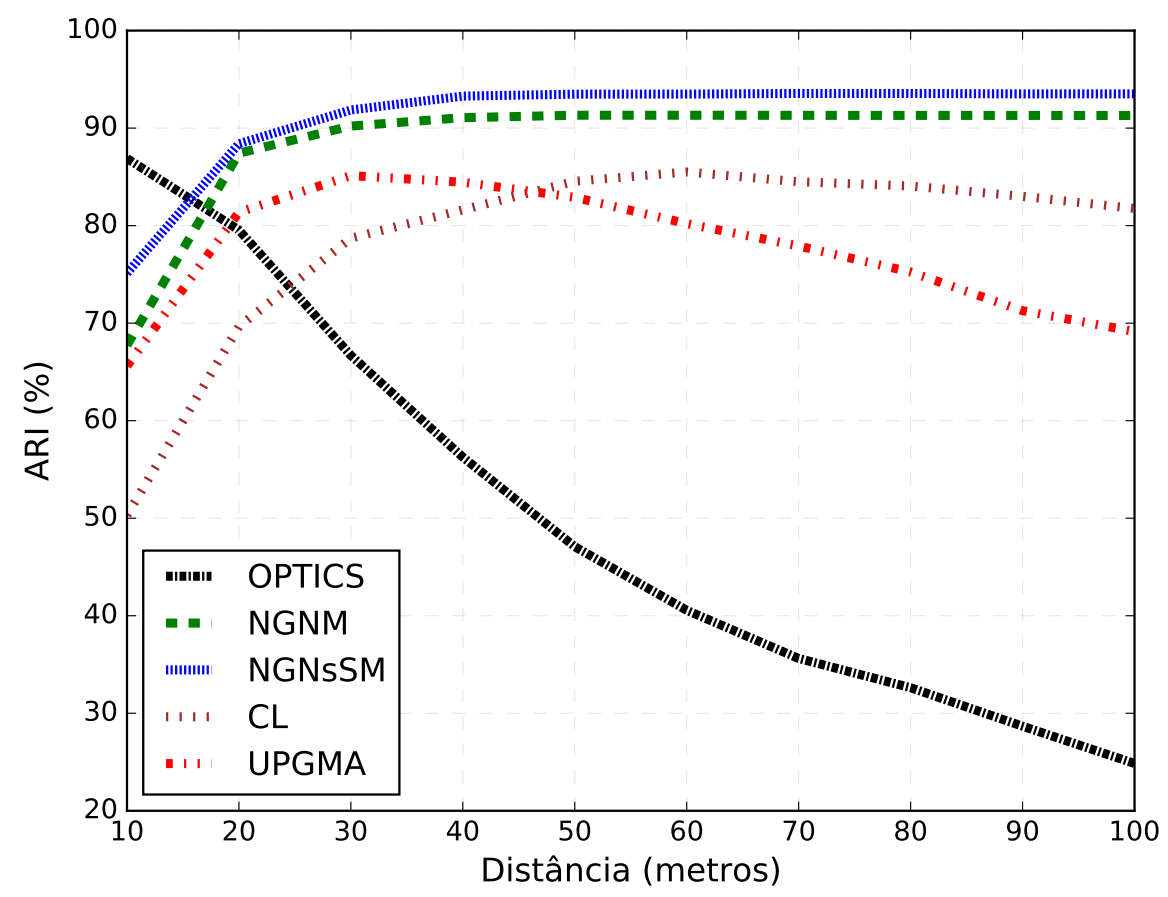

Fonte: Elaborada pelo autor.

diferenciar locais próximos através de vértices. Em contrapartida, as regiões correspondentes as cidades de: Atlanta, Kansas, Las Vegas, Tucson e Washington D.C. obtiveram os melhores resultados $A R I$ em todos os algoritmos, isso explica-se pela distribuição dos locais visitados em uma área consideravelmente maior, este fato é confirmado pelo baixo desvio padrão dos resultados $A R I$ dessas regiões, ou seja, todos os algoritmos obtiveram performances parecidas nestes conjuntos de dados.

O algoritmo UPGMA teve o desempenho médio do índice $A R I$ de $85,13 \%$ e desvio padrão de 9,41\% dos resultados. O UPGMA teve o melhor desempenho entre todos os algoritmos no conjunto de dados Brightkite - Tucson, no qual teve uma representação muito próxima da perfeita (99,15\%). O algoritmo $C L$ teve o pior desempenho ARI entre todos os algoritmos testados, porém na média apresenta resultados similares ao UPGMA.

O algoritmo OPT ICS teve o desempenho médio do índice ARI de 86,89\%, superando os algoritmos $C L$ e UPGMA. Porém, obteve o pior desvio padrão, 12,96\%, entre todos os algoritmos. Devido as suas características, o algoritmo OPTICS teve os dois piores resultados $(47,73 \%$ e $60,42 \%$ ) dentre todos os resultados, isto ocorreu nos conjuntos de dados equivalente a Universal Studios que é a região de menor área territorial. No entanto, teve o melhor desempenho nos conjuntos de dados Brightkite - Beverlly Hills, Brightkite - Manhattan e Brightkite - Washington.

O algoritmo NGNSSM possui os melhores resultados ARI e o menor desvio padrão entre 
Tabela 4 - Resultados do índice ARI para a melhor configuração dos algoritmos

\begin{tabular}{|c|c|c|c|c|c|c|c|}
\hline \multirow{2}{*}{ BD } & \multirow{2}{*}{ Região } & \multicolumn{5}{|c|}{ Métodos } & \multirow{2}{*}{$\sigma$} \\
\hline & & UPGMA & CL & OPTICS & NGNM & NGNsSM & \\
\hline \multirow{10}{*}{ Brightkite } & Atlanta & $75.75 \%$ & $64.88 \%$ & $96.14 \%$ & $96.34 \%$ & $96.90 \%$ & $14.83 \%$ \\
\hline & BeverllyHills & $87.70 \%$ & $87.26 \%$ & $93.40 \%$ & $92.75 \%$ & $93.05 \%$ & $3.07 \%$ \\
\hline & Indianapolis & $85.51 \%$ & $84.35 \%$ & $93.55 \%$ & $90.99 \%$ & $96.61 \%$ & $5.22 \%$ \\
\hline & Kansas & $94.86 \%$ & $94.52 \%$ & $95.59 \%$ & $96.20 \%$ & $96.55 \%$ & $0.86 \%$ \\
\hline & LasVegas & $94.06 \%$ & $94.21 \%$ & $94.57 \%$ & $94.93 \%$ & $93.11 \%$ & $0.69 \%$ \\
\hline & Manhattan & $78.35 \%$ & $79.06 \%$ & 83.68\% & $83.63 \%$ & $83.30 \%$ & $2.66 \%$ \\
\hline & Tucson & 99.15\% & $98.99 \%$ & $98.57 \%$ & $99.13 \%$ & $99.01 \%$ & $0.23 \%$ \\
\hline & Universal & $65.22 \%$ & $62.86 \%$ & $47.73 \%$ & $\mathbf{8 2 . 5 4 \%}$ & $79.31 \%$ & $13.99 \%$ \\
\hline & Walt Disney & $85.54 \%$ & $84.97 \%$ & $89.48 \%$ & $95.34 \%$ & 97.73\% & $5.74 \%$ \\
\hline & Washington & $96.57 \%$ & $96.18 \%$ & 98.19\% & $97.80 \%$ & $98.00 \%$ & $0.91 \%$ \\
\hline \multirow{10}{*}{ Gowalla } & Atlanta & $96.96 \%$ & $96.62 \%$ & $97.17 \%$ & $97.67 \%$ & $98.77 \%$ & $0.84 \%$ \\
\hline & BeverllyHills & $78.33 \%$ & $76.39 \%$ & $80.90 \%$ & $84.41 \%$ & 90.05\% & $5.40 \%$ \\
\hline & Indianapolis & $79.80 \%$ & $78.76 \%$ & $78.21 \%$ & $85.47 \%$ & $89.94 \%$ & $5.10 \%$ \\
\hline & Kansas & $87.54 \%$ & $87.21 \%$ & $87.69 \%$ & $91.12 \%$ & $94.45 \%$ & $3.14 \%$ \\
\hline & LasVegas & $94.82 \%$ & $94.84 \%$ & $95.63 \%$ & $96.43 \%$ & $\mathbf{9 7 . 3 9 \%}$ & $1.10 \%$ \\
\hline & Manhattan & $83.88 \%$ & $86.55 \%$ & $86.85 \%$ & $90.00 \%$ & $\mathbf{9 2 . 8 3 \%}$ & $3.45 \%$ \\
\hline & Tucson & $80.63 \%$ & $80.43 \%$ & $90.10 \%$ & $93.67 \%$ & $94.56 \%$ & $6.91 \%$ \\
\hline & Universal & $68.09 \%$ & $73.68 \%$ & $60.42 \%$ & $79.32 \%$ & $89.90 \%$ & $11.18 \%$ \\
\hline & Walt Disney & $81.96 \%$ & $81.06 \%$ & $79.64 \%$ & $87.95 \%$ & $93.96 \%$ & $5.97 \%$ \\
\hline & Washington & $87.94 \%$ & $88.12 \%$ & $90.29 \%$ & $90.54 \%$ & $95.00 \%$ & $2.85 \%$ \\
\hline \multicolumn{2}{|c|}{ Média } & $85.13 \%$ & $84.55 \%$ & $86.89 \%$ & $91.31 \%$ & $\mathbf{9 3 . 5 2} \%$ & $3.26 \%$ \\
\hline \multicolumn{2}{|c|}{ Desvio Padrão } & $9.41 \%$ & $10.14 \%$ & $12.96 \%$ & $5.76 \%$ & $5.08 \%$ & $3.95 \%$ \\
\hline
\end{tabular}

todos os algoritmos. O NGNSSM obteve o melhor desempenho em todos os conjuntos de dados derivados da base de dados da Gowalla, enquanto o desempenho nos conjuntos de dados derivados da Brightkite seus resultados foram similares ao algoritmo NGNM. No agrupamento perfeito visto na Tabela 3 , nota-se que os conjuntos de dados provenientes da base de dados Gowalla apresentam maior grau médio de vértices em relação aos conjuntos de dados do Brightkite, estes melhores resultados na Gowalla estão relacionados com a característica do algoritmo NGNsSM de utilizar as arestas entre vértices iterativamente na construção da rede. Portanto, quanto mais informação, neste caso conexões entre vértices, melhor o desempenho do algoritmo NGNsSM perante aos demais algoritmos.

Por fim, os resultados destes experimentos mostram que os dois melhores algoritmos que possuem maior capacidade de representação do mundo real por meio de redes são os algoritmos $N G N M$ e $N G N S S M$, pois são os algoritmos que apresentam melhores resultados de acordo com a Tabela 4 e também os que possuem o menor desvio padrão em seus resultados.

No geral, todos os algoritmos apresentam bons resultados em suas melhores parametrizações. Porém, utilizando uma parametrização não ideal nos algoritmos $C L, U P G M A$ e OPTICS a representação do mundo real fica comprometida. Os algoritmos $N G N M$ e $N G N s S M$ também são 
sensíveis a parametrização, porém utilizando valores altos de distância ( $\geq 50$ metros) e um valor de $k \geq 3$ os resultados são satisfatórios, como pode ser revisto na Figura 22.

\subsubsection{Análise de tempo}

Nesta seção são apresentados os tempos médios de processamento dos algoritmos testados neste capítulo.

Na Figura 27 é mostrado o gráfico dos tempos de processamento dos algoritmos selecionados para os experimentos. A coluna indica o tempo em minutos gasto no processamento e a linha indica o número de pontos de permanência utilizados no processamento. Os tempos foram processados na construção da rede hierárquica com dez níveis, como mostrado anteriormente.

Figura 27 - Gráfico de tempo de processamento dos algoritmos

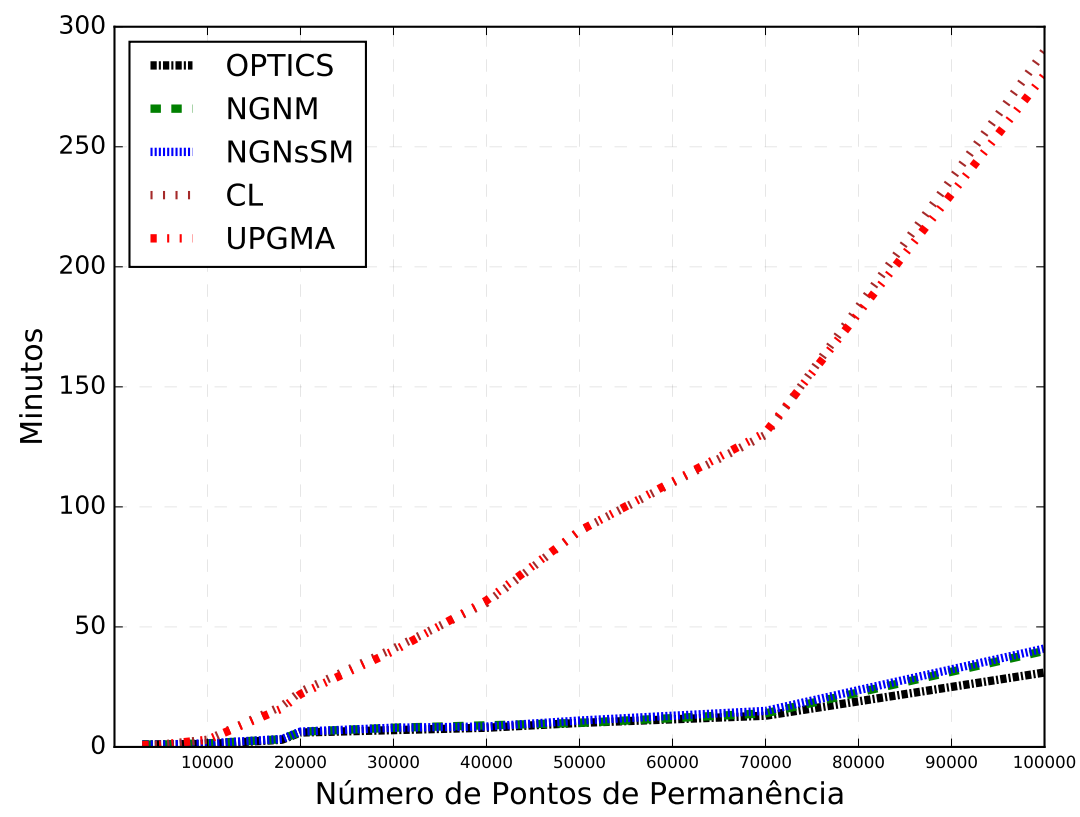

Fonte: Elaborada pelo autor.

Por terem abordagem hierárquica aglomerativa, os algoritmos $C L$ e $U P G M A$ apresentam tempos similares de processamento. Porém, a medida que aumenta o número de pontos de permanência o tempo de processamento cresce substancialmente, tornando os algoritmos $C L \mathrm{e}$ UPGMA proibitivos para grandes quantidade de pontos de permanência a serem processados. O algoritmo OPT ICS apresenta os menores tempos de processamento. Os algoritmos NGNM e NGNsSM apresentam tempos de processamento similares, porém com um tempo de processamento um pouco superior no geral em relação ao OPTICS. Assim, os algoritmos OPTICS, $N G N M$ e $N G N S S M$ são os algoritmos mais indicados com uma grande quantidade de pontos de permanência no conjunto de dados. 
Este capítulo apresenta as considerações finais deste projeto com o intuito de elucidar as principais contribuições e limitações do trabalho desenvolvido, além de apresentar novos trabalhos a serem realizados futuramente.

O objetivo principal deste trabalho foi desenvolver um método de construção de redes por meio de pontos de permanência que representasse de maneira mais exata possível o mundo real. A fase de contração foi escolhida para esta tarefa, pois pelo levantamento bibliográfico, foi visto que as redes são construídas apenas no final do processo. Assim, construindo a rede iterativamente é possível extrair características topológicas que auxiliam na contração da rede e, consequentemente, chegar a rede solução com uma representação mais fiel ao mundo real. A seguir, são apresentadas as contribuições mais relevantes deste trabalho.

- Criação de um método de avaliação para a tarefa de transformação de pontos de permanência em redes em relação ao mundo real. Esta contribuição gerou o seguinte artigo aprovado para publicação:

- (MINATEL, D.; VALEJO, A.; LOPES, A. Trajectory network assessment based on analysis of stay points cluster. In: BRACIS 2018)

- Análise de construção de redes por pontos de permanência.

- Utilização do paradigma multinível em dados geográficos. Não foi encontrada, no levantamento bibliográfico, outras abordagens que utilizam o paradigma multinível em dados geográficos.

- Criação de dois algoritmos de matching aplicados a dados geográficos. Esta contribuição gerou o seguinte artigo a ser submetido:

- (MINATEL, D.; LOPES, A. Multilevel approach to transforming trajectories by stay points into networks.) 
A abordagem desenvolvida neste trabalho pode ser utilizada em qualquer tipo de trajetória por pontos de permanência, independente do objeto móvel. Os experimentos realizados apresentam indícios que a abordagem desenvolvida possui melhores resultados na transformação de trajetórias por pontos de permanência em redes na representação do mundo real. Apesar de obter resultados satisfatórios é preciso destacar algumas limitações deste trabalho que são discutidas na seção a seguir.

\subsection{Limitações do Trabalho}

A principal limitação deste trabalho é a não utilização de base de dados de trajetórias geográficas reais. Apesar de existir poucas bases de dados (deste tipo) disponíveis, as bases de dados existentes, por característica dos dados, não apresentam rótulos o que impossibilita a verificação da qualidade de representação do mundo real. Essa limitação restringe adicionar mais conclusões a este trabalho, porém abre a possibilidade de criar uma base de dados com estas características e, consequentemente, contribuir com a comunidade científica.

Na literatura é pouco discutida a forma de construção de redes por pontos de permanência, o enfoque é dado na aplicação em si. Assim, a seleção de algoritmos para comparação dos resultados ficou restrita ao método aceito na área de mineração de trajetórias e de algoritmos que apresentam características semelhantes ao método em questão.

\subsection{Trabalhos Futuros}

Apresentadas as principais contribuições e limitações do trabalho desenvolvido é possível direcionar os próximos passos aplicados a aprimorar e expandir a pesquisa apresentada neste documento. Deste modo, são listados os trabalhos futuros para continuação desta pesquisa:

- Implementar detecção em tempo real de pontos de permanência no RadrPlus (ALVAREZ, 2017). RadrPlus é uma rede social geocalizada desenvolvida sob a tutoria do Prof. Dr. Alneu de Andrade Lopes. A detecção em tempo real permite que o usuário indique uma etiqueta para o local em questão no momento que o ponto de permanência for detectado. Portanto, com esta implementação as trajetórias por pontos de permanência seriam rotuladas, consequentemente, seria criada uma base de dados real e rotulada, isto implicaria em uma melhor análise dos algoritmos testados neste trabalho.

- Implementado o item anterior possibilita um estudo da distribuição dos pontos de permanência detectados em um mesmo local. Conhecer a distribuição dos pontos de permanência que representam um mesmo local auxiliaria a otimização dos algoritmos propostos ou na criação de novas abordagens para transformar trajetórias por pontos de permanência em redes. 
- Expandir os estudos e análises das características topológicas de redes por trajetórias e assim, encontrar novas características que auxiliem na otimização dos métodos propostos.

- Expandir as análises para outros tipos de algoritmos de agrupamento.

- Realizar análises da estrutura hierárquica das redes hierárquicas. 



\section{REFERÊNCIAS}

ALBERT, R.; BARABáSI, A. lászló. Statistical mechanics of complex networks. Reviews of Modern Physics, p. 74:48-98, 2002. Citado na página 31.

ALVAREZ, R. M. P. Mineração de trajetórias em redes sociais geolocalizadas. In: Dissertação de Mestrado em Ciências de Computação e Matemática Computacional. São Carlos : Instituto de Ciências Matemáticas e de Computação, Universidade de São Paulo., 2017. Disponível em: $<$ http://www.teses.usp.br/teses/disponiveis/55/55134/tde-21092017-140230/pt-br.php>. Citado na página 80.

ANKERST, M.; BREUNIG, M. M.; KRIEGEL, H.-P.; SANDER, J. Optics: Ordering points to identify the clustering structure. SIGMOD Rec., ACM, New York, NY, USA, v. 28, n. 2, p. 4960, jun. 1999. ISSN 0163-5808. Disponível em: <http://doi.acm.org/10.1145/304181.304187>. Citado nas páginas 28 e 44.

BAYRAK, A. E.; POLAT, F. Examining place categories for link prediction in location based social networks. In: Proceedings of the 2016 IEEE/ACM International Conference on Advances in Social Networks Analysis and Mining. Piscataway, NJ, USA: IEEE Press, 2016. (ASONAM '16), p. 976-979. ISBN 978-1-5090-2846-7. Disponível em: <http://dl.acm.org/ citation.cfm?id=3192424.3192608>. Citado na página 55 .

BAñOS, R.; GIL, C.; ORTEGA, J.; MONTOYA, F. A parallel multilevel metaheuristic for graph partitioning. Journal of Heuristics, v. 10, n. 3, p. 315-336, May 2004. ISSN 1572-9397. Disponível em: <https://doi.org/10.1023/B:HEUR.0000026898.11874.e7>. Citado na página 41.

BROWN, C.; NICOSIA, V.; SCELLATO, S.; NOULAS, A.; MASCOLO, C. The importance of being placefriends: Discovering location-focused online communities. In: Proceedings of the 2012 ACM Workshop on Workshop on Online Social Networks. New York, NY, USA: ACM, 2012. (WOSN '12), p. 31-36. ISBN 978-1-4503-1480-0. Disponível em: <http://doi.acm. org/10.1145/2342549.2342557>. Citado na página 55.

CAO, H.; MAMOULIS, N.; CHEUNG, D. W. Discovery of periodic patterns in spatiotemporal sequences. IEEE Transactions on Knowledge and Data Engineering, v. 19, n. 4, p. 453-467, April 2007. ISSN 1041-4347. Citado nas páginas 27 e 52.

CHEN, X.; SHI, D.; ZHAO, B.; LIU, F. Mining individual mobility patterns based on location history. In: 2016 IEEE First International Conference on Data Science in Cyberspace (DSC). [S.1.: s.n.], 2016. p. 252-259. Citado nas páginas 27, 28 e 57.

CHERNOSKUTOV, M.; INEICHEN, Y.; BEKAS, C. Heuristic algorithm for approximation betweenness centrality using graph coarsening. Procedia Computer Science, v. 66, p. 83 - 92, 2015. ISSN 1877-0509. 4th International Young Scientist Conference on Computational Science. Disponível em: <http://www.sciencedirect.com/science/article/pii/S1877050915033608>. Citado na página 41. 
CHO, E.; MYERS, S. A.; LESKOVEC, J. Friendship and mobility: User movement in locationbased social networks. In: Proceedings of the 17th ACM SIGKDD International Conference on Knowledge Discovery and Data Mining. New York, NY, USA: ACM, 2011. (KDD '11), p. 1082-1090. ISBN 978-1-4503-0813-7. Disponível em: <http://doi.acm.org/10.1145/2020408. 2020579>. Citado na página 67.

COSTA, L.; RODRIGUES, F.; TRAVIESO, G.; BOAS, P. Characterization of complex networks: A survey of measurements. Advances in Physics, Taylor \& Francis, v. 56, n. 1, p. 167-242, 2007. ISSN 0001-8732. Citado nas páginas 34 e 36.

COSTA, L. F.; Oliveira Jr., O. N.; TRAVIESO, G.; RODRIGUES, F. A.; Villas Boas, P. R.; ANTIQUEIRA, L.; VIANA, M. P.; ROCHA, L. E. C. Analyzing and modeling real-world phenomena with complex networks: a survey of applications. Advances in Physics, v. 60, n. 3, p. 329-412, 2011. Citado nas páginas 27, 31 e 37.

DAY, W. H. E.; EDELSBRUNNER, H. Efficient algorithms for agglomerative hierarchical clustering methods. Journal of Classification, v. 1, n. 1, p. 7-24, Dec 1984. ISSN 1432-1343. Disponível em: <https://doi.org/10.1007/BF01890115>. Citado na página 43.

DJIDJEV, H. N. A scalable multilevel algorithm for graph clustering and community structure detection. In: Algorithms and Models for the Web-Graph: Fourth International Workshop, WAW 2006, Banff, Canada, November 30 - December 1, 2006. Revised Papers. Berlin, Heidelberg: Springer Berlin Heidelberg, 2008. p. 117-128. ISBN 978-3-540-78808-9. Disponível em: <https://doi.org/10.1007/978-3-540-78808-9_11>. Citado na página 41.

DRIF, A.; BOUKERRAM, A.; SLIMANI, Y.; GIORDANO, S. Discovering interest based mobile communities. Mobile Networks and Applications, v. 22, n. 2, p. 344-355, Apr 2017. ISSN 1572-8153. Disponível em: <https://doi.org/10.1007/s11036-017-0811-3>. Citado nas páginas 27,28 e 57.

ERICSSON. Ericsson mobility report: 70 percent of world's population using smartphones by 2020. 2015. Disponível em: <http://www.ericsson.com/news/1925907>. Acesso em: 13.04.2018. Citado nas páginas 27 e 49.

ESTER, M.; KRIEGEL, H.-P.; SANDER, J.; XU, X. A density-based algorithm for discovering clusters a density-based algorithm for discovering clusters in large spatial databases with noise. In: Proceedings of the Second International Conference on Knowledge Discovery and Data Mining. AAAI Press, 1996. (KDD’96), p. 226-231. Disponível em: <http://dl.acm.org/citation. cfm?id=3001460.3001507>. Citado na página 44.

FACEBOOK. Company info. 2018. Disponível em: <https://newsroom.fb.com/company-info/>. Acesso em: 05.06.2018. Citado na página 37.

FENG, Z.; ZHU, Y. A survey on trajectory data mining: Techniques and applications. IEEE Access, v. 4, p. 2056-2067, 2016. ISSN 2169-3536. Citado na página 50.

GIANNOTTI, F.; NANNI, M.; PINELLI, F.; PEDRESCHI, D. Trajectory pattern mining. In: Proceedings of the 13th ACM SIGKDD International Conference on Knowledge Discovery and Data Mining. New York, NY, USA: ACM, 2007. (KDD '07), p. 330-339. ISBN 978-159593-609-7. Disponível em: <http://doi.acm.org/10.1145/1281192.1281230>. Citado nas páginas 27 e 52. 
GREENFELD, J. S. Matching GPS observations to locations on a digital map. In: Proceedings of the 81st Annual Meeting of the Transportation Research Board. [S.1.: s.n.], 2002. Citado na página 53.

HUANG, X.; ZHAO, Y.; MA, C.; YANG, J.; YE, X.; ZHANG, C. Trajgraph: A graph-based visual analytics approach to studying urban network centralities using taxi trajectory data. IEEE Transactions on Visualization and Computer Graphics, v. 22, n. 1, p. 160-169, Jan 2016. ISSN 1077-2626. Citado nas páginas 27, 28 e 54.

HUBERT, L.; ARABIE, P. Comparing partitions. Journal of Classification, v. 2, n. 1, p. $193-$ 218, Dec 1985. ISSN 1432-1343. Disponível em: <https://doi.org/10.1007/BF01908075>. Citado na página 46.

KANDA, T.; SHIOMI, M.; PERRIN, L.; NOMURA, T.; ISHIGURO, H.; HAGITA, N. Analysis of people trajectories with ubiquitous sensors in a science museum. In: Proceedings 2007 IEEE International Conference on Robotics and Automation. [S.1.: s.n.], 2007. p. 4846-4853. ISSN 1050-4729. Citado na página 56.

KANUNGO, T.; MOUNT, D. M.; NETANYAHU, N. S.; PIATKO, C. D.; SILVERMAN, R.; WU, A. Y. An efficient k-means clustering algorithm: Analysis and implementation. IEEE Trans. Pattern Anal. Mach. Intell., IEEE Computer Society, Washington, DC, USA, v. 24, n. 7, p. 881-892, jul. 2002. ISSN 0162-8828. Disponível em: <http://dx.doi.org/10.1109/TPAMI.2002. 1017616>. Citado na página 42.

KARAGIORGOU, S.; PFOSER, D.; SKOUTAS, D. A layered approach for more robust generation of road network maps from vehicle tracking data. ACM Trans. Spatial Algorithms Syst., ACM, New York, NY, USA, v. 3, n. 1, p. 3:1-3:21, maio 2017. ISSN 2374-0353. Disponível em: $<$ http://doi.acm.org/10.1145/3061713>. Citado nas páginas 27, 28 e 54.

KARYPIS, G.; KUMAR, V. A fast and high quality multilevel scheme for partitioning irregular graphs. SIAM J. Sci. Comput., Society for Industrial and Applied Mathematics, Philadelphia, PA, USA, v. 20, n. 1, p. 359-392, dez. 1998. ISSN 1064-8275. Disponível em: <http://dx.doi. org/10.1137/S1064827595287997>. Citado nas páginas 29, 39, 40 e 41.

KAUFMAN, L.; ROUSSEEUW, P. Finding Groups in Data: an introduction to cluster analysis. [S.1.]: Wiley, 1990. Citado nas páginas 43 e 44.

KIVELä, M.; ARENAS, A.; BARTHELEMY, M.; GLEESON, J. P.; MORENO, Y.; PORTER, M. A. Multilayer networks. Journal of Complex Networks, v. 2, n. 3, p. 203-271, 2014. Disponível em: <http://dx.doi.org/10.1093/comnet/cnu016>. Citado na página 33.

KYLASA, S. B.; KOLLIAS, G.; GRAMA, A. Social ties and checkin sites: Connections and latent structures in location based social networks. In: Proceedings of the 2015 IEEE/ACM International Conference on Advances in Social Networks Analysis and Mining 2015. New York, NY, USA: ACM, 2015. (ASONAM '15), p. 194-201. ISBN 978-1-4503-3854-7. Disponível em: <http://doi.acm.org/10.1145/2808797.2809308>. Citado na página 55.

LASALLE, D.; KARYPIS, G. Multi-threaded modularity based graph clustering using the multilevel paradigm. J. Parallel Distrib. Comput., Academic Press, Inc., Orlando, FL, USA, v. 76, n. C, p. 66-80, fev. 2015. ISSN 0743-7315. Disponível em: <https://doi.org/10.1016/j.jpdc. 2014.09.012>. Citado na página 41. 
LI, Q.; ZHENG, Y.; XIE, X.; CHEN, Y.; LIU, W.; MA, W.-Y. Mining user similarity based on location history. In: Proceedings of the 16th ACM SIGSPATIAL International Conference on Advances in Geographic Information Systems. New York, NY, USA: ACM, 2008. (GIS '08), p. 34:1-34:10. ISBN 978-1-60558-323-5. Disponível em: <http://doi.acm.org/10.1145/ 1463434.1463477>. Citado nas páginas 28, 51, 56 e 57.

LI, Z.; DING, B.; HAN, J.; KAYS, R.; NYE, P. Mining periodic behaviors for moving objects. In: Proceedings of the 16th ACM SIGKDD International Conference on Knowledge Discovery and Data Mining. New York, NY, USA: ACM, 2010. (KDD '10), p. 1099-1108. ISBN 9781-4503-0055-1. Disponível em: <http://doi.acm.org/10.1145/1835804.1835942>. Citado nas páginas 27 e 52.

LI, Z.; WANG, J.; HAN, J. Mining event periodicity from incomplete observations. In: Proceedings of the 18th ACM SIGKDD International Conference on Knowledge Discovery and Data Mining. New York, NY, USA: ACM, 2012. (KDD '12), p. 444-452. ISBN 978-1-45031462-6. Disponível em: <http://doi.acm.org/10.1145/2339530.2339604>. Citado nas páginas 27 e 52 .

LUO, W.; TAN, H.; CHEN, L.; NI, L. M. Finding time period-based most frequent path in big trajectory data. In: Proceedings of the 2013 ACM SIGMOD International Conference on Management of Data. New York, NY, USA: ACM, 2013. (SIGMOD '13), p. 713-724. ISBN 978-1-4503-2037-5. Disponível em: <http://doi.acm.org/10.1145/2463676.2465287>. Citado nas páginas 27 e 54 .

MASCIARI, E.; SHI, G.; ZANIOLO, C. Sequential pattern mining from trajectory data. In: Proceedings of the 17th International Database Engineering \&\#38; Applications Symposium. New York, NY, USA: ACM, 2013. (IDEAS '13), p. 162-167. ISBN 978-1-4503-2025-2. Disponível em: <http://doi.acm.org/10.1145/2513591.2513653>. Citado nas páginas 27 e 52.

MAZIMPAKA, J. D.; TIMPF, S. Trajectory data mining: A review of methods and applications. Journal of Spatial Information Science, v. 2016, n. 13, p. 61-99, 2016. Citado na página 49.

MINATEL, D.; VALEJO, A.; LOPES, A. Trajectory network assessment based on analysis of stay points cluster. In: BRACIS 2018 (). [S.1.: s.n.], 2018. Citado nas páginas 29, 64, 65 e 66.

NEWMAN, M. Networks: An Introduction. New York, NY, USA: Oxford University Press, Inc., 2010. ISBN 0199206651, 9780199206650. Citado nas páginas 27, 31, 33, 34 e 37.

NEWMAN, M. E. J. Coauthorship networks and patterns of scientific collaboration. Proceedings of the National Academy of Sciences, National Academy of Sciences, v. 101, n. suppl 1, p. 5200-5205, 2004. ISSN 0027-8424. Disponível em: <http://www.pnas.org/content/101/suppl_1/ 5200>. Citado na página 32.

PINK, O.; HUMMEL, B. A statistical approach to map matching using road network geometry, topology and vehicular motion constraints. In: 2008 11th International IEEE Conference on Intelligent Transportation Systems. [S.1.: s.n.], 2008. p. 862-867. ISSN 2153-0009. Citado na página 53.

PUMA-ALVAREZ, R. M.; LOPES, A. de A. Reconstructing pedestrian trajectories from partial observations in the urban context. In: Information Management and Big Data - 4th Annual International Symposium, SIMBig 2017, Lima, Peru, September 4-6, 2017, Revised Selected Papers. [s.n.], 2017. p. 137-148. Disponível em: <https://doi.org/10.1007/978-3-319-90596-9\ _10>. Citado na página 28. 
ROSENBERG, A.; HIRSCHBERG, J. V-measure: A conditional entropy-based external cluster evaluation measure. In: Proceedings of the 2007 Joint Conference on Empirical Methods in Natural Language Processing and Computational Natural Language Learning(EMNLPCoNLL). [S.1.: s.n.], 2007. p. 410-420. Citado na página 45.

SILVA, V. Ferreira da. Otimização multinível em predição de links. In: Dissertação de Mestrado em Ciências de Computação e Matemática Computacional. São Carlos : Instituto de Ciências Matemáticas e de Computação, Universidade de São Paulo., 2018. Disponível em: <http://www. teses.usp.br/>. Citado na página 41.

VALEJO, A.; FERREIRA, V.; OLIVEIRA, M. C. F. de; LOPES, A. de A. Community detection in bipartite network: A modified coarsening approach. In: LOSSIO-VENTURA, J. A.; ALATRISTA-SALAS, H. (Ed.). Information Management and Big Data. Cham: Springer International Publishing, 2018. p. 123-136. ISBN 978-3-319-90596-9. Citado na página 41.

VALEJO, A.; OLIVEIRA, M. C. F. de; FILHO, G. P.; LOPES, A. de A. Multilevel approach for combinatorial optimization in bipartite network. Knowledge-Based Systems, v. 151, p. 45 61, 2018. ISSN 0950-7051. Disponível em: <http://www.sciencedirect.com/science/article/pii/ S0950705118301539>. Citado na página 41.

VALEJO, A.; VALVERDE-REBAZA, J.; LOPES, A. d. A. A multilevel approach for overlapping community detection. In: 2014 Brazilian Conference on Intelligent Systems. [S.1.: s.n.], 2014. p. 390-395. Citado na página 41.

VALVERDE-REBAZA, J.; ROCHE, M.; PONCELET, P.; LOPES, A. de A. Exploiting social and mobility patterns for friendship prediction in location-based social networks. In: 2016 23rd International Conference on Pattern Recognition (ICPR). [S.1.: s.n.], 2016. p. 2526-2531. Citado na página 55.

VALVERDE-REBAZA, J. C. Predição de links em redes complexas utilizando informações de estruturas de comunidades. In: Dissertação de Mestrado em Ciências de Computação e Matemática Computacional. São Carlos : Instituto de Ciências Matemáticas e de Computação, Universidade de São Paulo., 2013. Disponível em: <http://www.teses.usp.br/teses/disponiveis/ 55/55134/tde-05062013-104308/>. Citado na página 36.

VALVERDE-REBAZA, J. C.; ROCHE, M.; PONCELET, P.; LOPES, A. de A. The role of location and social strength for friendship prediction in location-based social networks. Information Processing Management, v. 54, n. 4, p. 475 - 489, 2018. ISSN 0306-4573. Disponível em: <http://www.sciencedirect.com/science/article/pii/S0306457317306246>. Citado na página 55.

VENDRAMIN, L.; CAMPELLO, R. J. G. B.; HRUSCHKA, E. R. Relative clustering validity criteria: A comparative overview. Stat. Anal. Data Min., John Wiley \& Sons, Inc., New York, NY, USA, v. 3, n. 4, p. 209-235, ago. 2010. ISSN 1932-1864. Disponível em: <http://dx.doi.org/ 10.1002/sam.v3:4>. Citado nas páginas 45 e 46.

WALSHAW, C. A multilevel algorithm for force-directed graph drawing. In: Proceedings of the 8th International Symposium on Graph Drawing. London, UK, UK: Springer-Verlag, 2001. (GD '00), p. 171-182. ISBN 3-540-41554-8. Disponível em: <http://dl.acm.org/citation.cfm?id= 647552.729414>. Citado na página 41.

Multilevel refinement for combinatorial optimisation problems. Annals of Operations Research, v. 131, n. 1, p. 325-372, Oct 2004. ISSN 1572-9338. Disponível em: <http://dx.doi. org/10.1023/B:ANOR.0000039525.80601.15>. Citado na página 41. 
XIAO, X.; ZHENG, Y.; LUO, Q.; XIE, X. Inferring social ties between users with human location history. Journal of Ambient Intelligence and Humanized Computing, v. 5, n. 1, p. 3-19, Feb 2014. ISSN 1868-5145. Disponível em: <https://doi.org/10.1007/s12652-012-0117-z>. Citado nas páginas 27,28 e 57.

XU, K.; ZOU, K.; HUANG, Y.; YU, X.; ZHANG, X. Mining community and inferring friendship in mobile social networks. Neurocomputing, v. 174, p. 605 - 616, 2016. ISSN 0925-2312. Disponível em: <http://www.sciencedirect.com/science/article/pii/S0925231215014034>. Citado na página 55.

XU, R.; WUNSCH, D. Survey of clustering algorithms. IEEE Transactions on Neural Networks, v. 16, n. 3, p. 645-678, May 2005. ISSN 1045-9227. Citado nas páginas 42 e 43 .

YANG, J.; XU, J.; XU, M.; ZHENG, N.; CHEN, Y. Predicting next location using a variable order markov model. In: Proceedings of the 5th ACM SIGSPATIAL International Workshop on GeoStreaming. New York, NY, USA: ACM, 2014. (IWGS '14), p. 37-42. ISBN 978-1-45033139-5. Disponível em: <http://doi.acm.org/10.1145/2676552.2676557>. Citado nas páginas 27,28 e 57.

YANG, M.; CHENG, C.; CHEN, B. Mining individual similarity by assessing interactions with personally significant places from gps trajectories. ISPRS International Journal of GeoInformation, v. 7, n. 3, 2018. Citado nas páginas 27, 28 e 57.

YUAN, J.; ZHENG, Y.; XIE, X.; SUN, G. Driving with knowledge from the physical world. In: Proceedings of the 17th ACM SIGKDD International Conference on Knowledge Discovery and Data Mining. New York, NY, USA: ACM, 2011. (KDD '11), p. 316-324. ISBN 978-14503-0813-7. Disponível em: <http://doi.acm.org/10.1145/2020408.2020462>. Citado nas páginas 28 e 54.

. T-drive: Enhancing driving directions with taxi drivers' intelligence. IEEE Transactions on Knowledge and Data Engineering, v. 25, n. 1, p. 220-232, Jan 2013. ISSN 1041-4347. Citado nas páginas 27, 28 e 54.

YUAN, J.; ZHENG, Y.; ZHANG, C.; XIE, W.; XIE, X.; SUN, G.; HUANG, Y. T-drive: Driving directions based on taxi trajectories. In: Proceedings of the 18th SIGSPATIAL International Conference on Advances in Geographic Information Systems. New York, NY, USA: ACM, 2010. (GIS '10), p. 99-108. ISBN 978-1-4503-0428-3. Disponível em: <http://doi.acm.org/10. 1145/1869790.1869807>. Citado na página 53.

ZENG, Q.; HUANG, H. Bayesian spatial joint modeling of traffic crashes on an urban road network. Accident Analysis Prevention, v. 67, p. 105 - 112, 2014. ISSN 0001-4575. Disponível em: <http://www.sciencedirect.com/science/article/pii/S0001457514000633>. Citado nas páginas 28 e 54.

ZHANG, C.; HAN, J.; SHOU, L.; LU, J.; PORTA, T. L. Splitter: Mining fine-grained sequential patterns in semantic trajectories. Proc. VLDB Endow., VLDB Endowment, v. 7, n. 9, p. 769-780, maio 2014. ISSN 2150-8097. Disponível em: <http://dx.doi.org/10.14778/2732939.2732949>. Citado nas páginas 27 e 52.

ZHANG, Y.; BIGHAM, J.; RAGLAND, D.; CHEN, X. Investigating the associations between road network structure and non-motorist accidents. Journal of Transport Geography, v. 42, p. 
34 - 47, 2015. ISSN 0966-6923. Disponível em: <http://www.sciencedirect.com/science/article/ pii/S0966692314002336>. Citado nas páginas 27, 28 e 54.

ZHAO, Y.-L.; CHEN, Q.; YAN, S.; CHUA, T.-S.; ZHANG, D. Detecting profilable and overlapping communities with user-generated multimedia contents in lbsns. ACM Trans. Multimedia Comput. Commun. Appl., ACM, New York, NY, USA, v. 10, n. 1, p. 3:1-3:22, dez. 2013. ISSN 1551-6857. Disponível em: <http://doi.acm.org/10.1145/2502415>. Citado na página 55.

ZHENG, K.; ZHENG, Y.; XIE, X.; ZHOU, X. Reducing uncertainty of low-sampling-rate trajectories. In: 2012 IEEE 28th International Conference on Data Engineering. [S.1.: s.n.], 2012. p. 1144-1155. ISSN 1063-6382. Citado nas páginas 28 e 54.

ZHENG, Y. Trajectory data mining: An overview. ACM Trans. Intell. Syst. Technol., ACM, New York, NY, USA, v. 6, n. 3, p. 29:1-29:41, maio 2015. ISSN 2157-6904. Disponível em: $<$ http://doi.acm.org/10.1145/2743025>. Citado nas páginas 28, 50, 51, 52 e 55.

ZHENG, Y.; XIE, X. Learning travel recommendations from user-generated gps traces. ACM Trans. Intell. Syst. Technol., ACM, New York, NY, USA, v. 2, n. 1, p. 2:1-2:29, jan. 2011. ISSN 2157-6904. Disponível em: <http://doi.acm.org/10.1145/1889681.1889683>. Citado na página 57.

ZHENG, Y.; ZHANG, L.; XIE, X.; MA, W.-Y. Mining interesting locations and travel sequences from gps trajectories. In: Proceedings of the 18th International Conference on World Wide Web. New York, NY, USA: ACM, 2009. (WWW '09), p. 791-800. ISBN 978-1-60558-487-4. Disponível em: <http://doi.acm.org/10.1145/1526709.1526816>. Citado nas páginas 28, 56 e 57.

ZHENG, Y.; ZHOU, X. Computing with Spatial Trajectories. 1st. ed. [S.1.]: Springer Publishing Company, Incorporated, 2011. ISBN 1461416280, 9781461416289. Citado nas páginas $28,37,38,39,50$ e 57.

ZOU, Z.; YU, Z.; CAO, K. An innovative gps trajectory data based model for geographic recommendation service. Transactions in GIS, v. 21, n. 5, p. 880-896, 2016. Disponível em: $<$ https://onlinelibrary.wiley.com/doi/abs/10.1111/tgis.12248>. Citado nas páginas 28 e 57. 


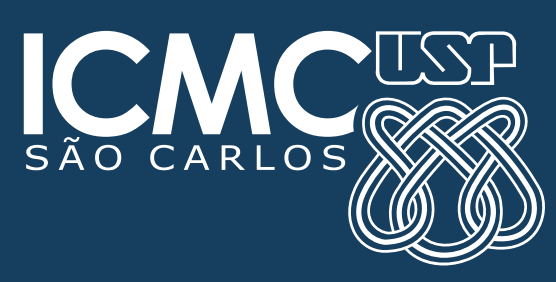

